
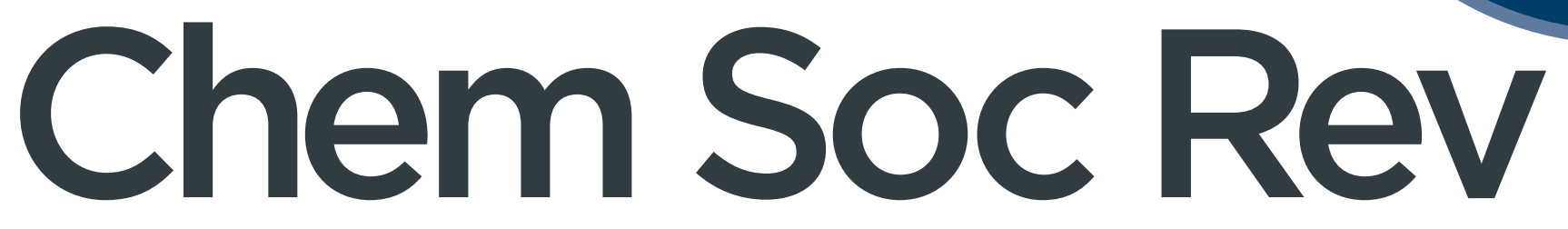

Number 2

21 January 2021

Pages 693-1470

Chemical Society Reviews

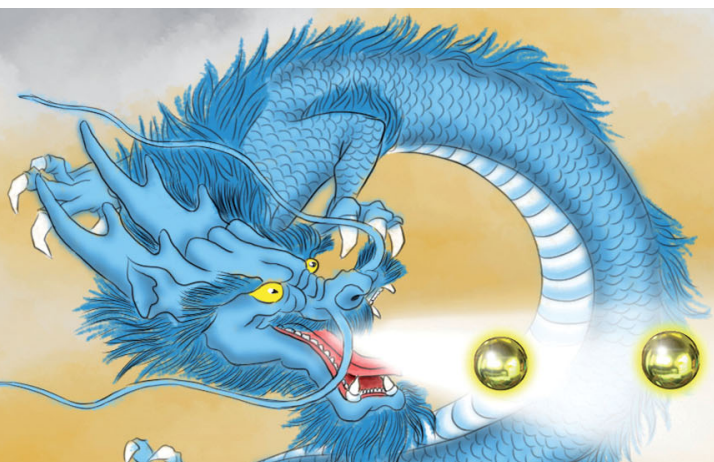

(e)
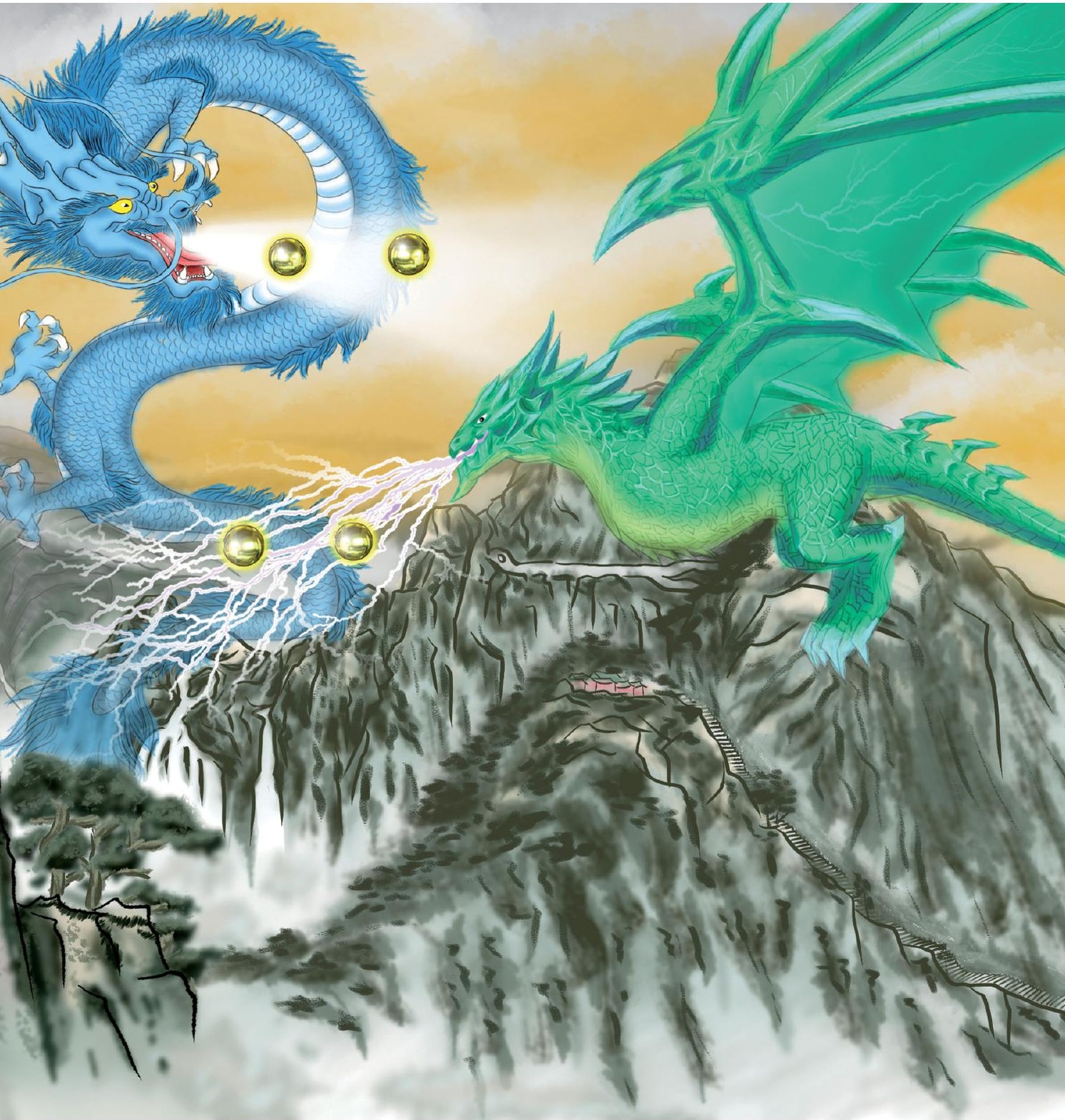

ISSN 0306-0012 


\section{Check for updates}

Cite this: Chem. Soc. Rev., 2021, 50,702

Received 7th July 2020

DOI: $10.1039 / \mathrm{d} 0 \mathrm{cs} 00861 \mathrm{c}$

rsc.li/chem-soc-rev

\title{
Two-photon small-molecule fluorescence-based agents for sensing, imaging, and therapy within biological systems
}

\author{
Luling Wu, (D) $\dagger^{\star^{a b}}$ Jihong Liu, $\dagger^{\mathrm{ab}}$ Ping Li, (D) *a Bo Tang (D) *a and Tony D. James (D) *abc
}

In this tutorial review, we will explore recent advances for the design, construction and application of two-photon excited fluorescence (TPEF)-based small-molecule probes. The advantages of TPEF-based probes include deep tissue penetration and minimal photo-damage. We discuss the underlying twophoton (TP) fluorophores including hemicyanine and design strategies such as Förster resonance energy transfer (FRET). Moreover, we emphasize applications for the detection or imaging of cations, anions, small neutral molecules, biomacromolecules, cellular microenvironments, subcellular localization and dual-responsive systems. Examples of photodynamic therapy (PDT) using TP irradiation are also illustrated.

Key learning points

(1) The review will provide a simple guide for the design principles involved in the construction of two-photon excitation-based sensors and imaging agents.

(2) The review will focus on biological applications, including sensing and imaging in a cellular environment. The review should provide a foundation and guidelines enabling the reader to develop their own novel two-photon excitation-based sensing systems including dual-responsive probes.

(3) In addition, we anticipate that the review will facilitate a deep understanding of two-photon excitation-based systems for photodynamic therapy.

\section{Introduction}

Small-molecule probes are powerful tools to monitor specific cellular processes via fluorescence detection and/or imaging. ${ }^{1}$ These molecular probes change their fluorescence emission when they respond to a specific analyte or environment. They have been widely used in diverse fields such as cellular imaging, drug screening and medical therapy. Small-molecule probes-based detection methods have specific advantages including: measurable fluorescence emission with good sensitivity and selectivity, spatial and temporal resolution in cell and animal imaging, and readily accessible fluorophores.

Combining one-photon (OP) probes and one-photon microscopy (OPM) is the most common tool for targeting various biomolecules and organelles. Common fluorophores including coumarin, BODIPY, fluorescein and rhodamine have been used

\footnotetext{
${ }^{a}$ College of Chemistry, Chemical Engineering and Materials Science, Key Laboratory of Molecular and Nano Probes, Ministry of Education, Collaborative Innovation Center of Functionalized Probes for Chemical Imaging in Universities of Shandong, Institutes of Biomedical Sciences, Shandong Normal University, Jinan, 250014, P. R. China. E-mail: lw960@bath.ac.uk, lip@sdnu.edu.cn, tangb@sdnu.edu.cn, t.d.james@bath.ac.uk

${ }^{b}$ Department of Chemistry, University of Bath, Bath, BA2 7AY, UK

${ }^{c}$ School of Chemistry and Chemical Engineering, Henan Normal University, Xinxiang 453007, P. R. China

$\dagger$ Equal contribution.
}

for the construction of OP probes using appropriate design strategies. $^{2}$ These fluorophores are usually excited by OPM using UV-visible excitation wavelengths (350-650 nm). Therefore, OP probes have restrictions for practical application. The main causes include: (1) short-wavelength excitation light that limits the penetration depth in biological samples; (2) photobleaching which makes the probe inappropriate for long-time imaging; (3) photo damage to biological samples; and (4) autofluorescence from biological species that interfere with the fluorescence signal. These problems of OPM can be overcome by two-photon excited fluorescence (TPEF) to different degrees. Notably, fluorophores exhibiting TPEF usually exhibit one-photon excited fluorescence (OPEF). The excitation spectra of most commonly used OP fluorophores is in the range of 400 to $500 \mathrm{~nm}$, whereas the wavelengths used to excite the same fluorophore with two-photon microscopy (TPM) is between 800 and $1000 \mathrm{~nm}$. As such TPM reduces photobleaching and increases penetration depth and provides higher spatial resolution than OPM.,

Two-photon absorption (TPA) was first proposed by Maria Göppert-Mayer as part of her doctoral dissertation in $1931,{ }^{5}$ which was then experimentally confirmed by Kaiser and Garret in 1961 after the invention of high-energy pulsed lasers. ${ }^{6}$ However, organic molecules or materials with large two-photon absorption cross section $(\delta)$ values are required to facilitate practical applications of 
TPA, because high-power laser beams can damage the sample. Which means that molecules with large $\delta$ would allow TP excitation at a lower laser power, minimizing photodamage to the sample. The strength of TPA can be described using $\delta$ which is dependent on the molecular structure. $\delta$ is quoted in the units of Göppert-Mayer (GM), where $1 \mathrm{GM}$ is $10^{-50} \mathrm{~cm}^{4} \mathrm{~s}$ per photon per molecule. TPA is a photophysical phenomenon by which a molecule or material absorbs two photons at the same time to reach an excited state through an intermediate virtual state (Scheme 1). TPA can be described as degenerate or nondegenerate depending on whether the two photons have the same or different frequencies (energies), respectively.

Optimizing $\delta$ is important in order to increase the optical sensitivity of fluorophores for TPM. Molecular $\delta$ at a given optical frequency $(\omega)$ is proportional to the imaginary part of the second hyperpolarizability, $\operatorname{Im}[\gamma(\omega)]$.

$$
\delta(\omega) \propto \operatorname{Im}[\gamma(\omega)]
$$

$\delta(\omega)$ can be increased by adjusting three molecular units: electron donor group (D), electron acceptor group (A) and the conjugated $\pi$-linker that connects the electron-donating and electron-accepting groups. Therefore, much research effort has been devoted to exploring the interplay between structure and the photophysical properties of TP fluorophores, in order to help rationalize the design principles towards fluorophores with large $\delta$. Significantly, it is well-known that an increase in the extent of internal charge transfer (ICT) can lead to larger $\delta$ values. Increasing the donor-acceptor $(D-\pi-A)$ electron strength or conjugation can improve the $\delta$ values of common TP fluorophores including $\mathrm{D}-\pi-\mathrm{A}$ dipoles, $\mathrm{D}-\pi-\mathrm{D}$ and $\mathrm{D}-\pi-\mathrm{A}-\pi-\mathrm{D}$ quadrupoles and two-dimensional octupoles (Scheme 2). However, increasing the $\delta$ value of a TP fluorophore is not the only parameter that requires careful consideration when designing probes for biological systems. Many applications require TP excitation to trigger a specific event including targeted fluorescence imaging, singlet oxygen generation, and photochemical activation. Fluorescence quantum yield $\left(\Phi_{\mathrm{f}}\right)$ is another indispensable parameter, therefore the two-photon action cross section $\left(\delta \times \Phi_{\mathrm{f}}\right)$ is usually used to help assess a particular TP probe. Moreover, the TP absorption wavelength of the laser is another key factor. For instance, a pulsed laser at $800 \mathrm{~nm}$ is relatively easy to obtain, as such the design of molecules with a maximum $\delta$ at around

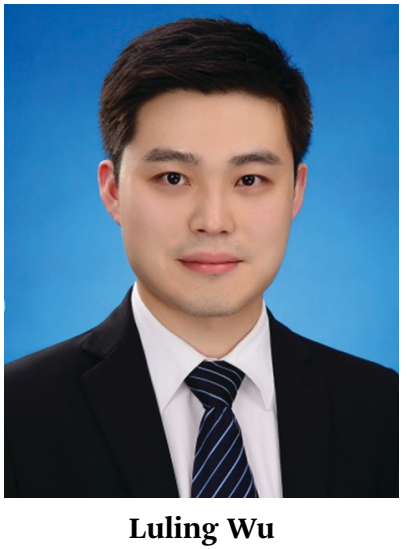

Luling $W u$ received his $M S c$ in 2017 from Shanghai Normal University. In 2017, he was awarded scholarships by the China Scholarship Council (CSC) and University of Bath to carry out a PhD at the University of Bath. He is a guest editor of a special issue on "Molecular Sensors and Molecular Logic Gates" for Frontiers of Chemical Science and Engineering (FCSE), and referee for Cell Reports. He is an editor for "Fluorescent Chemosensors" as part of the Monographs in Supramolecular Chemistry published by the Royal Society of Chemistry.

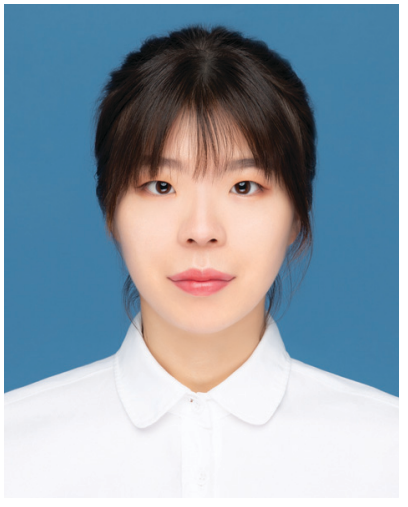

Jihong Liu
Jihong Liu is currently pursuing a $\mathrm{PhD}$ degree at the college of Chemistry, Chemical Engineering and Materials Science in Shandong Normal University with Professor Ping Li. Her research focuses on fluorescence imaging and sensors for reactive oxygen species (ROS).

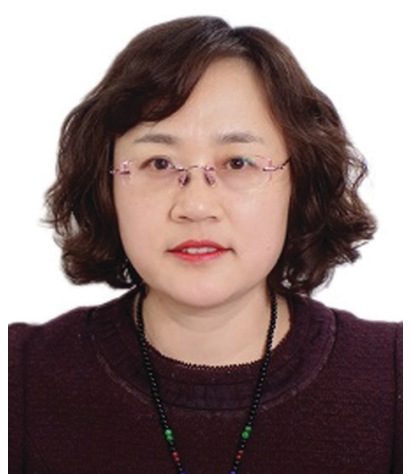

Ping Li
Ping Li received her $P h D$ degree in 2008 from Shandong Normal University. In 1998, she joined the faculty at Shandong Normal University, where she is currently a professor of College of Chemistry, Chemical Engineering and Materials Science. She is Taishan Distinguished Professor (2017), Millions of Talent Projects National candidates (2019) and the leader of the Changjiang Scholars and Innovative Research Team in University.

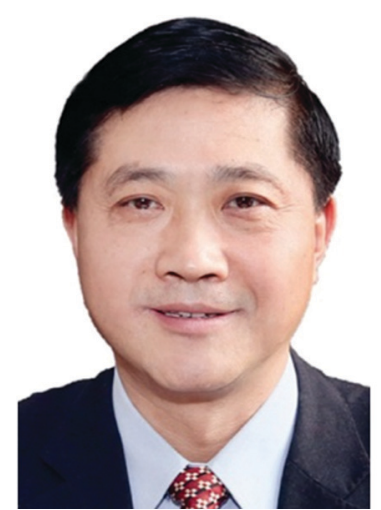

Bo Tang
Bo Tang is a professor of chemistry at Shandong Normal University. $\mathrm{He}$ received his $\mathrm{PhD}$ degree in 1994 from Nankai University. $\mathrm{He}$ began his independent career as a professor of chemistry at Shandong Normal University in 1994. He won National Fund for Outstanding Young Scientists in 2007, Chief scientist for 973 Program in 2012. He has contributed more than 300 journal articles, as well as 21 invited book chapters and reviews, and obtained 39 granted patents. 


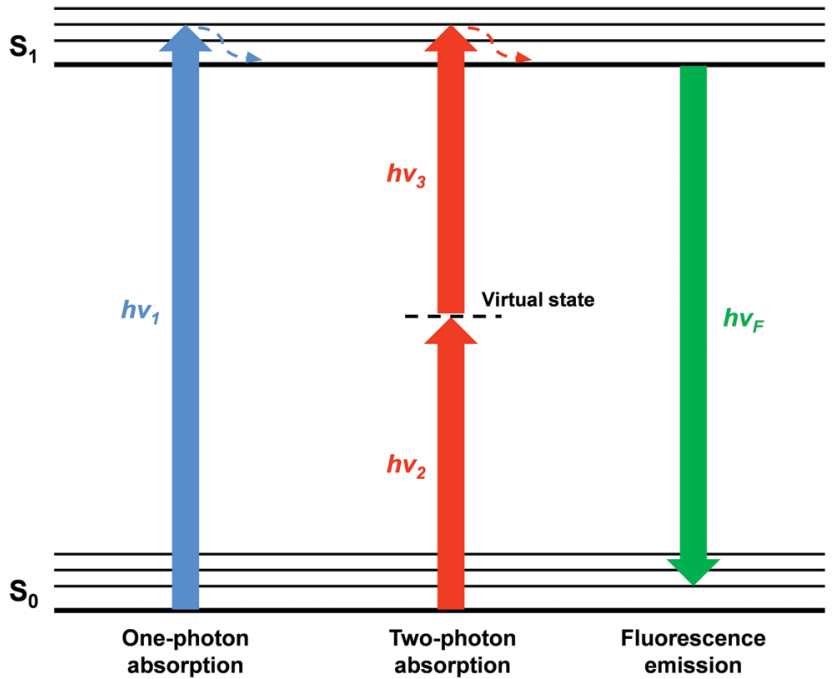

Scheme 1 Energy diagram of one-photon and two-photon excitation The fluorescence is emitted from the first electronic excited state regardless of the excitation mode.

$800 \mathrm{~nm}$ is advantageous for probes suitable for practical applications.

Design strategies for TP probes can be the same as those employed for OP probes. ${ }^{7}$ Generally, a TP probe is composed of three functional units: (1) TP fluorophore. Fluorescence emission intensity and wavelength of the TP probe will change when bound or having reacted with the target; (2) recognition receptor, which is designed to specifically bind or react with the target; and (3) linker, which connects the fluorophore and recognition receptor. Importantly, both TP probes and OP probes are fluorescent sensors that rely on the same types of sensing outputs including a change of intensity and/or

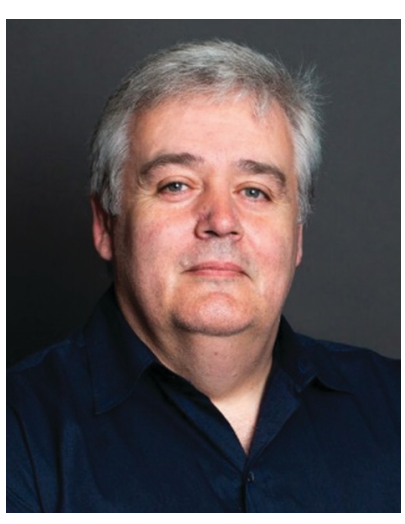

Tony D. James
Tony D. James is a Professor at the University of Bath, Fellow of the Royal Society of Chemistry and holds a prestigious Royal Society Wolfson Research Merit Award (2017-2022). He obtained his BSc from the University of East Anglia (1986), PhD from the University of Victoria (1991), and carried out Postdoctoral Research with Seiji Shinkai (1991-95). He was a Royal Society University Research Fellow at the University of Birmingham (1995-2000) before moving to the University of Bath in 2001. In 2013 he was awarded the Daiwa-Adrian Prize, in 2015 the inaugural CASE Prize and in 2018 the MSMLG Czarnik Award. His research interests include many aspects of Supramolecular chemistry, including molecular recognition, molecular selfassembly and sensor design. He is the author of over 330 papers and has an h-index of 71. emission wavelengths. Therefore, as with the development of OP probes, the construction of TP probes requires the assembly of appropriate receptors or recognition groups linked to a fluorophore. For example, oxygen-rich receptors are often used for sensing $\mathrm{Mg}^{2+}$ and $\mathrm{Ca}^{2+}$ while nitrogen-containing receptors such as the pyridine moiety are used for $\mathrm{Zn}^{2+}$ (e.g. probe 27) and $\mathrm{Cd}^{2+}$. Similarly the boronic ester group can be used to report peroxynitrite $\left(\mathrm{ONOO}^{-}\right)$or hydrogen peroxide $\left(\mathrm{H}_{2} \mathrm{O}_{2}\right)$ (e.g. probe 30).

A TP fluorophore for biological applications requires the following properties optimised for biological usage: (1) good water solubility, which can be improved by introducing watersolubilizing groups; (2) a large $\delta \times \Phi_{\mathrm{f}}$ to generate bright TPM images, which can be improved by modifying the donoracceptor strength or length of the intramolecular conjugation; (3) suitable photo-stability for the system being monitored, longer-duration imaging, can be facilitated by introducing rigid conjugated cyclic linkers. Compounds 6-14 with optimized structures meet these criteria and are suitable for the construction of practical TP probes (Fig. 1). In addition, compounds 15-25 have desirable photo-physical properties (e.g. large $\delta \times \Phi_{\mathrm{f}}$ value) and have functional groups suitable for appropriate modification in order to generate suitable TP probes (Fig. 1).

Photodynamic therapy (PDT) is a method of treating cancer based on a photochemical reaction involving a photosensitizer, light irradiation and molecular oxygen to generate cytotoxic species. The formation of singlet oxygen during type II photochemical reactions is the main cause of the observed cell damage. In particular the use of longer wavelength excitation light (i.e. $800-1100 \mathrm{~nm}$ ) in TP PDT is very important in order to improve both tissue penetration depth and reduce damage to surrounding healthy tissue when compared to OP PDT using UV or visible light excitation.

This review will summarize recent progress in the development of TP small-molecule probes. The goal is to provide an insight into the importance of this continually expanding area. Specifically, this review will describe the design principles required for the construction of TP small-molecule probes and provide guidance on function. Characteristic TP fluorophores published in the literature and their utility will be described. Reaction mechanisms are an important factor in the design of fluorescence-based sensors and imaging agents. Fluorescence mechanisms including ICT, ${ }^{8}$ Förster resonance energy transfer (FRET) ${ }^{9}$ and excited-state intramolecular proton-transfer (ESIPT) ${ }^{10}$ will be discussed. The relationship between the receptor and the change in photophysical properties will be illustrated when a TP probe interacts with analyte(s). Additionally, the potential biological applications of TP small-molecule probes will be highlighted. Finally, the future research directions and opportunities for the development of TP probes will be outlined. Since, this treatise is not a comprehensive review. We must apologize to some groups whose work has not been included due to restrictions in the number of references.

\section{Two-photon (TP) excitation-based fluorescent sensors for cations}

As structural or catalytic required cofactors, cellular metal ions play important roles in regulating cell function and participate in many cellular processes. Metal ion homeostasis can be 
a)
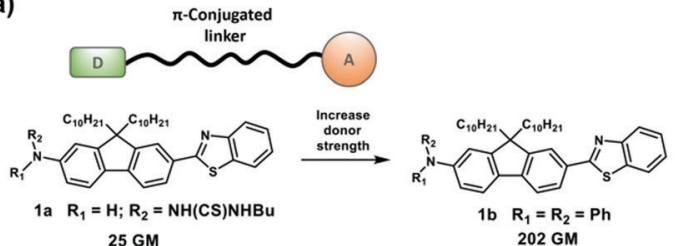

$25 \mathrm{GM}$

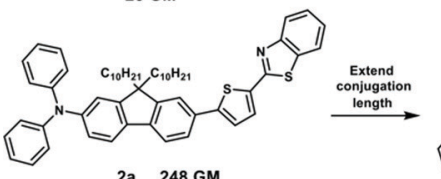

$2 \mathrm{a} \quad 248 \mathrm{GM}$

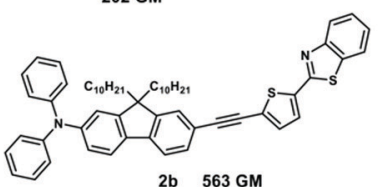

b)
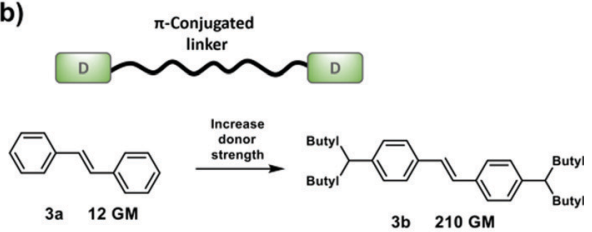

3a $12 \mathrm{GM}$

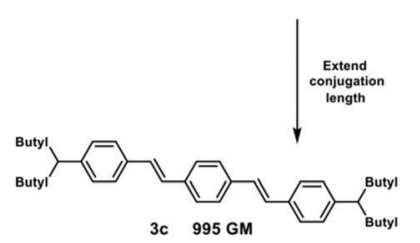

c)

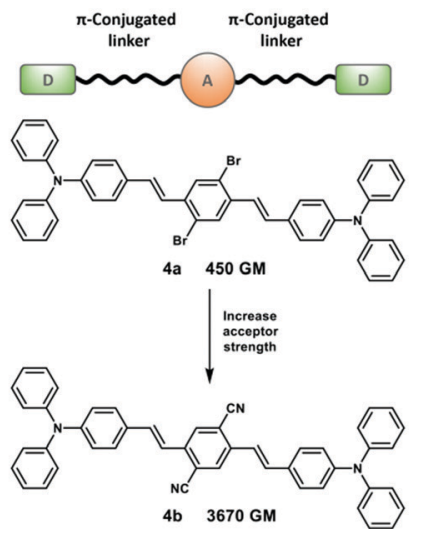

d)

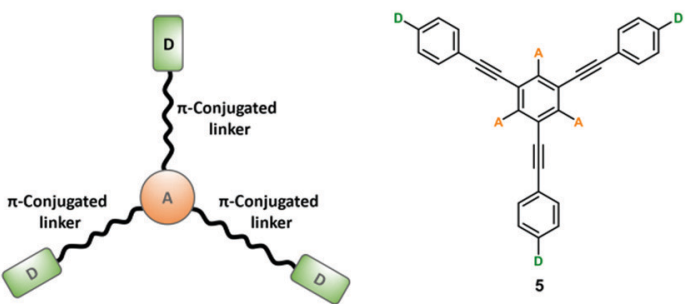

Scheme 2 Representative molecules and design strategy to increase $\delta$ values of (a) $D-\pi-A$ dipoles, (b) $D-\pi-D$ and (c) $D-\pi-A-\pi-D$ quadrupoles and (d) representative structural motif of two-dimensional octupoles.

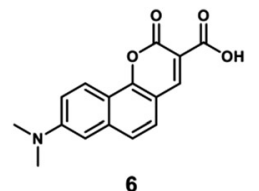<smiles>CC(=O)c1ccc2cc(C(C)C)ccc2c1</smiles><smiles></smiles><smiles>CC(C)c1ccc2cc(-c3nc4ccccc4cc3-c3ccc4ccccc4c3)ccc2c1</smiles><smiles></smiles><smiles>CCc1ccc2c(c1)C1c3ccc(-c4nc5ccccc5[nH]4)cc3C2c2ccc(C(CC)CC)cc21</smiles>

11<smiles>CCC(CC)(CC)c1ccc2c(c1)C(C)(C)C1CC(C(C)=O)C=CC21</smiles>

12<smiles>O=C1C=CC2=CC(=O)C3CCCC3OC2=C1</smiles>

13<smiles></smiles>

14<smiles>CC(=O)c1ccc2cc([N+](=O)[O-])ccc2c1</smiles>

15<smiles>Cc1ccc2cc(-c3cc4ccccc4o3)ccc2c1</smiles>

16<smiles>Cc1ccc2cc(C3=NC(=C4C=CC=C4)C=C3)ccc2c1</smiles>

17<smiles></smiles>

18

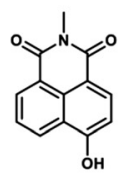

19<smiles>CC(C)c1cccc2c3c(ccc12)C(=O)N(C)C3=O</smiles>

20<smiles></smiles>

21

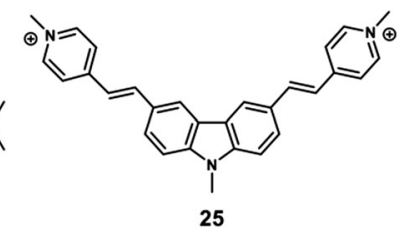

Fig. 1 Typical fluorophores used for the development of TP probes.

controlled by several families of proteins including diffusible cytoplasmic metallochaperone proteins and integral transmembrane transporters, while several neurodegenerative diseases are related to disruption of metal ions balance. As such it is vital to elucidate the 
biological function of metal ions in cells and living organisms, and to develop efficient TP probes for the detection and imaging of cellular metal ions in vivo. A large number of small-molecule fluorescent probes for metal ions have been developed using TP fluorophores which have significant $\delta$ and selective metal ion receptors. A variety of TP probes for the detection of metal ions have been constructed based on mechanisms which are widely used for the development of OP probes, such as ICT, through-bond energy transfer (TBET) and photoinduced electron transfer (PeT). Targeted metal ions trigger a turn-on TPEF emission or wavelength shift (hypsochromic or bathochromic shift) of TPEF spectra, which facilitates bio-imaging using TPM. This section will include some representative TP probes for biologically important cations (ferrous iron, zinc ions, and palladium ion), including working mechanism and biological applications.

Labile heme ( $\mathrm{LH})$, a tetrapyrrole macrocycle containing a central ferrous iron $\left(\mathrm{Fe}^{2+}\right)$ with a metal-chelate structure, acts as cofactors for many cellular proteins that control metabolic functions. As a protein prosthetic group, heme plays an important role in gene regulation, hormone metabolism and cell growth. For instance, tumorigenesis is associated with high expression levels of heme. Probe $\mathbf{2 6}$ is the first example of a LH-responsive small-molecule based fluorescent probe, that was constructed by conjugating the 4-amino-1,8-naphthalimide fluorophore and the endoperoxide bridge through a carbamate linker (Scheme 3). ${ }^{11}$ The design strategy was inspired by the bioactivation mechanism of artemisinin. In the presence of LH $(2 \mu \mathrm{M})$, the absorption peak of 26 in a PBS/DMSO solution at $375 \mathrm{~nm}$ shifted to $440 \mathrm{~nm}$, concomitant with a 13-fold fluorescence enhancement at $540 \mathrm{~nm}$. Moreover, 26 displayed high sensitivity for the detection of $\mathrm{LH}$, without interference from hemin, hemoproteins and zinc protoporphyrin. With the excellent fluorescent

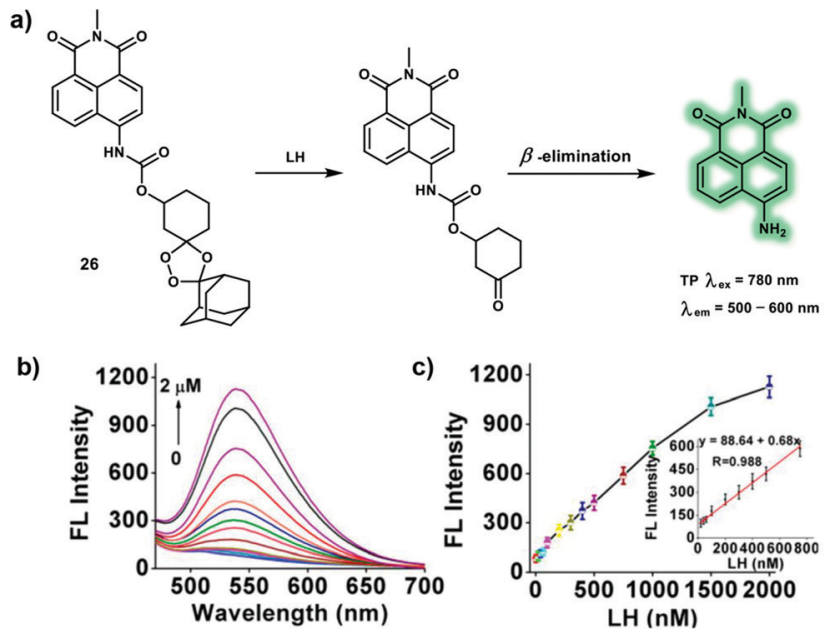

Scheme 3 (a) Proposed mechanism of TP probe 26 in response to LH. (b) Fluorescence emission spectra of $\mathbf{2 6}(2 \mu \mathrm{M})$ with different concentrations of $\mathrm{LH}(0-2 \mu \mathrm{M})$ in aqueous solution (PBS/DMSO = 9:1, v/v, $10 \mathrm{mM}, \mathrm{pH}$ 7.4). (c) Fluorescence intensity at $540 \mathrm{~nm}$ vs. LH concentrations. Inset: linear plot of the fluorescence intensity versus LH concentrations (20-750 nM). Reproduced with permission from ref. 11. Copyright (2020) American Chemical Society. properties of 26, the levels of endogenous LH in HEK293 cells were monitored. Subsequently, 26 was used to monitor LH fluctuations during the hemolysis process, TP confocal microscopy images of mice liver revealed that phenylhydrazine-induced hemolysis of mice displays up-regulated LH levels between 500$600 \mathrm{~nm}$ with TP excitation at $780 \mathrm{~nm}$, indicating the ability of 26 to monitor hemolysis.

As a trace element in our body, zinc ions $\left(\mathrm{Zn}^{2+}\right)$ play an important role in gene transcription, cell proliferation, protein metabolism, regulate immunity and anti-oxidation. Recent research has been directed towards the elucidation of the importance of biological $\mathrm{Zn}^{2+}$. Vesicular $\mathrm{Zn}^{2+}$ was found to be involved in neurotransmission functions of the brain. While $\mathrm{Zn}^{2+}$ concentrations in living systems have significant impact on function and cellular zinc homeostasis can be controlled by Zrt-Irt-like proteins (ZIP) and zinc transporters (ZnT). Hence, monitoring changes of $\mathrm{Zn}^{2+}$ levels is of great importance for the study $\mathrm{Zn}^{2+}$-related diseases, such as Alzheimer's disease, Parkinson's disease, and prostate cancer. A novel TP probe 27 for the detection of lysosomal $\mathrm{Zn}^{2+}$ was designed by conjugating a morpholine group and $N, N$-di-(2-picolyl)ethylenediamine (DPEN) ligand to a naphthalimide dye (Scheme 4). ${ }^{12}$ Upon addition of $\mathrm{Zn}^{2+}$ $(0-50 \mu \mathrm{M})$, the PeT processes were suppressed, resulting in a remarkable fluorescence enhancement of 27 at $\mathrm{pH}=5.0$. Probe 27 displayed a negligible fluorescence at $\mathrm{pH} 7.4$ even after binding with $\mathrm{Zn}^{2+}$, indicating that the probe was capable of specifically recognizing lysosomal $\mathrm{Zn}^{2+}$ rather than cytosolic $\mathrm{Zn}^{2+}$. Probe 27 displays strong binding affinity with an association constant $\left(K_{\mathrm{a}}\right)$ of $1.17 \times 10^{5} \mathrm{M}^{-1}$. Intracellular $\mathrm{Zn}^{2+}$ in lysosomes was detected by TPM under excitation at $900 \mathrm{~nm}$ in

a)
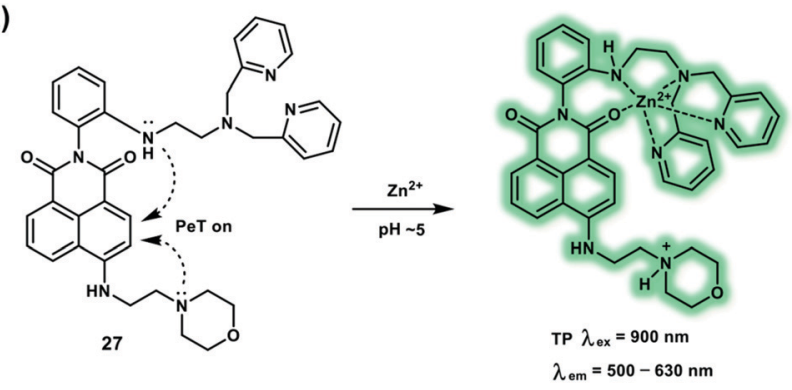

b)

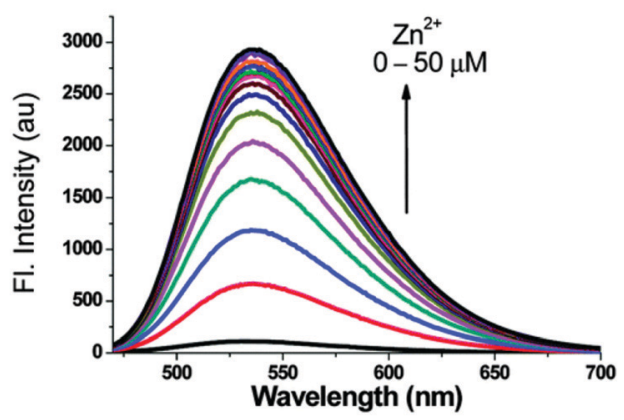

Scheme 4 (a) Detection of zinc ions under acidic conditions with TP probe 27, through the blocking of two PeT processes. (b) Fluorescence titration of probe $27(10 \mu \mathrm{M})$ with $\mathrm{Zn}\left(\mathrm{ClO}_{4}\right)_{2}$ in a pH 5.0 MES buffer containing $1 \% \mathrm{EtOH}$. Reproduced with permission from ref. 12. Copyright (2016) The Royal Society of Chemistry. 

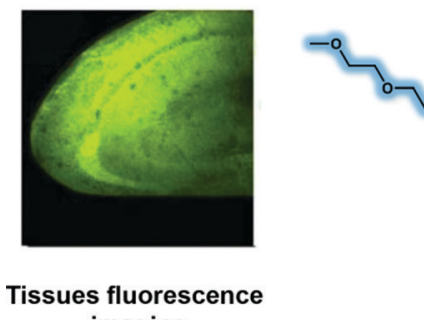
imaging
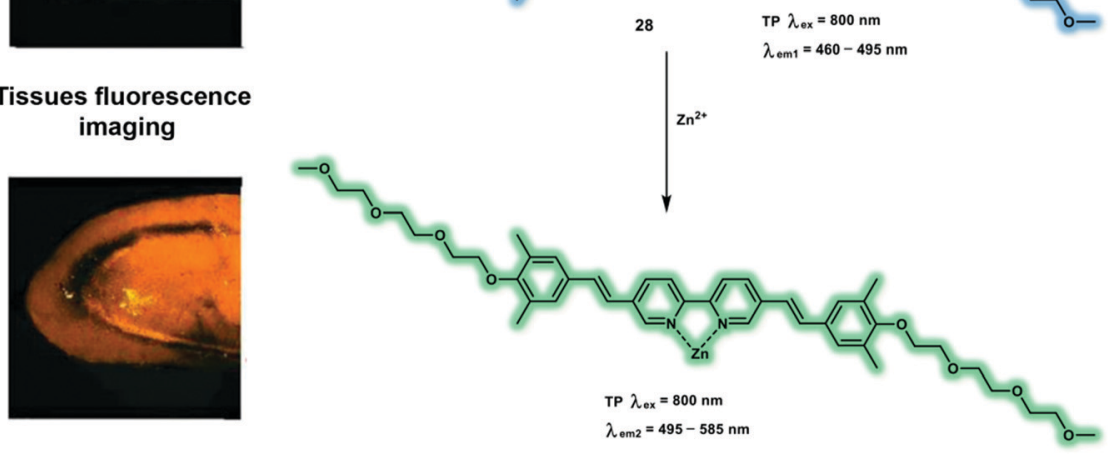

Zebrafish fluorescence imaging

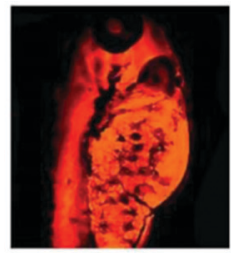

Scheme 5 TP response of probe $\mathbf{2 8}$ for imaging $\mathrm{Zn}^{2+}$ in brain tissue and zebrafish. Reproduced with permission from ref. 13. Copyright (2017) American Chemical Society.

NIH 3T3 cells. Moreover, probe 27 could be an effective tool to image endogenous $\mathrm{Zn}^{2+}$ in the deep tissues of a mouse brain via TP microscopic imaging.

Probe 28 is a ratiometric TP probe for $\mathrm{Zn}^{2+}$ based on ICT. Probe $\mathbf{2 8}$ was constructed by conjugating the 2,2'-dipyridyl group (electron acceptor) and benzene group (electron donor) with alkene linker, which behaves as D- $\pi-\mathrm{A}-\pi-\mathrm{D}$ (Scheme 5$){ }^{13}$ Increased conjugation length of the alkene group and stronger electron donating ability of the benzene group facilitated probe 28 to achieve a high $\delta$ with a value of $516 \pm 77 \mathrm{GM}$ at $700 \mathrm{~nm}$ excitation, which increased to $958 \pm 144 \mathrm{GM}$ after coordination of probe 28 with $\mathrm{Zn}^{2+}$. In addition, probe 28 displayed an enhanced $\Phi_{\mathrm{f}}$ with values from 0.59 to 0.71 in the absence and presence of $\mathrm{Zn}^{2+}$, respectively. The apparent dissociation constant for probe 28 was calculated to be $3.66 \pm 0.42 \mu \mathrm{M}$ in $\mathrm{MeOH} / \mathrm{buffer}(1: 19)$ solution. TP fluorescence emission spectra indicated that the addition of $\mathrm{Zn}^{2+}(80 \mu \mathrm{M})$ induced a red-shift of emission from $465 \mathrm{~nm}$ to $550 \mathrm{~nm}$ upon excitation at $800 \mathrm{~nm}$. The experimental results indicated that probe $\mathbf{2 8}$ behaved as a ratiometric TP fluorescent probe for the determination of $\mathrm{Zn}^{2+}$. The enhanced fluorescence emission ratio $I_{\text {red }} / I_{\text {green }}$ (red channel: 495-585 nm; green channel: 460-495 nm) was dose-dependent towards probe 28 (between 0 and $25 \mu \mathrm{M}$ ) in live SHSY-5Y cells, which was observed via TP confocal fluorescence imaging. In addition, probe 28 was used to monitor increased $\mathrm{Zn}^{2+}$ levels in mouse brains with Alzheimer's disease and 3 day-old zebrafish, confirming that it could be used as a robust TP probe to map endogenous levels of $\mathrm{Zn}^{2+}$.

As a member of platinum group elements, palladium has been largely used in aerospace, automobile manufacturing and catalytic industry. Palladium can disturb cellular functions which is attributed to the formation of palladium complexes between palladium ions $\left(\mathrm{Pd}^{2+}\right)$ and DNA, RNA, proteins and biomacromolecules. As a result of palladium toxicity, governments strictly restrict the residual palladium levels in pharmaceutical products $(5-10 \mathrm{ppm})$ to avoid health risks. A naphthalene- rhodamine based TP fluorescent probe 29 has been reported for the ratiometric detection of $\mathrm{Pd}^{2+}$ (Scheme 6). ${ }^{14}$ The TP fluorophore naphthalene derivative was selected as the energy donor and rhodamine spirolactam was chosen as the energy acceptor to develop a TBET platform. This platform exhibited two well-separated fluorescence emission maxima (wavelength difference of $100 \mathrm{~nm}$ ) and excellent energy transfer efficiency (90\%). When binding $\mathrm{Pd}^{2+}$, the spirolactam of the rhodamine $\mathrm{B}$ opened and resulted in enhanced fluorescence at $595 \mathrm{~nm}$ and concomitant fluorescence decrease at $495 \mathrm{~nm}$. Using this ratiometric probe, it was possible to image $\mathrm{Pd}^{2+}$ in HeLa cells and nude mice liver tissue via dual-channel mode (green channel was collected between $470-530 \mathrm{~nm}$ and the red channel was collected between 550-650 nm). The images collected from the two fluorescence channels using TPM indicated that probe 29 could be used to selectively assess changes of $\mathrm{Pd}^{2+}$ in living cells and mice liver tissue $(90-270 \mu \mathrm{m})$ with TP excitation.

\section{Two-photon (TP) excitation-based fluorescent sensors for anions}

Owing to the important role of anions in physiological and pathological processes, significant attention has been paid to the development of TP fluorescent probes for tracking endogenous anions in vivo, such as $\mathrm{ONOO}^{-}$, hypochlorite $\left(\mathrm{ClO}^{-} /\right.$ HOCl) and superoxide $\left(\mathrm{O}_{2}{ }^{-}\right)$. However, because of the high reactivity, short lifetime and transient conversion characteristics of some anions, real-time monitoring of anion fluctuations using anion-sensitive TP probes remain challenging. Recently, a number of reaction-based small-molecule fluorescent TP probes for anions were reported, which include oxidative reactions, reductive and nucleophilic reactions. In this section, we will summarize representative TP excitation-based fluorescent sensors for several representative reactive nitrogen species (RNS), reactive oxygen species (ROS) and reactive sulfur species (RSS), including recognition, and response mechanisms. 

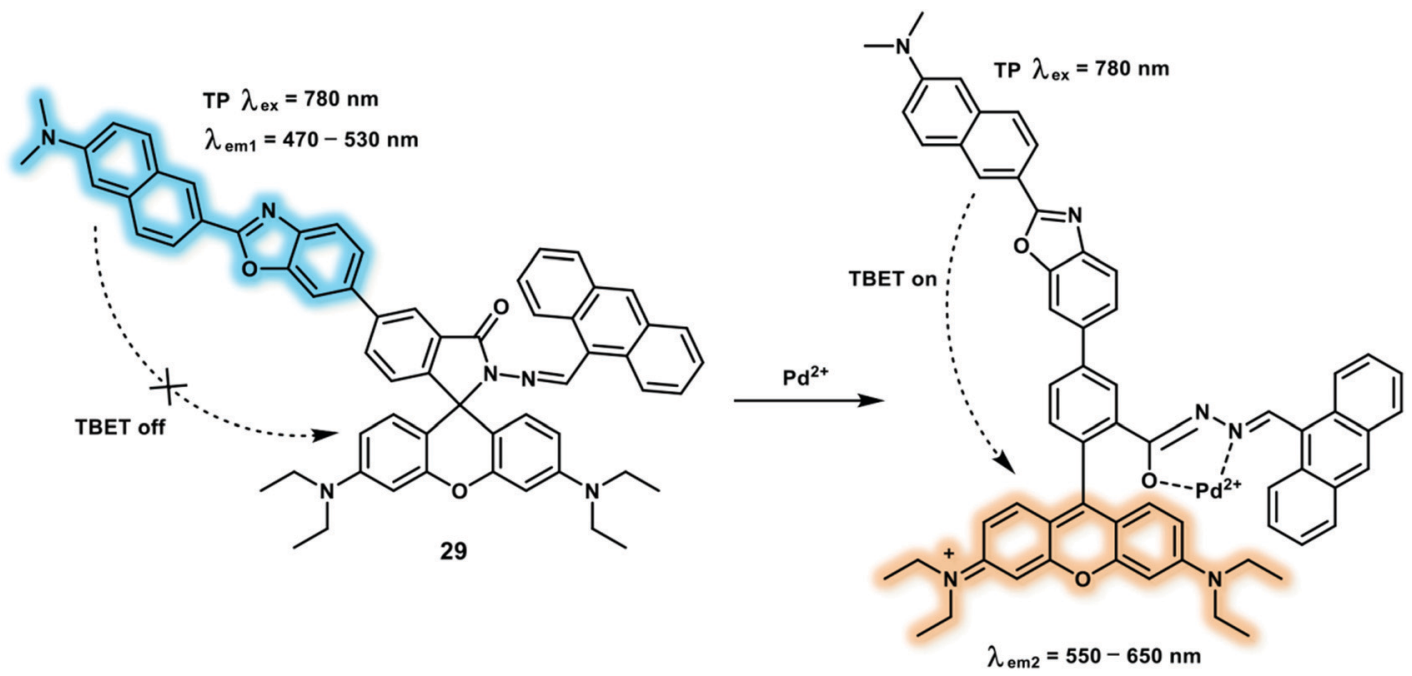

Scheme 6 TP probe 29 the ratiometric detection of $\mathrm{Pd}^{2+}$

As a RNS, $\mathrm{ONOO}^{-}$is generated from the diffusion limited combination of $\mathrm{O}_{2}{ }^{\cdot-}$ and nitric oxide (NO) at a rate of $1.9 \times 10^{10}$ $\mathrm{M}^{-1} \mathrm{~s}^{-1}$. $\mathrm{ONOO}^{-}$and its derived radicals (hydroxyl radical $\left({ }^{\bullet} \mathrm{OH}\right)$, nitrogen dioxide $\left({ }^{\bullet} \mathrm{NO}_{2}\right)$, and carbonate radical $\left(\mathrm{CO}_{3}{ }^{-}\right)$) can oxidize and nitrate many biomolecules, including DNA, thiols, protein tyrosine residues, lipids and nucleic acids. Tyrosine nitration caused by $\mathrm{ONOO}^{-}$acts as a mediator in cell apoptosis and death pathways. $\mathrm{ONOO}^{-}$overproduction has been implicated in many pathological processes including inflammation, neurodegenerative disease, ischemia-reperfusion injury and Alzheimer's disease. ${ }^{15} \mathrm{~A}$ large number of TP probes for $\mathrm{ONOO}^{-}$ containing highly reactive groups such as boronic acid, $\alpha$-ketoamide, phenol and selenides have been developed based on the high oxidative nature and nucleophilicity of $\mathrm{ONOO}^{-}$. Probe 30 (Scheme 7e) was developed as a turn-on TP probe for $\mathrm{ONOO}^{-}$ and $\mathrm{H}_{2} \mathrm{O}_{2}$, using an azulene fluorophore and boronate ester (responsive group) (Scheme 7b). ${ }^{16}$ The electron-withdrawing nature of the boronic ester leads to a decrease in the inherent polarization of azulene, which causes a reduction in the ICT character of azulene (Scheme 7a and c). However, after oxidation by $\mathrm{ONOO}^{-} / \mathrm{H}_{2} \mathrm{O}_{2}$, the as generated hydroxyl group reinforces the inherent polarization of the fluorophore and increases the ICT character (Scheme 7a and d). Probe 30 displays a turn-on response at $483 \mathrm{~nm}$ after oxidation in a mixed aqueous buffer/ methanol system and exhibits high selectivity for $\mathrm{ONOO}^{-}$over other ROS including $\mathrm{HOCl},{ }^{\bullet} \mathrm{OH}$, and $\mathrm{O}_{2}{ }^{\bullet-}$; high photostability; and low cytotoxicity. The detection limit of probe 30 for $\mathrm{ONOO}^{-}$ was calculated to be $21.7 \mathrm{nM}$, and the largest value of $\delta \times \Phi_{\mathrm{f}}$ of the product $\left(\mathbf{3 0}+\mathrm{ONOO}^{-}\right)$was calculated to be $3.2 \mathrm{GM}$ at $810 \mathrm{~nm}$ excitation. TPM images of probe 30 in phorbol myristate acetate (PMA) or lipopolysaccharide/ gamma interferon (LPS/IFN- $\gamma$ ) induced RAW264.7 macrophages revealed that endogenously elevated ROS/RNS levels could be monitored by probe $\mathbf{3 0}$ in biological systems. Finally, $\mathbf{3 0}$ was further used for TPEF imaging of $\mathrm{H}_{2} \mathrm{O}_{2}$ and $\mathrm{ONOO}^{-}$in rat hippocampus slices recorded by TPM at $800 \mathrm{~nm}$ excitation wavelength. While, using PMA or SIN-1 (source of exogenous $\mathrm{ONOO}^{-}$) a) Inherent polarization of azulene (Az)

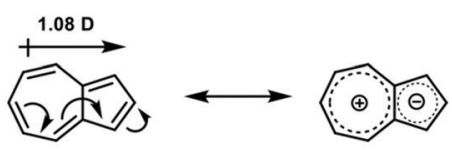

b) Az-6-Bpin: reaction with ROS/RNS gives Az-6-OH

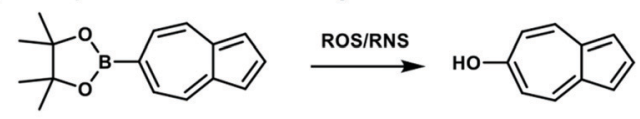

c) Az-6-Bpin: influence of EWG conflicts with inherent polarization

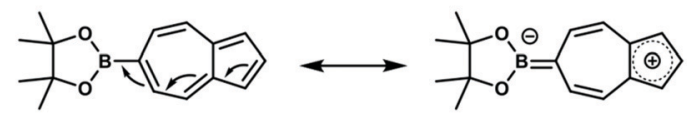

d) Az-6-OH: influence of EDG reinforces inherent polarization

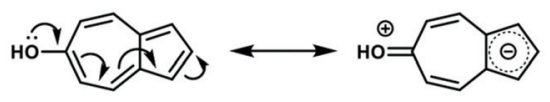

e)

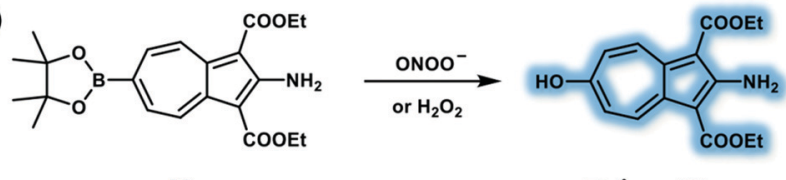

30

TP $\lambda_{\text {ex }}=800 \mathrm{~nm}$

$\lambda_{\text {em }}=400-600 \mathrm{~nm}$

Scheme 7 Design concept for azulene-based fluorescent probe towards ROS/RNS

pretreated slices exhibited about 2-fold fluorescence increase compared to control slices.

To achieve in vivo ratiometric imaging of $\mathrm{ONOO}^{-}$, a novel FRET-based TP probe $\mathbf{3 2}$ for the ratiometric detection of $\mathrm{ONOO}^{-}$has been developed. ${ }^{17}$ Probe 32 consists of a coumarin derivative as a TP fluorophore and compound $\mathbf{3 1}$ as the recognition group for $\mathrm{ONOO}^{-}$via a FRET strategy (Scheme 8). Probe 32 displays a 93-fold fluorescence ratio $\left(I_{473 \mathrm{~nm}} / I_{651 \mathrm{~nm}}\right)$ increase in the presence of $\mathrm{ONOO}^{-}(7.5 \mu \mathrm{M})$. The detection limit was calculated to be $11.3 \mathrm{nM}$. In addition, probe 32 exhibited excellent selectivity for 
a)

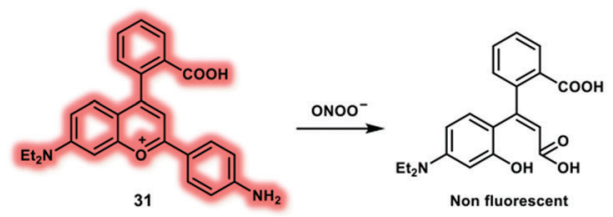

b)
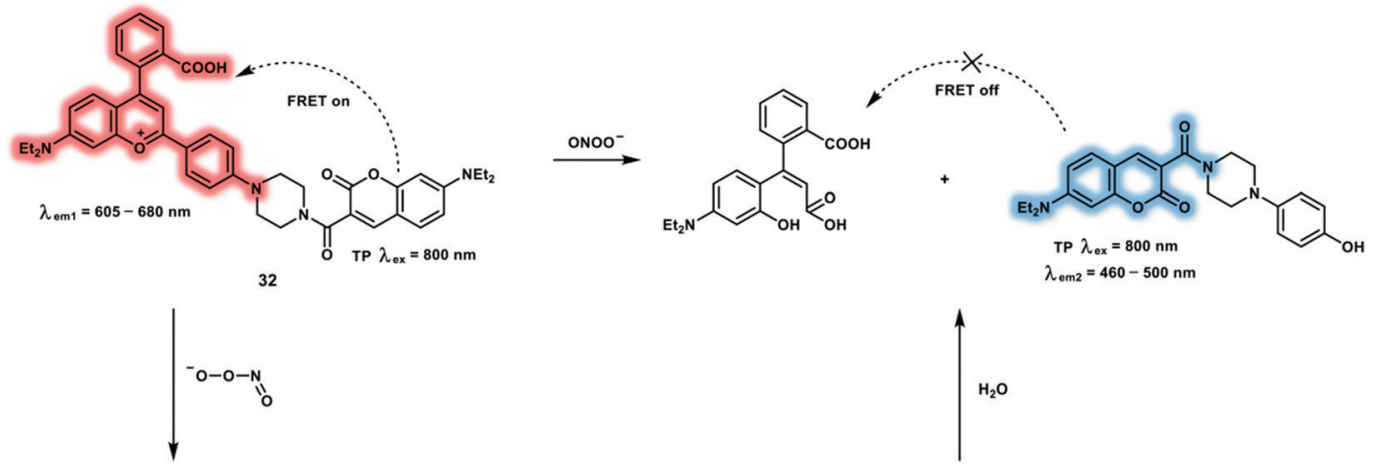

.

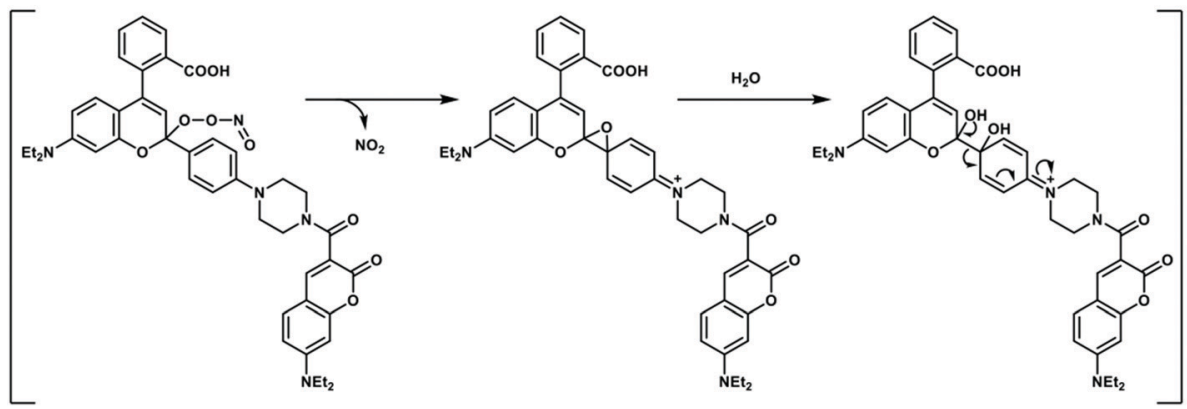

Scheme 8 (a) Reaction between compound 31 and ONOO-. (b) FRET-based TP probe 32 and its proposed reaction mechanism for the ratiometric detection of $\mathrm{ONOO}^{-}$. The non-fluorescent products in Fig. 7 of ref. 9 (Chem. Soc. Rev., 2020, 49, 5110-5139) were wrong, as such we have corrected them here in Scheme 8.

$\mathrm{ONOO}^{-}$over other biological ROS and RNS, and in particular could avoid interference by $\mathrm{H}_{2} \mathrm{O}_{2}$ (0-100.0 equiv.). The red fluorescence channel of probe $\mathbf{3 2}$ merged well with the green fluorescence channel of Mito-Tracker Green, with an overlap coefficient of 0.80 , which indicated that probe 32 could be used to detect mitochondrial $\mathrm{ONOO}^{-}$at subcellular levels. Using dual-channel TPEF imaging, a dramatic enhancement of the fluorescence signal ratio $\left(I_{\text {blue }} / I_{\text {red }}\right)$ in LPS/IFN- $\gamma$ pretreated HepG2 cells was observed. An obvious ratiometric signal ( $\left.I_{\text {blue }}\right)$ $\left.I_{\text {red}}\right)$ enhancement was observed in LPS-induced inflamed live mice using TP confocal microscopy upon excitation at $800 \mathrm{~nm}$.

Inspired by the fluorescence mechanism of 2-(2'-hydroxyphenyl)benzothiazole via an ESIPT process, Hu et al. have developed a turn-on TP probe 33 for the detection of ONOO $^{-}$(Scheme 9). ${ }^{18}$ The ESIPT effect was blocked by substituting the hydroxyl group with $N$-methyl- $p$-hydroxyaniline. In the presence of $\mathrm{ONOO}^{-}$, the phenol group of $N$-methyl- $p$-hydroxyaniline could be oxidized, and the $\mathrm{N}-\mathrm{C}$ bond was cleaved with proton donor $(\mathrm{N}-\mathrm{H})$ formation, restoring the ESIPT process. A dramatic 600-fold fluorescence intensity enhancement at $470 \mathrm{~nm}$ was observed upon addition of $\mathrm{ONOO}^{-}$( 2 equiv.) to probe 33 in PBS $(10 \mathrm{mM}$, $\mathrm{pH}$ 7.4). The in vitro experiments demonstrated that probe 33 exhibited high sensitivity and selectivity towards $\mathrm{ONOO}^{-}$;

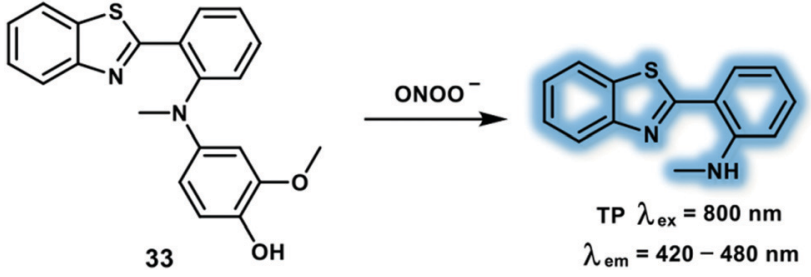

Scheme 9 ESIPT-based TP probe 33 for the detection of $\mathrm{ONOO}^{-}$.

good photostability; excellent pH stability; good blood-brain barrier penetration and low cytotoxicity. A linear relationship between the fluorescence intensity and $\mathrm{ONOO}^{-}(0-10 \mu \mathrm{M})$ was observed. The maximum $\delta$ of probe 33 towards $\mathrm{ONOO}^{-}$was calculated to be $3.6 \mathrm{GM}$ using excitation at $820 \mathrm{~nm}$. Using probe 33 in conjunction with TPM, facilitated the measurement of the dynamic elevation of $\mathrm{ONOO}^{-}$during ischemia progression in rose bengal-treated or laser irradiation-induced live mouse brain using a TP excitation wavelength of $800 \mathrm{~nm}$.

As an effective antimicrobial oxidant of neutrophils, hypochlorous acid ( $\mathrm{HOCl}$ ) is mainly produced by myeloperoxidase catalyzed peroxidation of $\mathrm{H}_{2} \mathrm{O}_{2}$ and chloride ion $\left(\mathrm{Cl}^{-}\right)$in phagolysosomes. $\mathrm{HOCl}$ is of particular importance for antimicrobial action in 
a)

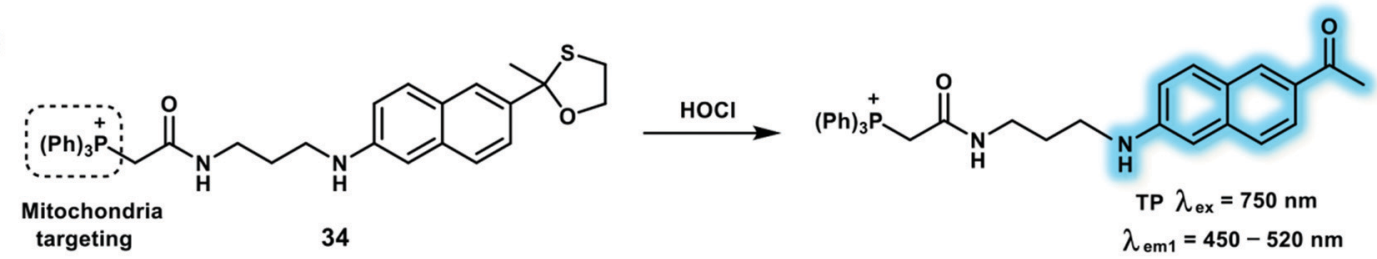

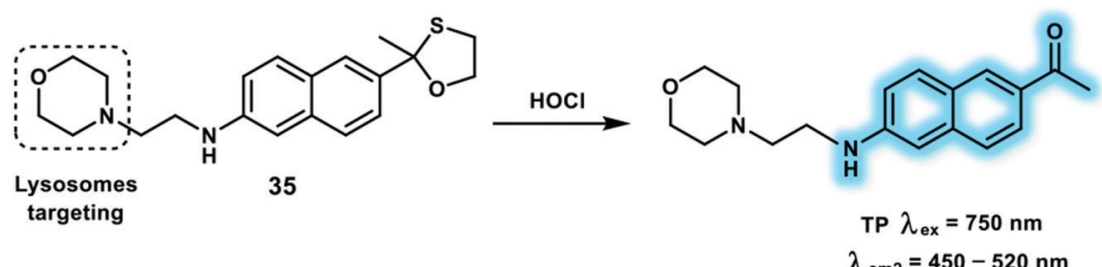

b)

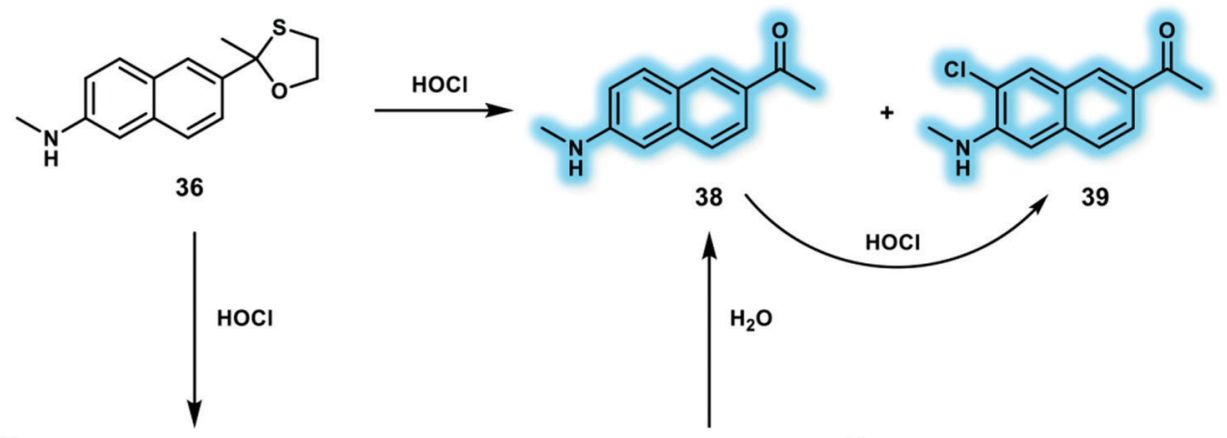<smiles>CNc1ccc2cc(C3(C)OCCS3=O)ccc2c1</smiles>

Scheme 10 (a) TP probes 34 and 35 for the detection of $\mathrm{HOCl}$ in mitochondria and lysosomes, respectively. (b) Proposed sensing mechanism for HOCl by 36.

the innate immune system and can oxidatively modify various protein functional groups (sulfhydryl and amino groups) to generate chloramine and aldehyde products, and improve immunity. It is reported that excess $\mathrm{HOCl}$ is associated with many diseases, such as rheumatoid arthritis, Parkinson's disease, Alzheimer's disease and cancers. Hence, it is necessary to develop HOCl-responsive probes in order to understand the biological effects. Many fluorescent probes have been reported for the detection of HOCl, which exploit its oxidizing capability towards recognition units such as $p$-methoxyphenol, dibenzoylhydrazine, oxime, thiol and selenide. Since, TPM facilitates higher spatial resolution and greater tissue penetration, numerous TP probes allowing TPEF imaging of $\mathrm{HOCl}$ in live systems have been developed. The reaction mechanism of 36 towards $\mathrm{HOCl}$ is shown in Scheme 10b. Probe $\mathbf{3 6}$ is oxidized by $\mathrm{HOCl}$ to form sulfoxide $\mathbf{3 7}$ which undergoes further oxidization to form an unstable sulfone which is hydrolyzed to generate 38 . Finally, 38 is partially chlorinated by excess $\mathrm{HOCl}$ to produce 39 . Probes 34 and 35 were developed for the detection of mitochondrial and lysosomal HOCl, respectively (Scheme 10a). ${ }^{19}$ Triphenylphosphine and morpholine were used as subcellular targeting groups for
34 and 35, respectively. Both 34 and 35 used acedan as the TP fluorophore and oxathiolane as reaction site towards HOCl. Deprotection of the oxathiolane to a ketone led to a strong "push-pull" system, as well as simultaneous fluorescence enhancement. The subcellular targeting abilities of probes $\mathbf{3 4}$ and $\mathbf{3 5}$ were evaluated in HeLa and LPS/IFN- $\gamma$-stimulated macrophage cells using MitoTracker Red and Lyso-Tracker Red, respectively. The application of the probes for tracking the in situ production of HOCl in the LPS-induced inflamed tissue of mice paws using TPEF imaging, indicated that the overproduction of $\mathrm{HOCl}$ could be detected under inflammation conditions.

The ratiometric TP probe $\mathbf{4 0}$ was developed for the detection of $\mathrm{HOCl}$ using the same recognition receptors as probes $\mathbf{3 4}$ and 35 , using a different TP fluorophore (quinolone) (Scheme 11). ${ }^{20}$ Oxidation and deprotection of the oxathiolane group by $\mathrm{HOCl}$ led to an enhanced ICT effect, with a red-shifted fluorescence. Moreover, the reaction product with a typical "push-pull" structure facilitated TP excitation, enabling the detection of HOCl fluctuations by TPM. The fluorescence response of probe $\mathbf{4 0}$ towards $\mathrm{HOCl}$ was investigated in $10 \mathrm{mM}$ PBS ( $\mathrm{pH}=7.4$, containing $5 \% \mathrm{DMF}$ ) 


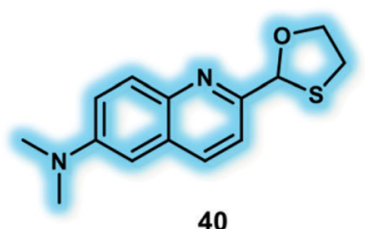

40

TP $\lambda_{\text {ex }}=820 \mathrm{~nm}$

$\lambda_{\mathrm{em} 1}=\mathbf{4 0 0}-\mathbf{5 0 0} \mathrm{nm}$

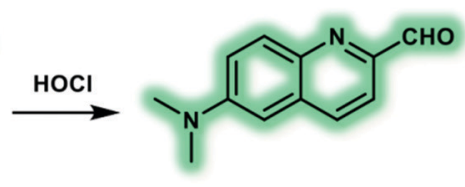

TP $\lambda_{\text {ex }}=820 \mathrm{~nm}$

$\lambda_{\text {em2 }}=550-600 \mathrm{~nm}$

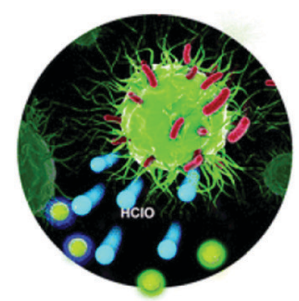

Scheme 11 Quinolone-based TP probe $\mathbf{4 0}$ for the ratiometric detection of HClO. Reproduced with permission from ref. 20. Copyright (2018) The Royal Society of Chemistry.

buffer solution. The addition of HOCl resulted in a decrease of the emission at $492 \mathrm{~nm}$ and concomitant increase in emission at $562 \mathrm{~nm}$. The reaction mechanism between probe 40 and $\mathrm{HOCl}$ was confirmed using mass spectroscopic analysis. Addition of $25 \mu \mathrm{M} \mathrm{HOCl}$ caused a maximal fluorescence ratio $\left(I_{562 \mathrm{~nm}} /\right.$ $\left.I_{492 \mathrm{~nm}}\right)$ value of 4.0. While, the maximum $\delta \times \Phi_{\mathrm{f}}$ value of $\mathbf{4 0}$ was determined to be $25 \mathrm{GM}$. The detection limit of probe $\mathbf{4 0}$ for $\mathrm{HOCl}$ was calculated to be $89 \mathrm{nM}$. In addition, detection of endogenous $\mathrm{HOCl}$ induced by LPS and PMA was achieved in RAW264.7 cells using TP excitation at $820 \mathrm{~nm}$. More importantly, overproduced HOCl during wound healing was monitored using probe $\mathbf{4 0}$ and ratiometric TPEF imaging.

Yoon et al. have developed a TP probe $\mathbf{4 1}$ for the detection of $\mathrm{HOCl}$ based on $\mathrm{B}-\mathrm{H}$ bond oxidation and it was used to visualize exogenous and endogenous HOCl in living systems by TPM. ${ }^{21}$ The pyrene of probe $\mathbf{4 1}$ serves as a TP fluorophore while the $\mathrm{N}$-heterocyclic carbene (NHC) boranes were used as specific responsive groups towards $\mathrm{HOCl}$ (Scheme 12). A low polarity environment promoted probe $\mathbf{4 1}$ to form colloidal aggregates and emit pyrene excimer fluorescence. Then HOCl triggered an oxidative hydrolysis reaction of the $\mathrm{B}-\mathrm{H}$ bond, leading to imidazolium salt formation, deaggregation and monomer fluorescence. Treatment of probe $\mathbf{4 1}$ with $\mathrm{HOCl}$ resulted in a decrease of emission intensity at $477 \mathrm{~nm}$, accompanied by an increase in emission intensity at $374 \mathrm{~nm}$. In addition, probe $\mathbf{4 1}$ exhibited excellent sensitivity and selectivity with a detection limit of $3 \mu \mathrm{M}$ towards HOCl over other ROS and RNS such as $\mathrm{ONOO}^{-}$and $\mathrm{H}_{2} \mathrm{O}_{2}$. These results prompted the use of probe $\mathbf{4 1}$ to visualize HOCl using TPM. Using NaOCl or LPS/IFN- $\gamma /$ PMA in RAW264.7 cells resulted in a reduced fluorescence ratio $\left(I_{\text {green }} / I_{\text {blue }}\right)$ under $710 \mathrm{~nm}$ excitation, demonstrating the possibility to monitor exogenous and endogenous HOCl fluctuations in live cells. Similar reduced fluorescence emission ratios $\left(I_{\text {green }} / I_{\text {blue }}\right)$ were observed in PMA-stimulated rat hippocampal slices using TPM.

Hypochlorite anion $\left(\mathrm{ClO}^{-}\right)$equilibrates with $\mathrm{HOCl}\left(\mathrm{p} K_{\mathrm{a}}\right.$ of 7.46) under physiological conditions at micromolar concentrations. However, abnormal levels of $\mathrm{ClO}^{-}$are related to various disorders and diseases. In biological systems, $\mathrm{ClO}^{-}$is mainly produced by the myeloperoxidase catalyzed reaction of $\mathrm{Cl}^{-}+\mathrm{H}_{2} \mathrm{O}_{2} \rightarrow \mathrm{HOCl}$. Inspired by good water solubility and stable photophysical properties of imidazolium salts, the Yoon group developed a turn-on TP probe 42 derived from imidazoline-2-thiones for the detection of $\mathrm{ClO}^{-}$ (Scheme 13). ${ }^{22}$ Probe 42 was non-fluorescent in PBS solution, then upon the addition of $\mathrm{ClO}^{-}(0-10 \mu \mathrm{M})$, a new emission peak at a)

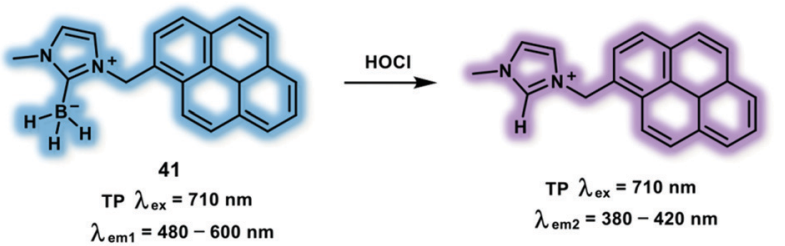

b)

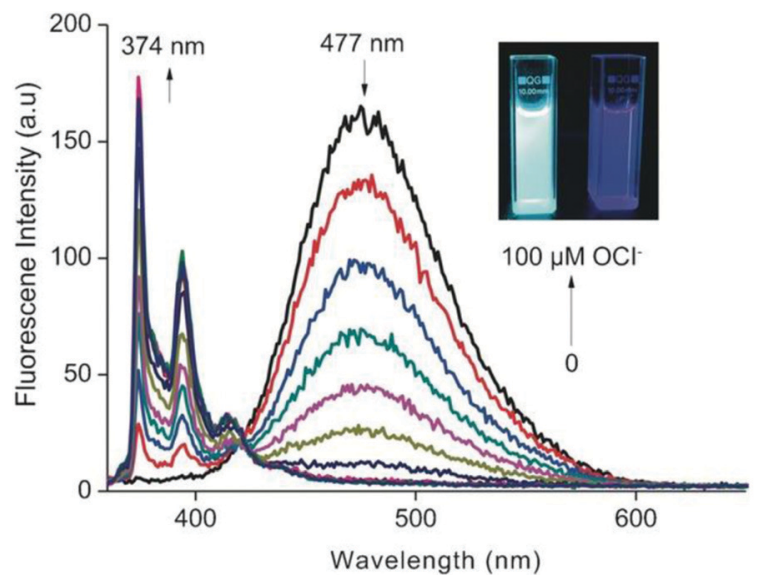

Scheme 12 Pyrene-based TP probe $\mathbf{4 1}$ for the ratiometric detection of $\mathrm{HOCl}$. (b) Fluorescence titration of $41(10 \mu \mathrm{M})$ with $\mathrm{NaOCl}(0-100 \mu \mathrm{M})$ in PBS (10 mM, pH 7.4) after $1 \mathrm{~min}$ at room temperature, with $350 \mathrm{~nm}$ excitation. Inset: Photographs of $\mathbf{4 1}$ before (left) and after (right) the addition 10 equiv. of $\mathrm{NaOCl}$ under UV irradiation (365 nm). Reproduced with permission from ref. 21. Copyright (2018) Wiley-VCH Verlag GmbH \& Co. KGaA, Weinheim.

around $505 \mathrm{~nm}$ emerged due to the formation of an imidazolium salt. The detection limit of probe $\mathbf{4 2}$ for $\mathrm{ClO}^{-}$was calculated to be $0.071 \mu \mathrm{M}$. TP photophysical properties of probe 42 indicated maximum $\delta \times \Phi_{\mathrm{f}}$ values of probe $\mathbf{4 2}$ and product $\mathbf{4 3}$ in ethanol at $800 \mathrm{~nm}$ excitation to be 0.4 and $8.4 \mathrm{GM}$, respectively. Similarly, 43 exhibited a higher $\Phi_{\mathrm{f}}$ than probe 42. RAW264.7 cells stained with probe 42 and pre-stimulated with exogenous $\mathrm{NaOCl}(200 \mu \mathrm{M})$ displayed an over 3-fold fluorescence increase compared to the control group under TP excitation at $800 \mathrm{~nm}$, Upon addition of the stimulants (LPS, IFN- $\gamma$ and PMA), similar enhanced fluorescence signals were observed. Significantly, using probe 42, elevated $\mathrm{ClO}^{-}$ levels in PMA stimulated rat hippocampal slice could be monitored at a depth of up to $100 \mu \mathrm{m}$ through TPEF imaging.

Sulfur dioxide $\left(\mathrm{SO}_{2}\right)$ can be regarded as a common environmental pollutant, usually equilibrating with sulfite $\left(\mathrm{SO}_{3}{ }^{2-}\right)$ and 


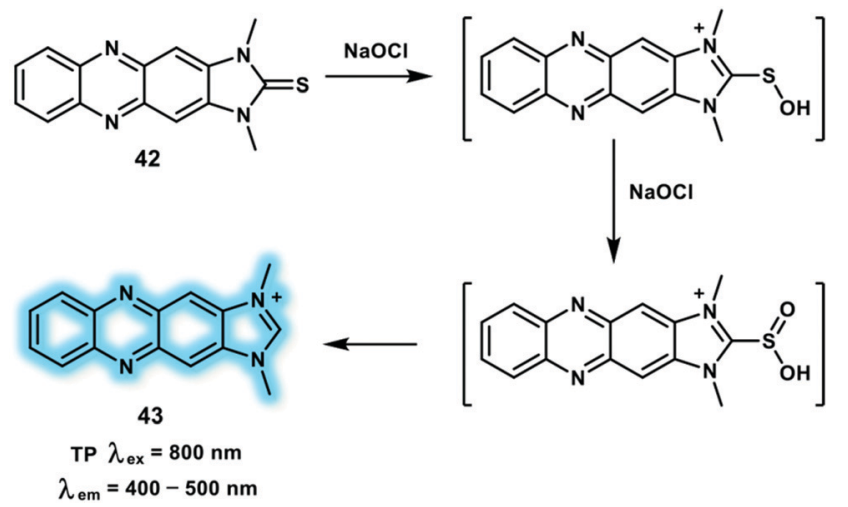

Scheme 13 Proposed mechanism of TP probe $\mathbf{4 2}$ for the detection of $\mathrm{ClO}^{-}$

bisulfite $\left(\mathrm{HSO}_{3}{ }^{-}\right)$in living systems. Due to its excellent preservative and antimicrobial properties, $\mathrm{SO}_{3}{ }^{2-}$ has been widely used in foods, beverages and medicines. Exposure to $\mathrm{SO}_{3}{ }^{2-}$ mainly through consuming food containing additives and contact in the workplace may induce a variety of adverse effect, including allergic skin reactions (dermatitis, urticaria) and respiratory symptoms (asthma, rhinitis). $\mathrm{SO}_{3}{ }^{2-}$ cytotoxicity has been reported to be mediated by enhanced ROS formation, which can lead to lipid peroxidation, DNA and protein damage. Excessive $\mathrm{SO}_{2}$ inhalation is connected with neurological disorders, for instance, stroke, migraine headaches, and brain cancer. Hence, there is an urgent need to develop effective imaging tools for monitoring sulfite $\left(\mathrm{SO}_{3}{ }^{2-}\right)$ and bisulfite $\left(\mathrm{HSO}_{3}{ }^{-}\right.$) levels in living systems. As such a near-infrared (NIR) TP probe 44, which is capable of the ratiometric detection of lysosomal bisulfite species, was developed (Scheme 14). ${ }^{23}$ The one-step condensation reaction between 8-hydroxyjulolidine and $o$-hydroxynaphthaldehyde formed benzopyronin derivative $\mathbf{4 4}$, where the morpholine group served as a lysosome-targeting group. Then bisulfite can trigger a 1,6-conjugate addition to benzopyronin dye, shortening the conjugated system, leading to a blue shifted fluorescence emission from $704 \mathrm{~nm}$ to $512 \mathrm{~nm}$.
The $\mathrm{HSO}_{3}{ }^{-}$reaction mechanism was confirmed using ${ }^{1} \mathrm{H}$ NMR and ${ }^{1} \mathrm{H}^{-13} \mathrm{C}$ heteronuclear single quantum coherence (HSQC) NMR analysis. Emission intensity ratios at 512 and $704 \mathrm{~nm}$ $\left(I_{512 \mathrm{~nm}} / I_{704 \mathrm{~nm}}\right)$ are linear with bisulfite concentration ranges from 0 to $50 \mu \mathrm{M}$ with a detection limit of $0.09 \mu \mathrm{M}$. Therefore, probe $\mathbf{4 4}$ was able to quantify bisulfite levels ratiometrically. The $\delta$ values of probe $\mathbf{4 4}$ and probe $\mathbf{4 4}+\mathrm{HSO}_{3}{ }^{-}$were determined to be 37 and $23 \mathrm{GM}$, respectively, under TP excitation at $750 \mathrm{~nm}$. The incubation of living HeLa cells with probe $\mathbf{4 4}$ and $\mathrm{NaHSO}_{3}$ displayed an increased green fluorescence signal (500$550 \mathrm{~nm}$ ) together with a decreased red fluorescence signal (625$665 \mathrm{~nm}$ ) under TP excitation at $750 \mathrm{~nm}$, which demonstrated that probe $\mathbf{4 4}$ could be used for real-time monitoring of intracellular bisulfite changes using TPM.

The most important primary ROS produced in living systems is $\mathrm{O}_{2}{ }^{--}$which plays an important role in maintaining the cellular redox homeostasis. As the precursor of most ROS/ RNS $\left(\mathrm{H}_{2} \mathrm{O}_{2},{ }^{\bullet} \mathrm{OH}, \mathrm{ONOO}^{-}\right), \mathrm{O}_{2}{ }^{--}$is generated by one-electron reduction of oxygen, which occurs mainly in the mitochondrial electron transport chain. However, excessive intracellular levels of $\mathrm{O}_{2}{ }^{\bullet-}$ contribute to ischemia reperfusion, degenerative disorders and many other oxidative-stress-induced diseases. In order to precisely understand the biological roles of $\mathrm{O}_{2}{ }^{--}$, wellestablished fluorescence imaging approaches have been used to detect native $\mathrm{O}_{2}{ }^{--}$levels in living cells and in vivo. These probes are based on either the redox reaction or non-redox mechanism, for instance, protection/deprotection strategy and nucleophilic reactions, allowing selective recognition of $\mathrm{O}_{2}{ }^{-{ }^{-}}$in systems where multiple ROS co-exist. Illuminated by previous work using the phosphinate group which is susceptible to highly nucleophilic $\mathrm{O}_{2}{ }^{--}$and $\mathrm{ONOO}^{-}$, a novel turn-on phosphinothioate-based TP probe $\mathbf{4 5}$ was developed for sensing $\mathrm{O}_{2}{ }^{\bullet-}$ (Scheme 15). ${ }^{24}$ With this research the phosphinothioate moiety was used as a specific reactive site towards $\mathrm{O}_{2}{ }^{--}$for the first time. Notably, probe $\mathbf{4 5}$ was easy to synthesize through onestep reaction and was particularly sensitive and selective towards $\mathrm{O}_{2}{ }^{--}$. The emission intensity at $470 \mathrm{~nm}$ of probe 45 exhibited a linear relationship towards $\mathrm{O}_{2}{ }^{\bullet-}$ concentrations (0-20 equiv.) due

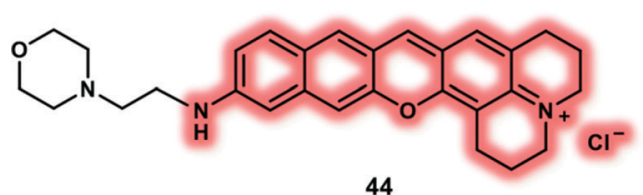

44

TP $\lambda_{\text {ex }}=750 \mathrm{~nm}$

$\lambda_{\mathrm{em} 1}=625-665 \mathrm{~nm}$

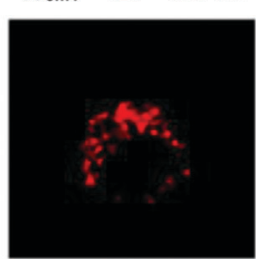

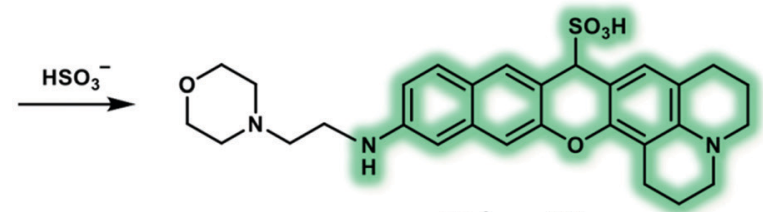

TP $\lambda_{\text {ex }}=750 \mathrm{~nm}$

$\lambda_{\text {em2 }}=500-550 \mathrm{~nm}$

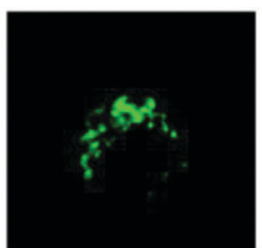

Scheme 14 Benzopyronin-based TP probe $\mathbf{4 4}$ for the ratiometric detection of lysosomal $\mathrm{HSO}_{3}{ }^{-}$. Reproduced with permission from ref. 23. Copyright (2019) American Chemical Society. 
a)<smiles>CN(C)c1cccc2c(P(=O)(O)c3ccccc3)cccc12</smiles>

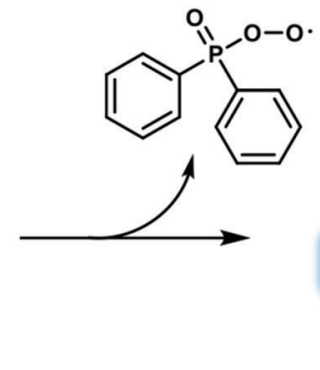

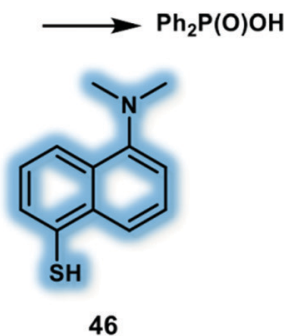

45

TP $\lambda_{\text {ex }}=740 \mathrm{~nm}$

$\lambda_{\text {em }}=400-600 \mathrm{~nm}$

b)

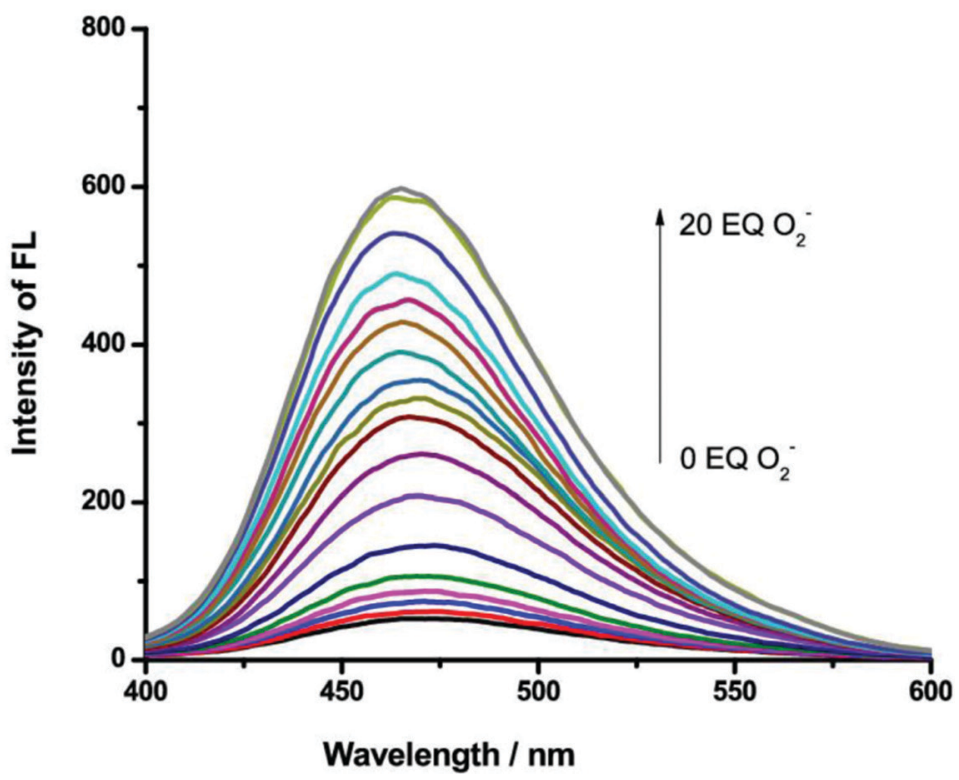

Scheme 15 (a) Sensing mechanism of phosphinothioate-based TP probe $\mathbf{4 5}$ for the detection of $\mathrm{O}_{2}{ }^{--}$. (b) Fluorescence spectra of probe $\mathbf{4 5}$ in the mixture of PBS/DMF ( $/ \mathrm{v}=7: 3)$ was obtained upon additions of $\mathrm{O}_{2}{ }^{-}(0-200 \mu \mathrm{M}) ; \lambda_{\mathrm{ex}}=345 \mathrm{~nm} ; \mathrm{slit}, 5 / 5 \mathrm{~nm}$. Reproduced with permission from ref. 24 . Copyright (2019) American Chemical Society.

to the formation of fluorescent compound 46. The response of probe 45 towards $\mathrm{O}_{2}^{\bullet-}$ was investigated by evaluating the kinetics and resulted in the determination of a pseudo-first-order rate constant $\left(k_{\text {obs }}\right)$ of $1.0 \times 10^{-2} \mathrm{~min}^{-1}$. A 2-fold TPEF intensity enhancement was observed in PMA-induced RAW264.7 macrophages confirming the feasibility of using probe $\mathbf{4 5}$ to detect endogenous $\mathrm{O}_{2}{ }^{\bullet-}$ levels in living cells. Finally, probe $\mathbf{4 5}$ was used to image endogenous $\mathrm{O}_{2}{ }^{\bullet-}$ in fresh rat hippocampal tissue with a TP excitation at $740 \mathrm{~nm}$. Similar to the fluorescence behavior in cells, significant fluorescence enhancement was observed in rat hippocampal slices under PMA-stimulation.

\section{Two-photon (TP) excitation-based fluorescent sensors for small neutral molecules}

Owing to pivotal role neutral molecules play in maintaining normal biological function and regulating multiple critical biological processes, it is essential to monitor neutral molecules in living systems. To date, many TP probes have been developed for neutral molecules in complicated biological systems, exhibiting high sensitivity and the selective detection of neutral molecules in vitro and in vivo. In this section, some representative TP probes for biologically important small neutral molecules will be summarized, and the working mechanisms and biological applications of the TP probes will be discussed.

Nitroxyl (HNO), is a one electron reduced form of nitric oxide (NO), that is involved in many important biological functions. It has been demonstrated that HNO has a cardioprotective role in acute heart failure. In addition, HNO serves as a signaling molecule that promotes vasorelaxation and suppresses vascular smooth muscle cell proliferation. The $\mathrm{p} K_{\mathrm{a}}$ value of HNO is 11.4, and therefore HNO predominates over the nitroxyl anion $\left(\mathrm{NO}^{-}\right)$at physiological $\mathrm{pH}$. Due to its high reactivity and facile dimerization and dehydration to nitrous oxide $\left(\mathrm{N}_{2} \mathrm{O}\right)$, Angeli's salt (AS, a source of HNO) have been widely used to explore HNO in vivo. A turn-on probe 47 has been developed based on the TP fluorophore 6-hydroxyl-quinoline-2benzothiazole for the detection of HNO (Scheme 16). ${ }^{25}$ With probe 47, 2-(diphenylphosphino)benzoate was used as the reactive site towards $\mathrm{HNO}$. In the presence of $\mathrm{HNO}$, probe 47 undergoes an aza-ylide reaction by forming 48, which then 
a)
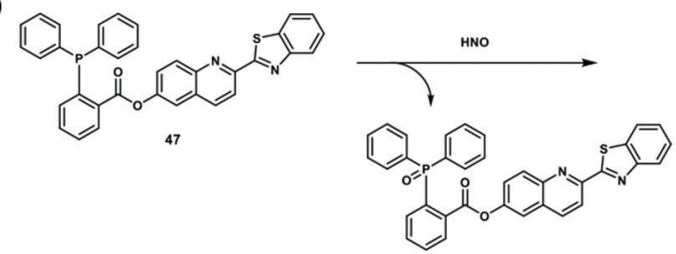

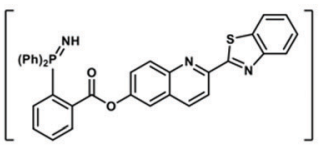

48

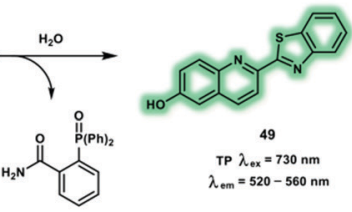

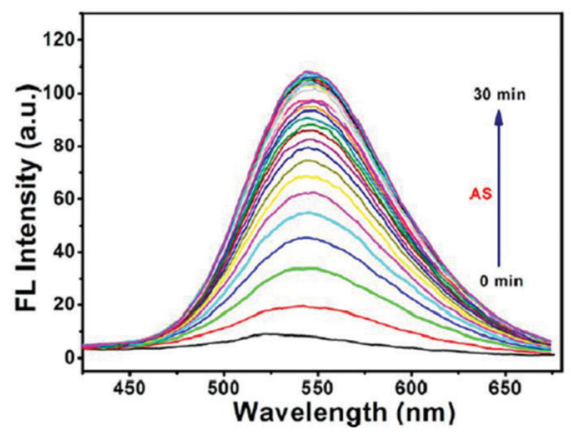

c)

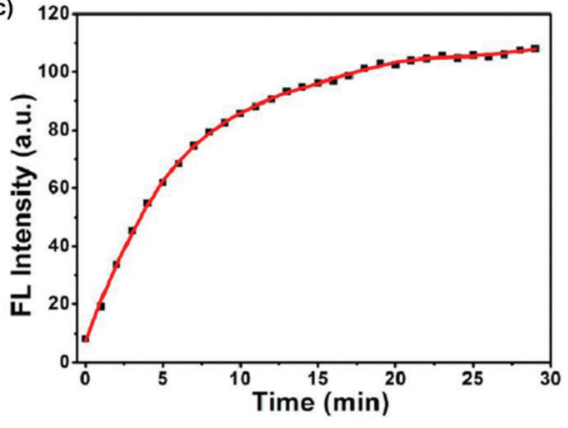

Scheme 16 (a) Sensing mechanism of TP probe $\mathbf{4 7}$ for the detection of HNO. (b and c) Response time of probe $\mathbf{4 7}$ toward HNO. $\lambda_{\mathrm{ex}}=363 \mathrm{~nm}$, slit: $5 / 5 \mathrm{~nm}$. Reproduced with permission from ref. 25. Copyright (2018) American Chemical Society.

undergoes Staudinger ligation to generate 49 (Scheme 16a), resulting in a fluorescence enhancement at $550 \mathrm{~nm}$ in PBS buffer solution (Scheme 16b and c). Probe 47 exhibited advantageous properties including high sensitivity (detection limit of $0.19 \mu \mathrm{M})$ and rapid response $(20 \mathrm{~min})$. Subsequently, the probe was used to track exogenous and endogenous HNO levels using TPM. Using living RAW264.7 cells with probe 47 an obvious increased green fluorescence signal upon TP excitation at $730 \mathrm{~nm}$ after incubation with AS was observed. In addition endogenous HNO was monitored in living HeLa cells upon addition of $\mathrm{L}$-ascorbate and sodium nitroprusside (a source of NO), which forms HNO in biological media. These results indicated that probe $\mathbf{4 7}$ can detect fluctuations of HNO in living cells using TPM.

NO is a gaseous biological signaling molecule, which is produced from NO synthase by catalyzing the reaction of L-arginine, molecular oxygen and reduced nicotinamide-adeninedinucleotide phosphate (NADPH). It was found that NO acts as a key signaling molecule for the regulation of many physiological and pathological processes. In particular, NO could function as a neurotransmitter, which acts on adjacent neurons by diffusion in the central nervous system. In addition, the cardiovascular protective ability of NO has been demonstrated. A dysfunction in NO homeostasis has been implicated in many disorders and diseases, such as Alzheimer's disease, pulmonary fibrosis, ischemia-reperfusion injury, and cancer. To understand the biological role of NO, numerous fluorescent probes derived from $o$-phenylenediamine and transition-metal have been developed. Due to the extended $\pi$-conjugated system and easily polarized electronic structure Nile Red, a far-red emissive TP probe $\mathbf{5 0}$ has been developed for NO (Scheme 17). ${ }^{26}$ Probe $\mathbf{5 0}$ was constructed using $o$-phenylenediamine as a NO recognition site and Nile Red as red-emissive TP fluorophore. Initially, the fluorescence of Nile Red was blocked by the $o$-phenylenediamine unit via a PeT process. When probe $\mathbf{5 0}$ comes into contact with NO the $o$-phenylenediamine is transformed into a triazole which disrupts the PeT process, resulting in a far-red emission (maximum at $650 \mathrm{~nm}$ ). The maximum $\delta \times \Phi_{\mathrm{f}}$ value of the reaction product was calculated to be $38 \mathrm{GM}$ using an excitation of $820 \mathrm{~nm}$, facilitating the use of probe $\mathbf{5 0}$ for tracking NO under TP excitation. The fast response of probe $\mathbf{5 0}$ towards NO within $180 \mathrm{~s}$ with a low detection limit of $46 \mathrm{nM}$ was observed. The non-toxic probe $\mathbf{5 0}$ was then used for the TPEF imaging of exogenous and endogenous NO in HeLa and RAW264.7 cells respectively, using $820 \mathrm{~nm}$ excitation. Additionally, NO in mouse liver tissues at a depth of $168 \mu \mathrm{m}$ was imaged using probe 50. The resultant fluorescence intensity exhibited a dose-dependent response towards NO in inflamed mouse tissues.

$\mathrm{H}_{2} \mathrm{O}_{2}$, a key regulator of cellular signaling, is derived from $\mathrm{O}_{2}{ }^{\cdot-}$ through NADPH oxidase complex activation. $\mathrm{H}_{2} \mathrm{O}_{2}$ participates in various biological responses and stimulates cell proliferation, differentiation, migration and cell death. $\mathrm{H}_{2} \mathrm{O}_{2}$ mediates cellular signaling processes by oxidizing critical thiols within redox-sensitive proteins. Increasing evidence points to excessive $\mathrm{H}_{2} \mathrm{O}_{2}$ generation being involved with many diseases, for instance, cardiovascular diseases, neurodegenerative disorders, and cancer. Therefore, developing an efficient $\mathrm{H}_{2} \mathrm{O}_{2}$-responsive fluorescent probe is of great significance for elucidating the biological function of $\mathrm{H}_{2} \mathrm{O}_{2}$. Carbon monoxide (CO) is regarded as a promoter for vasorelaxation. Probe $\mathbf{5 1}$ is a TP flavonol-boronate-based fluorescent sensor, which enables specific $\mathrm{H}_{2} \mathrm{O}_{2}$ response and precise CO release in a photo-controllable manner (Scheme 18) ${ }^{27}$ Probe $\mathbf{5 1}$ incorporates a boronate group to specifically recognize $\mathrm{H}_{2} \mathrm{O}_{2}$ and upon the addition of $\mathrm{H}_{2} \mathrm{O}_{2}$ the protected hydroxyl group of 51 was liberated. Triggering an ESIPT process, causing an increased emission at $585 \mathrm{~nm}$. A 19-fold enhancement of fluorescence intensity at $585 v s .485 \mathrm{~nm}\left(I_{585 n m} / I_{485 \mathrm{~nm}}\right)$ in the presence of 5 equiv. of $\mathrm{H}_{2} \mathrm{O}_{2}$ was observed, with a detection limit of $66 \mathrm{nM}$. After continuous irradiation using a $405 \mathrm{~nm}$ light source with power $15 \mathrm{~mW} \mathrm{~cm}{ }^{-2}$, the fluorescence emission at $585 \mathrm{~nm}$ decreased dramatically, indicating CO photo-release. Incubation of probe $\mathbf{5 1}$ with PMA in vascular smooth muscle 
a)

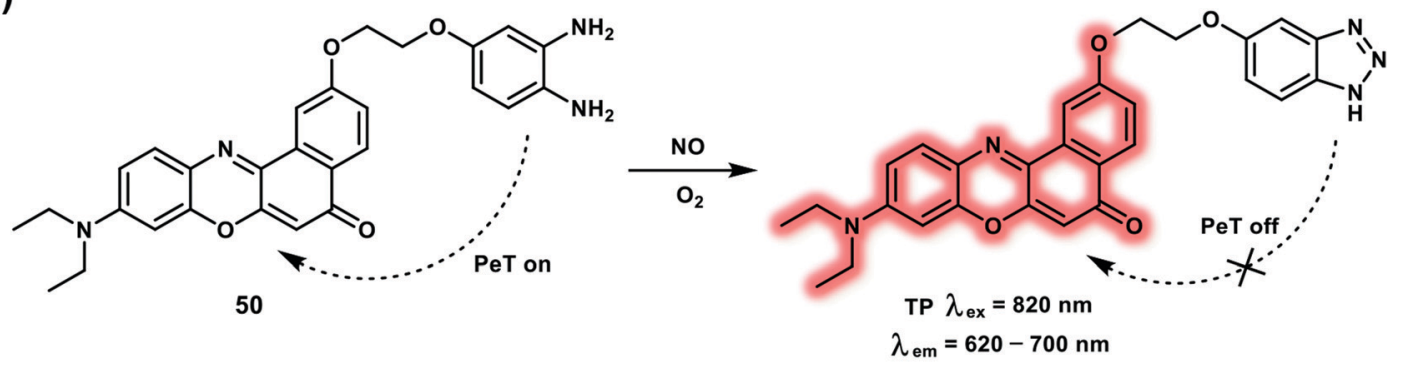

b)

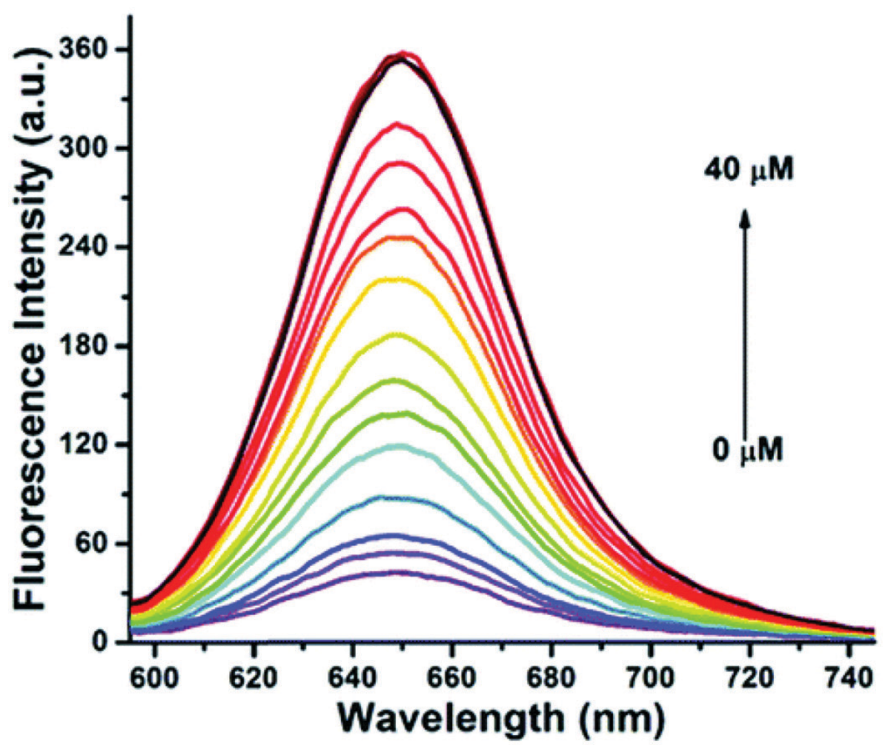

Scheme 17 (a) TP probe $\mathbf{5 0}$ for the detection of NO. (b) Fluorescence spectra of $5.0 \mu \mathrm{M}$ of $\mathbf{5 0}$ with NO $(0-40 \mu \mathrm{M})$ after $180 \mathrm{~s}$ in $10 \mathrm{mM}$ PBS (pH = 7.4 , containing 10\% DMF). Reproduced with permission from ref. 26. Copyright (2016) The Royal Society of Chemistry.

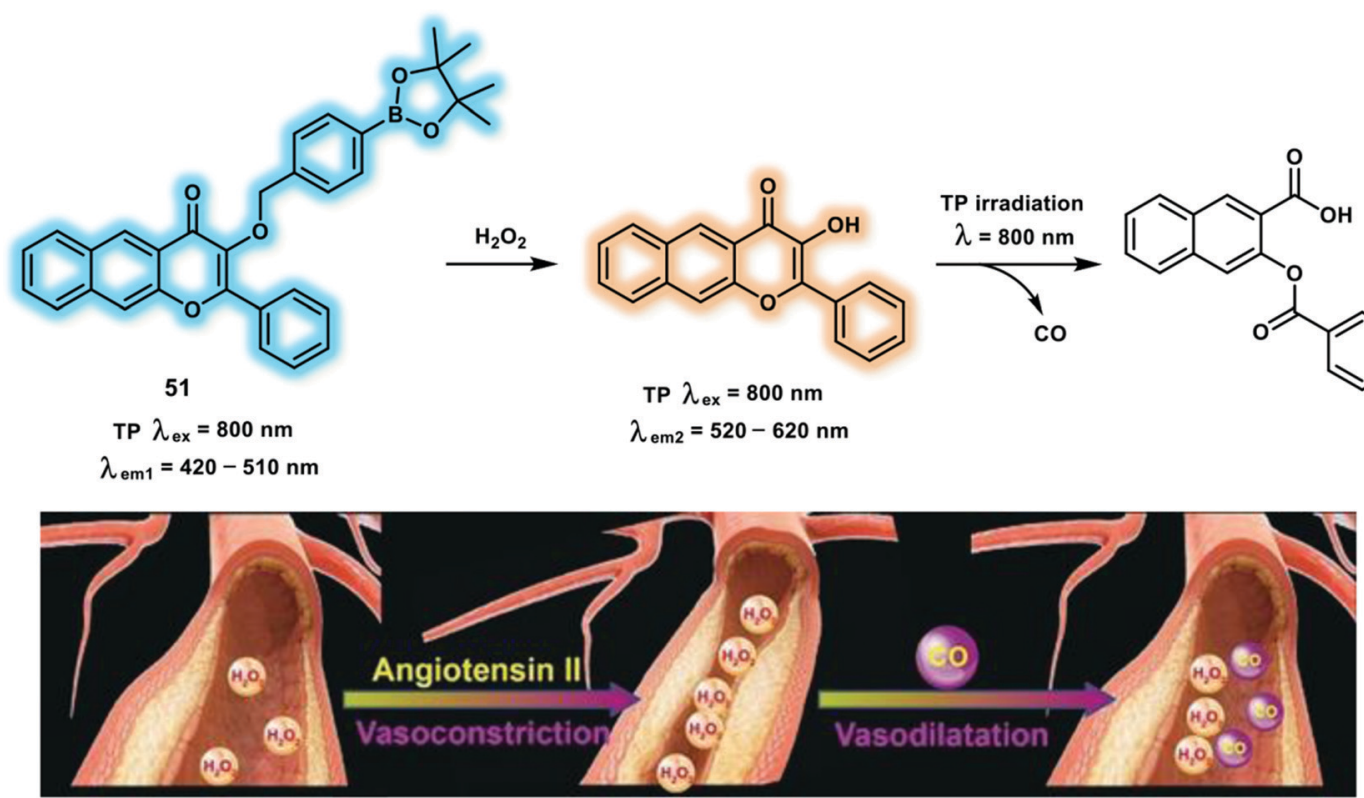

Scheme 18 The chemical structure of TP probe $\mathbf{5 1}$ and the proposed CO photo-release mechanism. Reproduced with permission from ref. 27. Copyright (2018) Wiley-VCH Verlag GmbH \& Co. KGaA, Weinheim.

cells (VSMCs), resulted in PMA dose-dependent $\mathrm{H}_{2} \mathrm{O}_{2}$ fluctuations, as such probe $\mathbf{5 1}$ could be used to map $\mathrm{H}_{2} \mathrm{O}_{2}$ levels in living cells. Furthermore, during light irradiation with a TP laser at $800 \mathrm{~nm}$, the fluorescence signals ratio $\left(I_{420-510 \mathrm{~nm}} / I_{520-620 \mathrm{~nm}}\right)$ 
a)

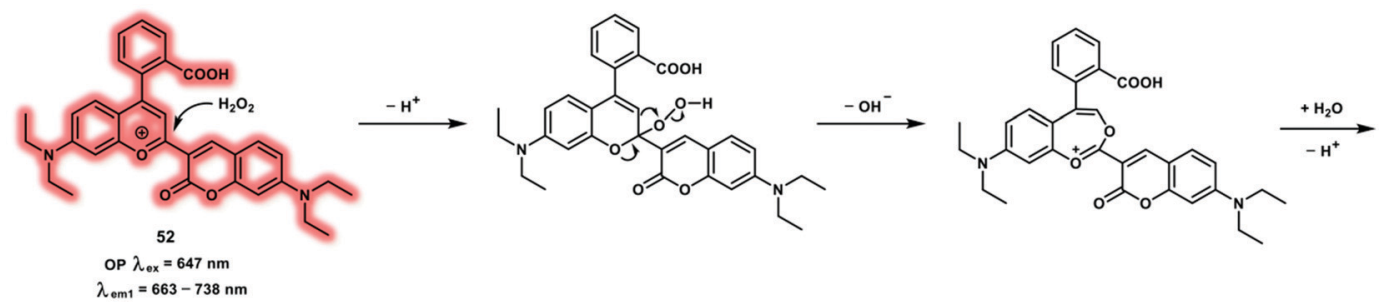

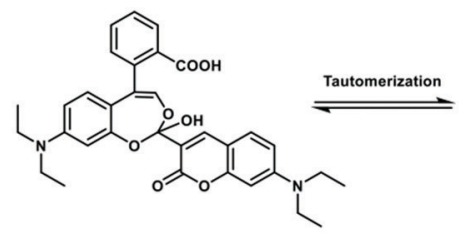

b)

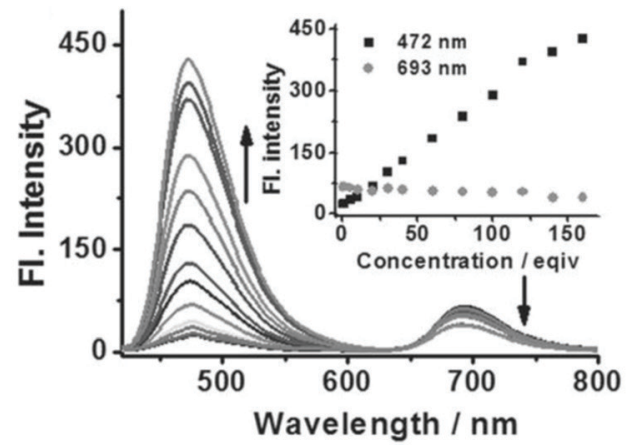

c)

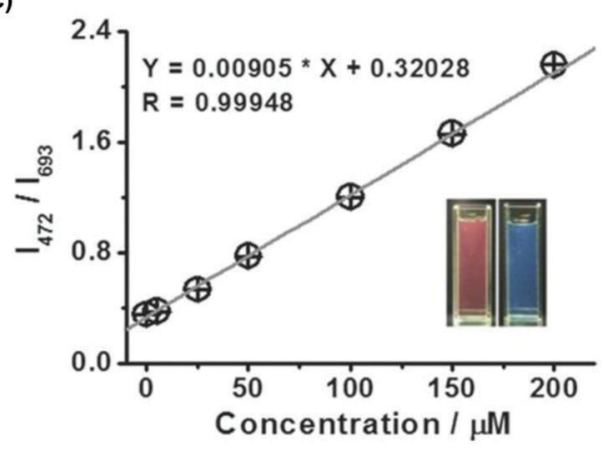

Scheme 19 (a) Sensing mechanism of probe $\mathbf{5 2}$ for the detection of $\mathrm{H}_{2} \mathrm{O}_{2}$ with simultaneous NIR and TP emissions. (b) Fluorescence spectra of $\mathbf{5 2}$ $(5 \mu \mathrm{M})$ in the presence of different concentrations of $\mathrm{H}_{2} \mathrm{O}_{2}$ under $\lambda_{\text {ex }}$ at $410 \mathrm{~nm}$ in PBS, inset: the fluorescence intensities at 472 and $693 \mathrm{~nm}$ as a function of $\mathrm{H}_{2} \mathrm{O}_{2}$ concentration. (c) Linear relationship between $I_{472 \mathrm{~nm}} / I_{693 \mathrm{~nm}}$ and $\mathrm{H}_{2} \mathrm{O}_{2}$ concentration in the range, inset: photographs of $\mathbf{5 2}$ in the absence (left) and presence (right) of $\mathrm{H}_{2} \mathrm{O}_{2}$ (120 equiv.) under $365 \mathrm{~nm}$ ultraviolet radiation. Reproduced with permission from ref. 28. Copyright (2018) Wiley-VCH Verlag GmbH \& Co. KGaA, Weinheim.

reduced, indicating $\mathrm{CO}$ photo-release. Time-dependent $\mathrm{H}_{2} \mathrm{O}_{2}$ fluctuations and TP-induced CO release were monitored in larval zebrafish. Upon angiotensin II administration, upregulated $\mathrm{H}_{2} \mathrm{O}_{2}$ levels associated with oxidative stress in VSMCs were observed. More importantly, vasodilatation effect of $\mathrm{CO}$ was also visualized in vessel of zebrafish.

A ratiometric probe $\mathbf{5 2}$ with a novel oxonium response site for $\mathrm{H}_{2} \mathrm{O}_{2}$, was constructed for the simultaneous NIR and TP fluorescence imaging of $\mathrm{H}_{2} \mathrm{O}_{2}$ in living systems. A large $\pi$-conjugated system was constructed based on chromenylium and coumarin groups. Probe 52 exhibited a large NIR emission at $693 \mathrm{~nm}$ and a small emission at $472 \mathrm{~nm}$, facilitating NIR fluorescence imaging (Scheme 19). ${ }^{28}$ Upon the addition of $\mathrm{H}_{2} \mathrm{O}_{2}$, probe 52 exhibited a fluorescence enhancement at $472 \mathrm{~nm}$ along with a decrease at $693 \mathrm{~nm}$ (Schemes 19b and c). This was rationalized by oxidative breakdown of the oxonium and the sensing mechanism is based on Baeyer-Villiger reaction (Scheme 19a). The detection limit of $\mathrm{H}_{2} \mathrm{O}_{2}$ established by probe 52 was calculated to be $3.15 \mu \mathrm{M}$. The maximum $\delta$ of 53 was reported to be $164.7 \mathrm{GM}$ at $760 \mathrm{~nm}$, enabling the possibility of the simultaneous detection of $\mathrm{H}_{2} \mathrm{O}_{2}$ using NIR and TP fluorescence. Using probe 52, exogenous and endogenous $\mathrm{H}_{2} \mathrm{O}_{2}$ were imaged in living HeLa cells and RAW264.7 macrophages, respectively, using NIR and TP fluorescence channels.
Furthermore, probe 52 was used to image $\mathrm{H}_{2} \mathrm{O}_{2}$ fluctuations in zebrafish using both the OP and TP modes.

As a fundamental constituent amino acid of proteins, cysteine (Cys) plays important roles in protein synthesis and new tissue growth in the body. Total Cys levels in plasma are around $200 \mu \mathrm{M}$. Low levels of Cys in living systems has been correlated with liver damage, lethargy, edema and skin lesions. The polarized sulfur atom of Cys is prone to post-translational oxidative modifications, which control various biological processes, such as protein turnover, metal binding, catalysis and signal transduction. Over the past few years, diverse Cys-responsive fluorescent probes have been developed using the redox properties and nucleophilicity of sulfydryl within Cys. Since, the structure and reactivity of Cys is like homocysteine (Hcy) and glutathione (GSH), the differentiation of Cys, Hcy and GSH in living systems still remains a challenge. The commercial compound $\mathbf{5 4}$ has been reported for the selective detection of Cys after screening experiments (Scheme 20). ${ }^{29}$ Probe 54 went through aromatic nucleophilic substitution with the thiol group of Cys, producing the cyclized product 55 with large fluorescence enhancement. The strong electron-donating amino group on the aromatic core and inflexible cyclized structure of $\mathbf{5 5}$, resulting in the selective detection of Cys with TPEF using probe $\mathbf{5 4}$. 


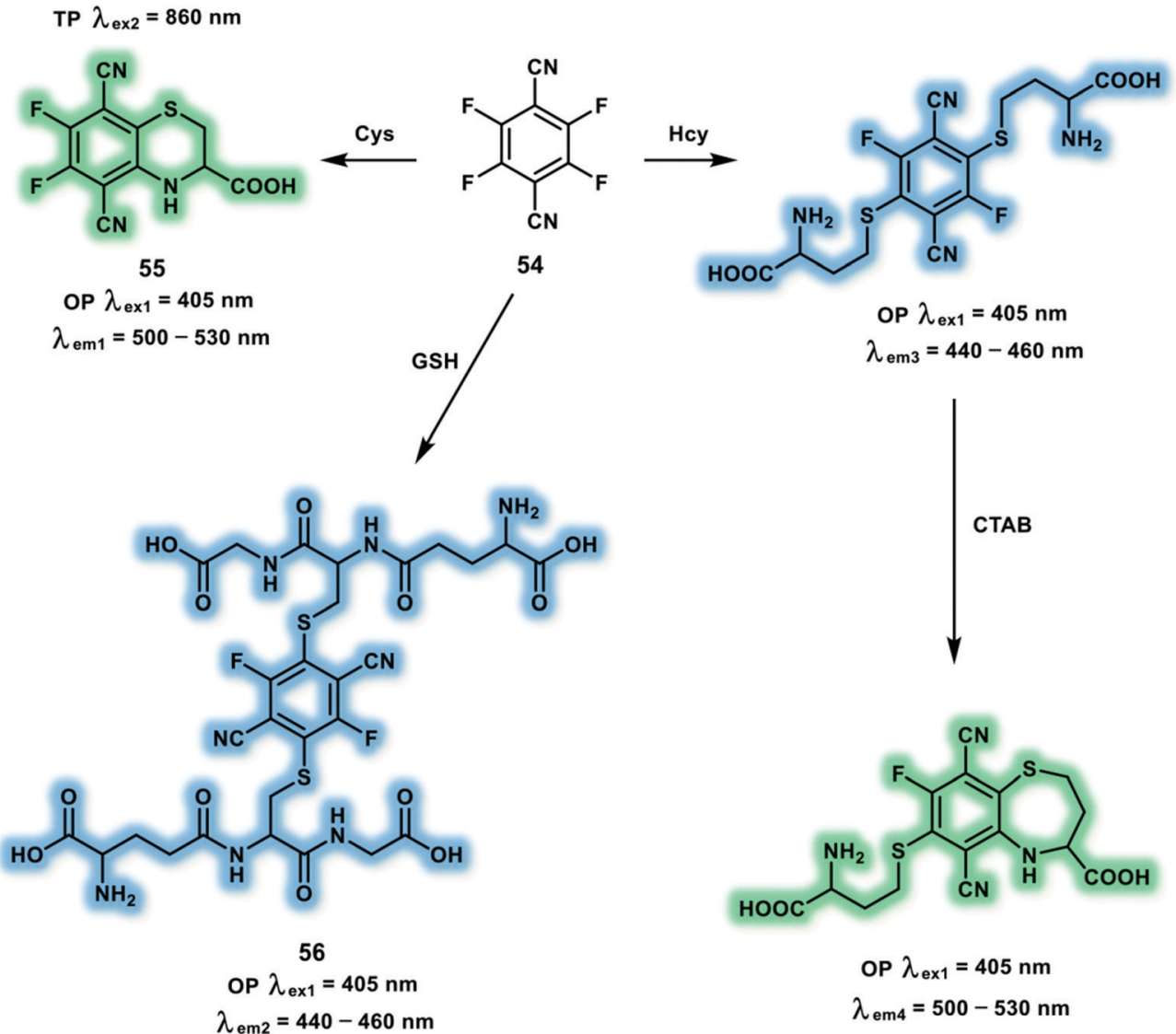

Scheme 20 Probe $\mathbf{5 4}$ for the selective detection of Cys. Note: fluorescence of the products $\mathbf{5 5}$ and $\mathbf{5 6}$ are not interfered by CTAB.

A significant fluorescence intensity enhancement at $500 \mathrm{~nm}$ was observed under excitation at $420 \mathrm{~nm}$. Probe 54 exhibited fluorescence emission centered at $450 \mathrm{~nm}$ when exposed to Hcy or GSH under $350 \mathrm{~nm}$ excitation. Moreover, addition of cetyltrimethylammonium bromide (CTAB) to the product of $\mathbf{5 4}$ and Hcy induced a fluorescent colour change from blue to green, which was due to the intramolecular cyclisation. Probe 54 exhibited good performance for the imaging of Cys levels in living cells, displaying a bright green fluorescence with TP excitation.

A TP fluorescent probe $\mathbf{5 7}$ was constructed based on a TP coumarin 120 fluorophore for the specific detection of Cys without interference from other biothiols (Scheme 21). ${ }^{30}$ With probe $\mathbf{5 7}$, the thiobenzoate was chosen as the specific recognition site. Probe 57 exhibits negligible fluorescence at $443 \mathrm{~nm}$ because of the weakened electron-donating ability of the amino group. In the presence of Cys $(100 \mu \mathrm{M})$, nucleophilic reaction and five-membered ring formation results in enhanced electron-donating ability and increased push-pull electronic effect, leading to 25-fold fluorescence increase at $443 \mathrm{~nm}$ under excitation with OP (340 nm). After reaction with Cys, the $\delta$ changed from 7.39 to $18.01 \mathrm{GM}$, with an increased $\Phi_{\mathrm{f}}$ from 0.16 to 0.49 . Furthermore, no significant fluorescence change was observed upon the addition of Hcy or GSH, indicating that the probe could differentiate Cys over Hcy and GSH. The specificity was confirmed using high-performance liquid chromatography. Using probe 57 a 2.1-fold fluorescence decrease was observed in the brains of mice susceptible to chronic unpredictable mild stress (CUMS) using TPEF imaging, demonstrating that Cys levels in the CUMS mice was reduced.

Carbon monoxide (CO) is a gaseous signaling molecule in living systems, which plays important roles in cytoprotection due to its vasodilating, anti-inflammatory properties during oxidative stress and ischemia-reperfusion injury. Endogenous sources of CO are generated from heme oxygenase-mediated heme oxidative breakdown. The toxic effect of CO is caused by binding to hemoglobin strongly and forming carboxyhemoglobin, thereby leading to reduction in the oxygen-carrying capacity of the blood. The affinity of hemoglobin for CO is around 210 to 250 times that for oxygen. It has been reported that CO has a significant correlation with some diseases, such as vascular injury, ventilator-induced lung injury, ischemia-reperfusion and cancer. Probes for CO have been developed using palladiumcontaining complexes to track CO in biological systems. Probe $\mathbf{5 8}$ is a TP excitation NIR emissive probe suitable for the detection of $\mathrm{CO}$ that was derived from Nile Red dye as the fluorogen, with heteroatoms acting as ligands for the Pd (Scheme 22). ${ }^{31}$ The quenched fluorescence of the Nile Red dye by Pd atoms could be restored through the reaction of CO with Pd. Therefore, in presence of 100 equiv. CO, a 60-fold fluorescence enhancement at $660 \mathrm{~nm}$ was observed in PBS (10 mM PBS, pH 7.4, with 5\% DMSO as cosolvent) with excitation at $580 \mathrm{~nm}$. The advantageous features of probe $\mathbf{5 8}$ 
a)

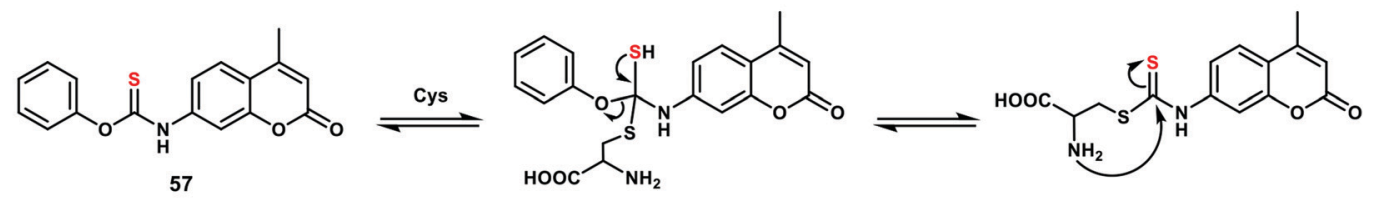

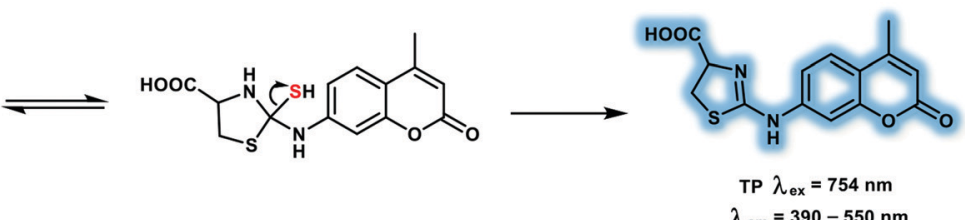

b)

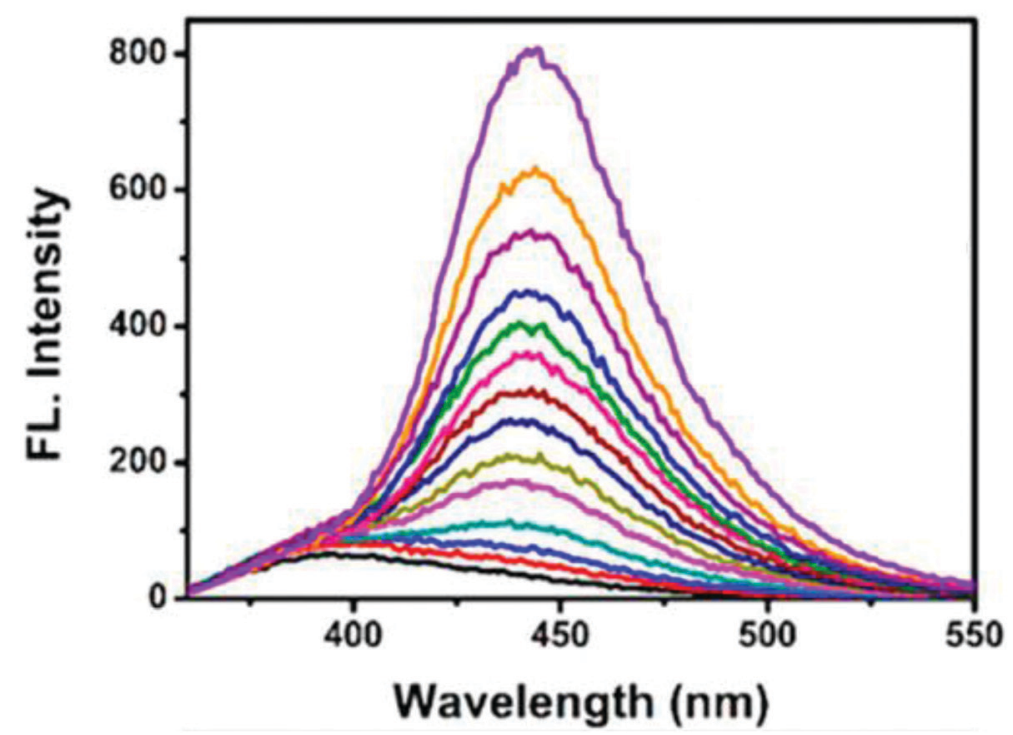

Scheme 21 (a) TP probe $\mathbf{5 7}$ for the detection of Cys. (b) Changes in the fluorescence of $\mathbf{5 7}(20 \mu \mathrm{M})$ after the addition of various concentrations of Cys $(0-100 \mu M)$. Reproduced with permission from ref. 30. Copyright (2019) American Chemical Society.

includes high sensitivity with a detection limit down to $50 \mathrm{nM}$, a large fluorescence enhancement, high selectivity and TP excitation with NIR emission. Interestingly, the merits of probe $\mathbf{5 8}$ enabled the tracking of endogenous $\mathrm{CO}$ in zebrafish embryos and exogenous $\mathrm{CO}$ in mouse tissues using TPEF imaging. Excessive production of $\mathrm{CO}$ was visualized in zebrafish embryos under conditions of hypoxia using TP excitation at $760 \mathrm{~nm}$. Stronger NIR fluorescence was observed for CORM-2 (CO donor)-treated liver tissue slices at a depth of up to $130 \mu \mathrm{m}$ using TPM.

Palladium-based fluorescent probes have been developed for the detection of $\mathrm{CO}$, however these probes have many drawbacks such as delayed fluorescent response times, and they contain highly toxic heavy metal salts. Probe $\mathbf{5 9}$ is a TP probe based on ruthenium(II) vinyl complex (Scheme 23a). ${ }^{32}$ With probe 59, a TP fluorophore 5-(3-thienyl)-2,1,3-benzothiadiazole (TBTD) was used as fluorescence reporter and an oligoethylene glycol moiety was used to improve water solubility. Probe $\mathbf{5 9}$ displayed a weak fluorescence emission at $500 \mathrm{~nm}$ under $355 \mathrm{~nm}$ excitation, that was attributed to quenching of the TBTD fluorescence by the ruthenium(II) center (heavy atom effect). Exposure to $\mathrm{CO}$ gas resulted in binding with the ruthenium(II) complex and release of the TBTD fluorophore via indicator displacement (i.e. the system is an IDA), resulting in a fluorescence enhancement at $500 \mathrm{~nm}$ in PBS (pH 7.4)acetone 99.9: $0.1 \mathrm{v} / \mathrm{v}$ solution (Scheme 23b). A dose-dependent CORM-3 and hemin TPEF intracellular response was observed for RAW264.7 cells with a $715 \mathrm{~nm}$ excitation. Probe $\mathbf{5 9}$ was used to image CO in a LPS-induced air pouch inflammation mouse model using a multiphoton microscopy.

Adenosine triphosphate (ATP), serves as a fast neurotransmitter or neuromodulator and plays an important role in mediating synaptic transmission and synaptic efficacy. In addition, ATP can participate in immunogenic cell death as a signaling molecule. Deficiencies in ATP levels are associated with hypoglycaemia, ischemia injury and neuronal disorders. Thus, monitoring ATP levels in living systems is important in order to help evaluate biological mechanisms, and signaling pathways that are mediated by ATP. Ahn et al. reported on the monitoring a lysosomal membrane fusion processes in living cells using a novel ratiometric TP fluorescent probe, which enables the quantitative tracking of lysosomal ATP fluctuations. A TP probe 60 was constructed by linking a BODIPY dye and rhodamine $6 \mathrm{G}$ using a tetramine chain for the ratiometric detection of lysosomal ATP (Scheme 24). ${ }^{33}$ Under excitation at $403 \mathrm{~nm}$, the probe 
a)

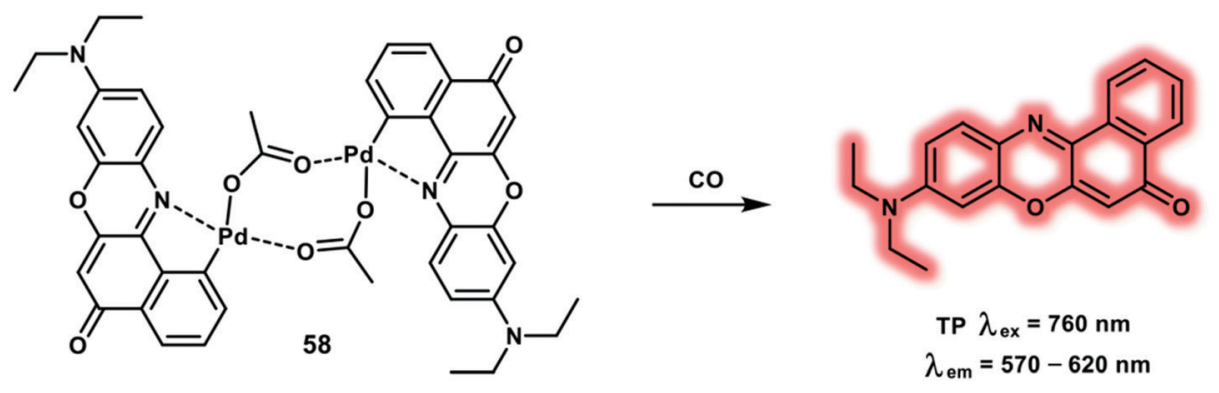

b)
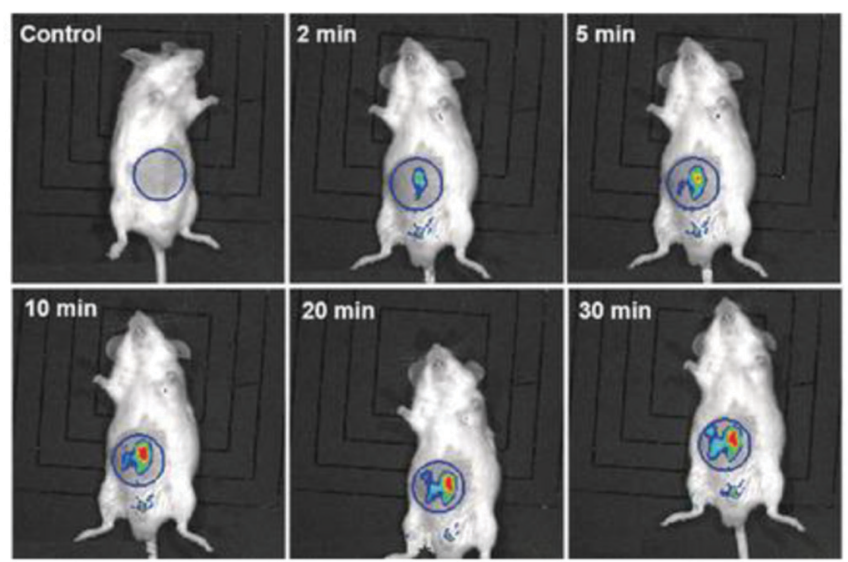

C)
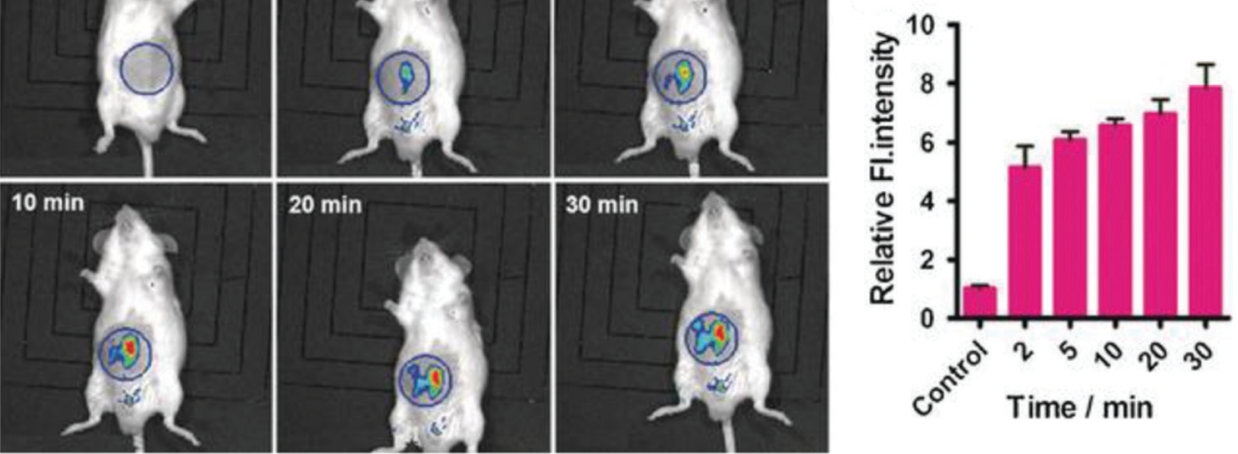

Scheme 22 (a) Nile Red-based TP probe $\mathbf{5 8}$ for the detection of CO with NIR emission. (b) Time-dependent fluorescence images for CO in mice. Control group: $100 \mu \mathrm{L}$ of $10 \mu \mathrm{M} 58$ was injected. Other groups: $100 \mu \mathrm{L}$ of $10 \mu \mathrm{M} \mathbf{5 8}$ was injected, then $100 \mu \mathrm{L}$ of $100 \mu \mathrm{M}$ CORM-2 was injected and imaged. (c) The relative average fluorescence intensity change in the blue circle area. Error bars represent \pm S.D., $n=3 . \lambda_{\mathrm{ex}}=580 \mathrm{~nm}, \lambda_{\mathrm{em}}=660 \mathrm{~nm}$. Reproduced with permission from ref. 31. Copyright (2017) Wiley-VCH Verlag GmbH \& Co. KGaA, Weinheim.

exhibited BODIPY blue fluorescence emission at $454 \mathrm{~nm}$. Then after binding with ATP, an apparent yellow fluorescence of rhodamine $6 \mathrm{G}$ at $557 \mathrm{~nm}$ and a slight increased blue fluorescence at $454 \mathrm{~nm}$ was observed, which was attributed to the restored FRET process from the BODIPY dye to rhodamine $6 \mathrm{G}$ and suppressed PeT. The fluorescence response of probe $\mathbf{6 0}$ towards ATP was evaluated using the fluorescence ratio $\left(I_{454 \mathrm{~nm}} / I_{557 \mathrm{~nm}}\right)$ at acidic $\mathrm{pH}$, suggesting that probe $\mathbf{6 0}$ was capable of monitoring lysosomal ATP. Probe 60 exhibited high sensitivity towards ATP due to strong ionic interactions and $\pi-\pi$ stacking interactions. TPM images of probe 60-stained mouse brain corpus callosum (CC) indicated that lysosomal ATPs were distributed mainly in the CC area. Moreover, two different lysosomal changes in ATP levels were observed during "kiss-and-run" and the "full-collapse membrane fusion" process using probe 60 and TPM.

Hydroxyl radical $\left({ }^{\bullet} \mathrm{OH}\right)$ is regarded as the primary cause of damage due to oxidative stress, where it attacks biomacromolecules and induces irreparable damage. Endogenous ${ }^{\bullet} \mathrm{OH}$ is generated from the Fenton reaction and Haber-Weiss process using $\mathrm{H}_{2} \mathrm{O}_{2}$. The ${ }^{\bullet} \mathrm{OH}$ then damages cells through direct oxidation of lipids, proteins, and DNA. It has been reported that ${ }^{\bullet} \mathrm{OH}$ concentration imbalances are related to diseases, such as breast cancer, neurodegeneration and depression. The TP turn-on probe $\mathbf{6 1}$ based on coumarin (Cou151) bearing a trifluoromethyl group as the TP reporter was developed to image in situ brain ${ }^{\circ} \mathrm{OH}$ (Scheme 25). ${ }^{34}$ With probe 61, 3-methyl-pyrazolone was chosen as the specific reaction site for ${ }^{\bullet} \mathrm{OH}$. The one-electron oxidation reaction between ${ }^{\circ} \mathrm{OH}$ and 3-methyl-pyrazolone, cleaved the electronwithdrawing ring and restored the push-pull electron effect of the coumarin ring. Probe 61 exhibited an absorption band centered at around $350 \mathrm{~nm}$ and a weak fluorescence at $500 \mathrm{~nm}$. After reaction with ${ }^{\bullet} \mathrm{OH}$, a remarkable fluorescence enhancement with increased $\Phi_{\mathrm{f}}$ (from 0.037 to 0.25 ) and $\delta$ (from $5.0 \mathrm{GM}$ to $42.6 \mathrm{GM}$ ) was observed, which was attributed to enhanced ICT within product 62. The fluorescence intensity of probe $\mathbf{6 1}$ at $500 \mathrm{~nm}$ exhibited a linear relationship towards ${ }^{\circ} \mathrm{OH}$ concentrations from 0 to $20 \mu \mathrm{M}$ and a low detection limit of $2.4 \mathrm{nM}$. The trifluoromethyl group enabled probe 61 to cross the blood-brain barrier allowing an increase of ${ }^{\bullet} \mathrm{OH}$ in the brain of the mice under restraint stress to be monitored using TPEF imaging. Subsequently, up-regulated ${ }^{\bullet} \mathrm{OH}$ levels of mice susceptive to CUMS were visualized under TP excitation at $800 \mathrm{~nm}$.

\section{Two-photon (TP) excitation-based fluorescent sensors for biomacromolecules}

Abnormal enzymatic activities are related to the development of numerous diseases including Parkinson's disease, Alzheimer's disease and cancer. Identifying the location and expression levels of these enzymes in live cells are vital for the early-stage diagnoses and monitoring the efficient of therapies of diseases. ${ }^{35,36}$ In this section we will discuss three representative enzymes (steroid sulfatase, $\beta$-secretase and acetylcholinesterase) and their corresponding TP probes. 
a)

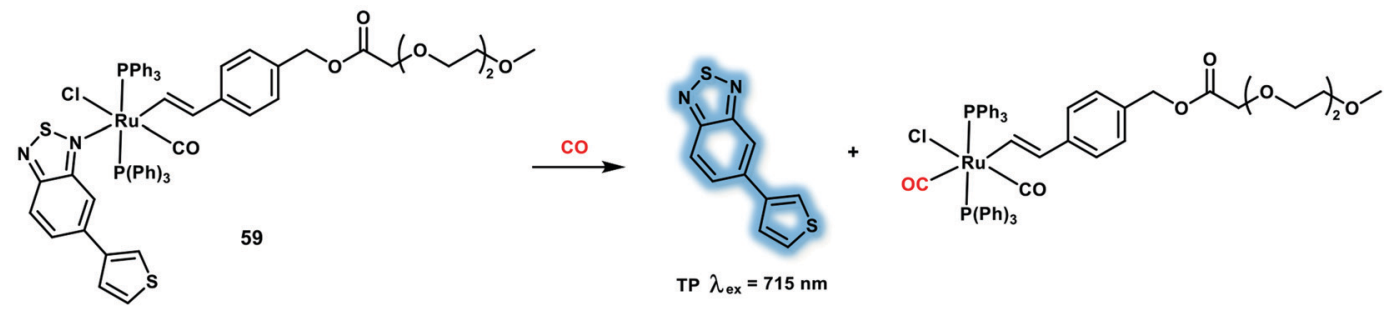

b)

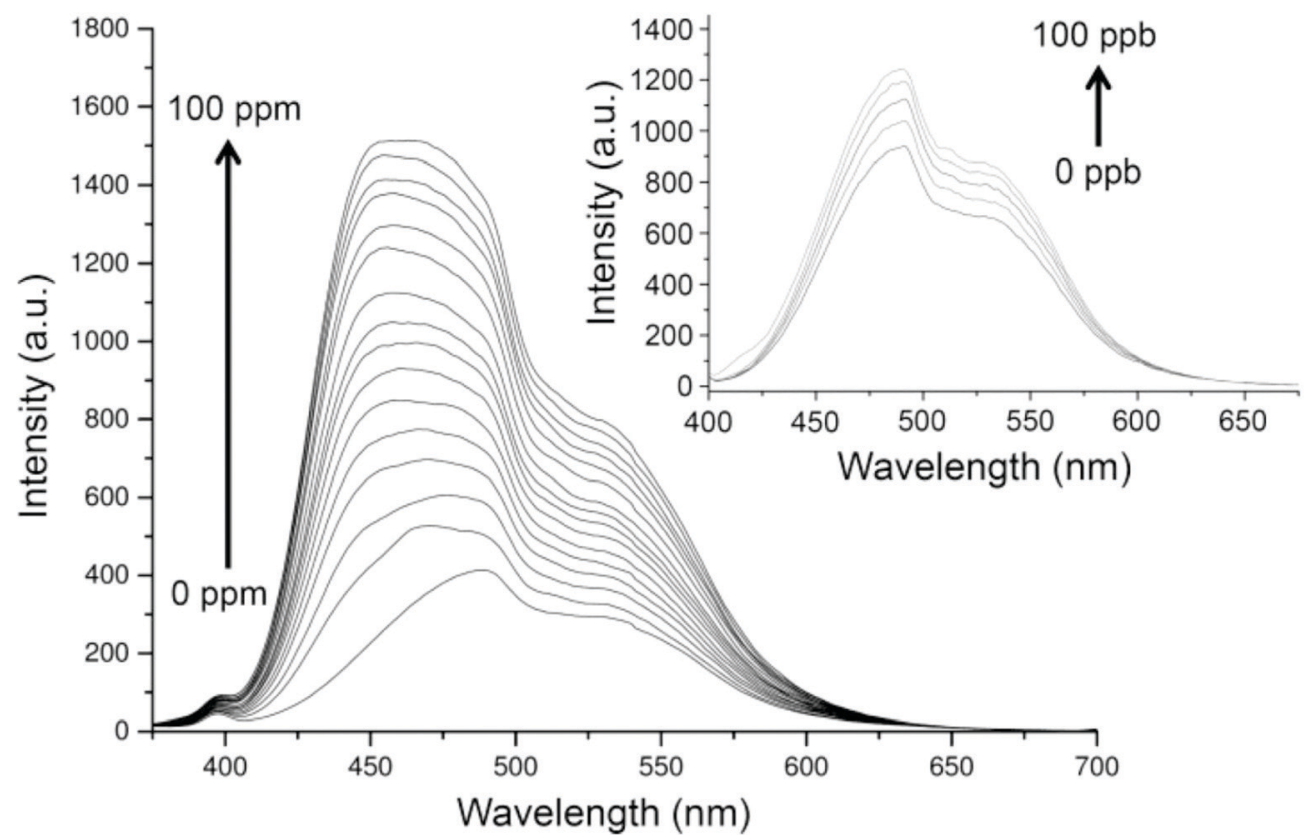

Scheme 23 (a) Ruthenium(॥) vinyl complex-based TP probe $\mathbf{5 9}$ for the detection of CO. (b) Turn-on fluorescence response ( $\left.\lambda_{\text {ex }}=355 \mathrm{~nm}\right)$ of $\mathbf{5 9}$ (10 $\mu$ M) in PBS (pH 7.4)-acetone 99.9: $0.1 \mathrm{v} / \mathrm{v}$ solution upon addition of increasing quantities of CO (0-100 ppm and 0-100 ppb). Reproduced with permission from ref. 32. Copyright (2017) American Chemical Society.

Steroid sulfatase (STS) is primarily produced in the endoplasmic reticulum and responsible for the hydrolysis of aryl and alkyl steroid sulfate. The activity and reactions of STS is associated with physiological processes and pathological conditions including estrogen-related breast cancer. Inactive estrone sulfate can be hydrolyzed to estrone via STS desulfation, then bind to the estrogen receptor and stimulate the pathophysiology of breast cancer. In addition, STS expression is increased in breast tumors tissues when compared with normal tissues and has prognostic significance. The TP probe 63 was constructed based on a TP dye (4-hydroxy-1,8-naphthalimide) for the ratiometric detection of STS. With probe 63, a sulfate group and the methyl sulfonamide group serve as STS recognition site and an endoplasmic reticulum targeting group respectively (Scheme 26). ${ }^{37} \mathrm{~A}$ red-shifted emission was observed upon addition of STS due to enzymatic hydrolysis and release of the phenol form. Probe $\mathbf{6 3}$ was used to monitor the enhanced STS activity of breast tumor tissues over normal tissues using TP 3-dimensional imaging. Compared to single-photon imaging, TPEF imaging exhibited a penetration depth up to $120 \mu \mathrm{m}$ using an excitation wavelength of $820 \mathrm{~nm}$. Moreover STX64 (a STS inhibitor) was used to confirm the specific response between 63 and STS using TP ratiometric imaging.
$\beta$-Secretase (BACE1) is an important enzyme in the etiology of Alzheimer's disease. Production and accumulation of $\beta$-amyloid peptides $(A \beta)$ is responsible for Alzheimer's disease pathogenesis. $A \beta$ is generated by sequential cleavage from BACE1. In brief, BACE1 cleaves amyloid precursor protein at the $\beta$ site, releasing a C-terminal fragment (CTF $\beta)$. The remaining CTF $\beta$ can then be cleaved by $\gamma$-secretase to yield $A \beta$. In addition, oxidative stress leads to enhanced BACE1 expression and activity in Alzheimer's disease. The TP probe 64 was developed based on FRET for the ratiometric detection of BACE1 ${ }^{38}$ With probe $\mathbf{6 4}$, the merocyanine derivative (mCyd) and Alexa Fluor 633 (AF633) are the energy donor and acceptor, respectively (Scheme 27). mCyd and AF633 are connected by a peptide (EVNL-DAEFRHDSGYK), which ensures that probe 64 can be cleaved with high selectively by BACE1 at its $\beta$ site. The sensing mechanism was confirmed using mass spectrometry. Probe $\mathbf{6 4}$ exhibited a maximum emission at $651 \mathrm{~nm}$ upon TP excitation at $820 \mathrm{~nm}$, which was ascribed to the emission profile of the fluorescent acceptor AF633. These observations were consistent with the design expectations for probe 64, that is prior to interaction with BACE1, FRET was observed. Subsequently, addition of BACE1 results in reduced AF633-based fluorescence emission at 
a)
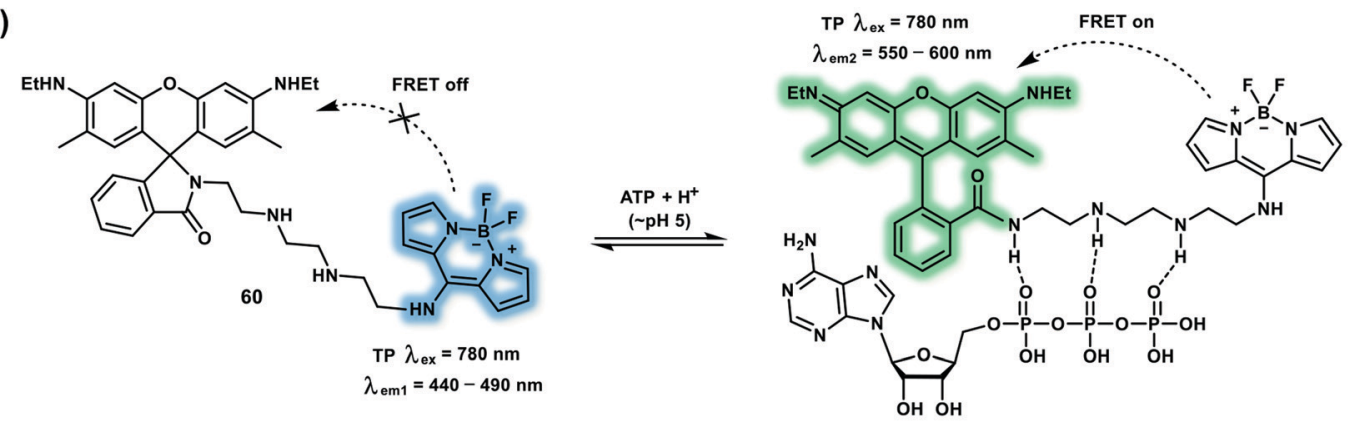

b)
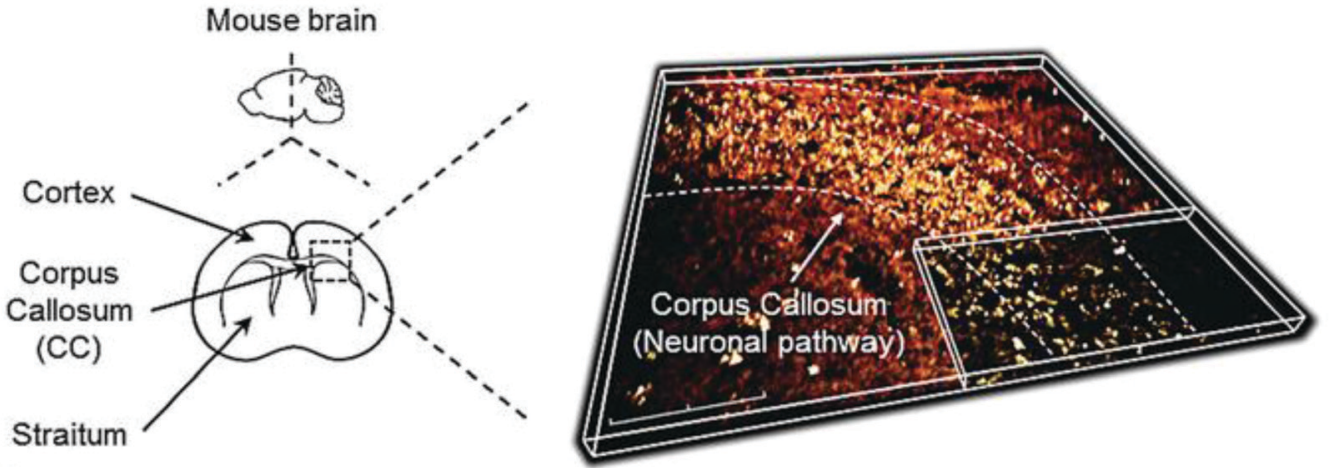

c)

Overlay Ch.

d)

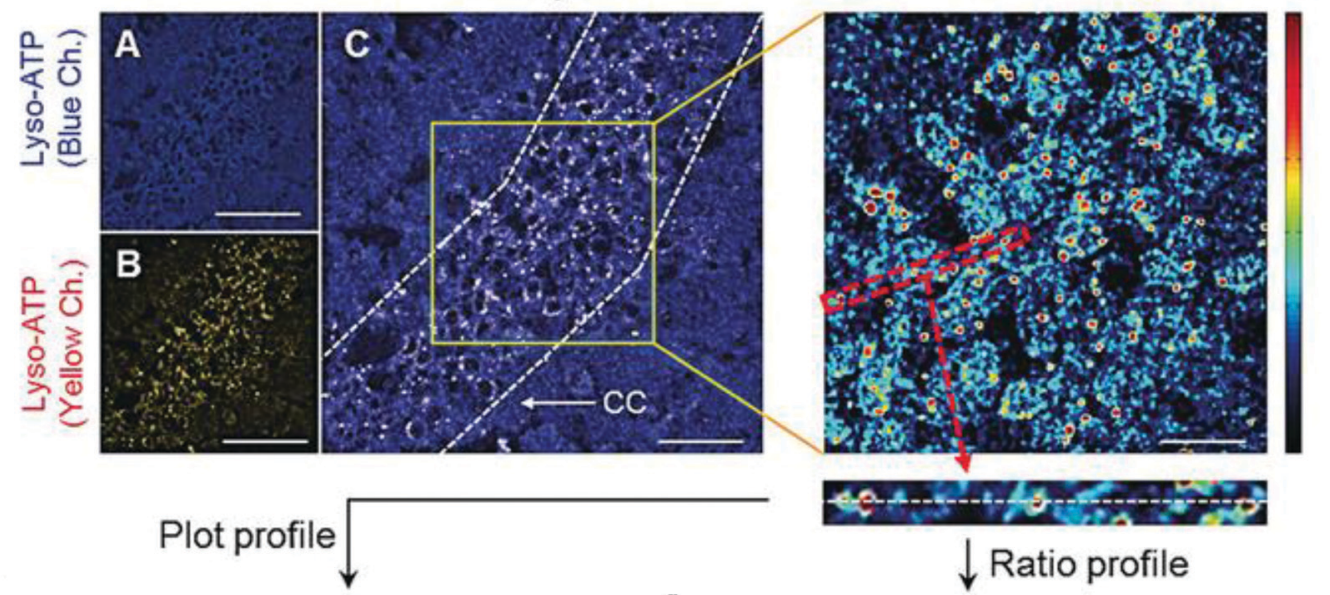

e)

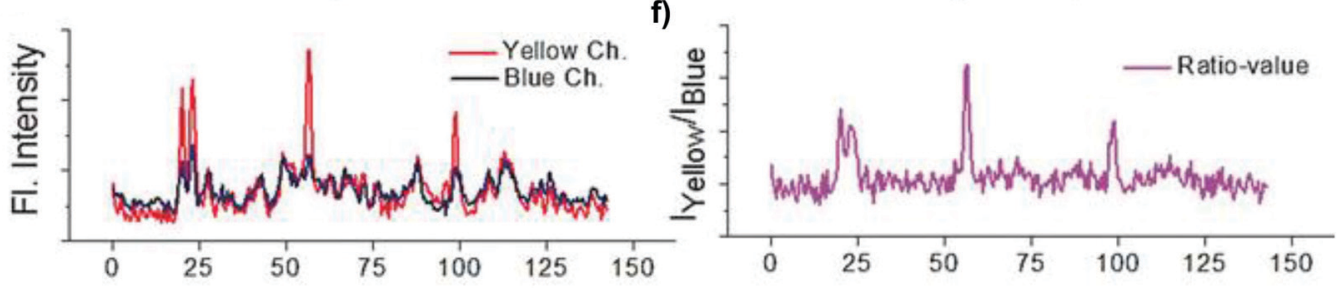

Scheme 24 (a) A FRET-based TP probe 60 for the ratiometric detection of lysosomal ATP. (b) 3-Dimensional TP image of brain slice of CC constructed based on the yellow channel of $60(30 \mu \mathrm{M})$. (c) Cross-section images of the blue channel (A), yellow channel (B), and overlay (C). (d) Ratiometric image representing the ratio of the yellow to the blue channel from (c). (e) Profile of blue and yellow channels obtained from (d). (f) Ratio values of (e). Scale bars $=80 \mu \mathrm{m}$ (b), $40 \mu \mathrm{m}$ (c), and $20 \mu \mathrm{m}$ (d). Reproduced with permission from ref. 33. Copyright (2018) Wiley-VCH Verlag GmbH \& Co. KGaA, Weinheim.

$651 \mathrm{~nm}$ and an increase in the emission at $578 \mathrm{~nm}$. Probe 64 exhibits a linear fluorescence correlation with the concentration of BACE1 from 0.1 to $40.0 \mathrm{nM}$ and TPEF emission ratio $I_{\text {green }} / I_{\text {red }}$ (green: 560-620 nm, red: 640-700 $\mathrm{nm}$ ) in fresh cell lysates containing $0.05 \%$ DMSO, $\mathrm{pH}=4.5$. The detection limit was calculated to be $65.3 \pm 0.1 \mathrm{pM}$. In addition probe 64 was able to visualize BACE1 changes using Axon 1125 (an inhibitor of BACE1) or superoxide in neurons by ratiometric fluorescence imaging. Moreover, compared to OP imaging (excitation at $552 \mathrm{~nm}$ ), TP imaging (excitation at $820 \mathrm{~nm}$ ) could detect BACE1 in the hippocampus region of $\mathrm{AD}$ mouse brain with deep penetration up to a thickness $300 \mu \mathrm{m}$. TP ratiometric imaging 


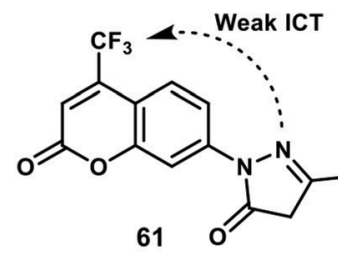<smiles>[C+]1=CC=CC=C1</smiles><smiles>COc1cc(C)nn1-c1ccc2c(C(F)(F)F)cc(=O)oc2c1</smiles><smiles>CC(C)C(C)O</smiles><smiles></smiles>

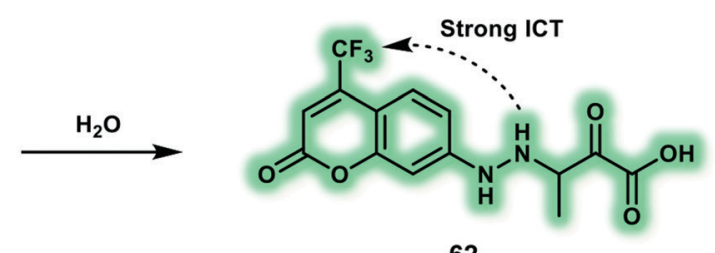

62

Scheme 25 TP probe 61 for the detection of $\bullet \mathrm{OH}$.

a)

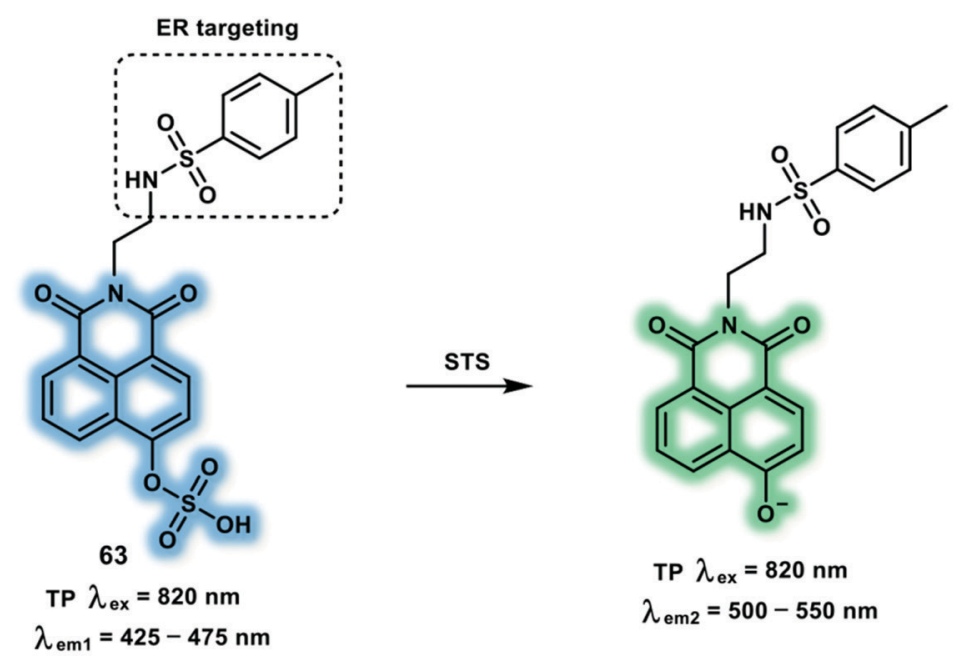

b)
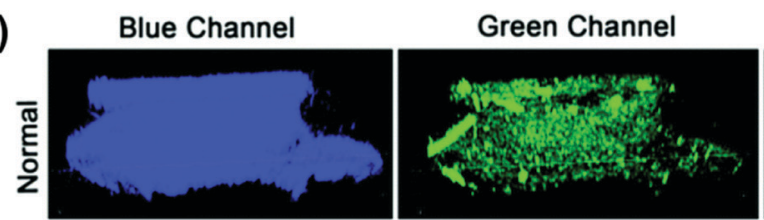

TP $\lambda_{\text {ex }}=800 \mathrm{~nm}$

$\lambda_{\text {em }}=400-650 \mathrm{~nm}$
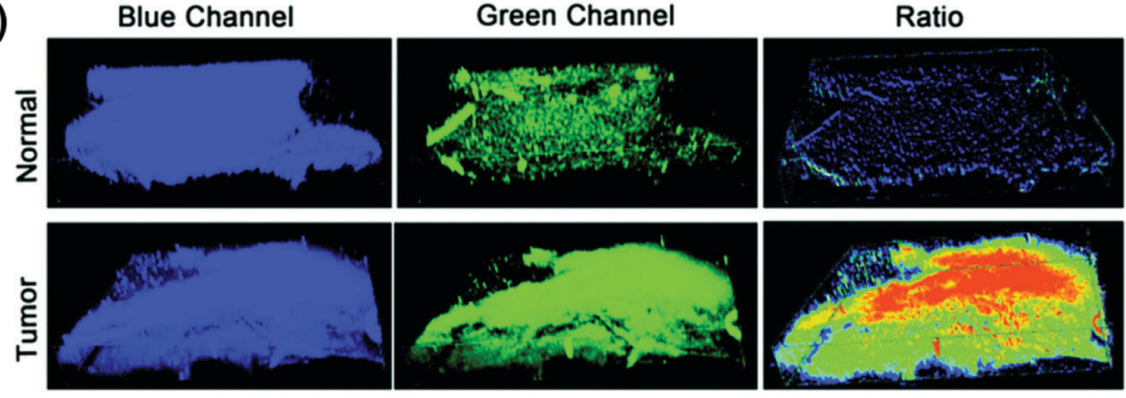

Scheme 26 (a) TP probe 63 for the ratiometric detection of STS in endoplasmic reticulum. (b) The 3-dimensional TP fluorescence image of normal and tumor tissues with a magnification of $10 \times$. Blue channel $(425-475 \mathrm{~nm})$ and green channel $(500-550 \mathrm{~nm})$; ratio images generated from the green channel and blue channel. Reproduced with permission from ref. 37. Copyright (2020) The Royal Society of Chemistry.

was then used to indicate higher concentrations of BACE1 in the $\mathrm{S} 1 \mathrm{BF}$ and $\mathrm{CA1}$ regions than $\mathrm{CPu}$ and $\mathrm{LD}$ regions in $\mathrm{AD}$ mouse brain. It has been reported that oxidative stress is likely to increase BACE1 gene promoter activity and cause BACE1 over transcription. Then, in order to gain more insight, a commercial ROS probe DCFH-DA was used to image oxidative stress where it was found that stress was higher in S1BF and CA1 over CPu and LD regions of Alzheimer's diseased brain slices. In addition, 


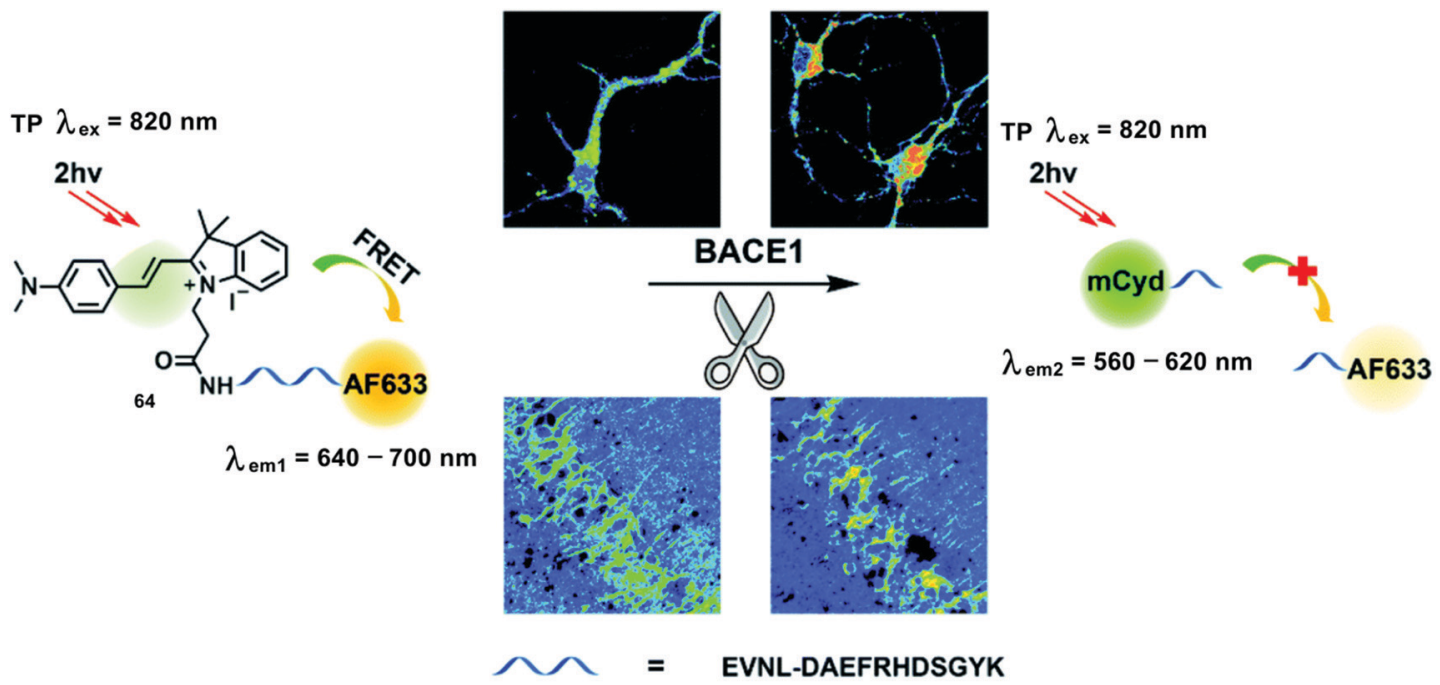

Scheme 27 Illustration for the working principle of the designed TP ratiometric fluorescent probe $\mathbf{6 4}$ for the determination of BACE1 in neurons and mouse brain tissue slice. Reproduced with permission from ref. 38. Copyright (2020) The Royal Society of Chemistry.

it was observed that both BACE1 and oxidative stress for each of those four regions in normal mouse brain slices were lower than in Alzheimer's disease mouse brain slices.

Depression is a common illness worldwide which can happen to people of all ages. When people are depressed, they feel persistently sad for weeks or months, rather than just a few days. Depression is responsible for worsening the effects of many chronic health conditions including arthritis, asthma, and diabetes. In a worse case scenario, depression can also lead to suicide. Oxidative stress in depression is a primary cause of neurotransmitter metabolism dysfunction in the brain. Acetylcholinesterase (AChE) is a key hydrolase that can catalyze the breakdown of acetylcholine (ACh). Therefore, abnormal concentrations of AChE correlate with the degradation of neurotransmission within the brain. Inspired by neostigmine (an AChE inhibitor), the novel TP probe 65 was developed to visualize the AChE activity during depression in mice brains (Scheme 28). ${ }^{39}$ The carbamate of neostigmine can bind covalently to a serine residue in the active site of AChE and then lead to carbamoylation of the active site serine in AChE. This specific binding induces the deactivation of AChE, which was employed as the recognition principle for AChE with probe 65. For probe 65, hemicyanine was chosen as a TP fluorophore and its inherent nitrogen cation $\left(\mathrm{N}^{+}\right)$facilitated binding with the anionic site of the hydrolytic center of AChE. Moreover, dimethyl carbamate is the specific recognition group towards AChE. The interaction between the carbamate and the hydroxyl group of the serine at the hydrolytic center of AChE results in carbamoylation of the serine. Probe 65 exhibits minimal fluorescence due to its pull-pull electron structure. When the protecting group of probe 65 was cleaved by AChE, the D- $\pi-A^{-}$ based hemicyanine is released resulting in an emission band centered at $560 \mathrm{~nm}$ using a TP excitation at $800 \mathrm{~nm}$ in PBS buffer solution. Probe 65 was then used to monitor AChE activity in PC12 cells using TPEF imaging. Probe 65 was then evaluated in mice brains due to its excellent performance in cellular imaging and excellent biocompatibility with cells. It is found that mice with depression-like behavior induced by chronic-restraint stress have elevated AChE activity in their brains. Finally, the relationship between $\mathrm{O}_{2}{ }^{--}$and AChE activity was evaluated using probe 65 in PC 12 cells using TP imaging. It was found that increased $\mathrm{O}_{2}{ }^{--}$resulted in an increase of AChE activity. However, a decrease in AChE activity was observed when caffeic acid ethyl ester $\left(\mathrm{a} \mathrm{O}_{2}{ }^{\bullet-}\right.$ scavenger) was used to relieve the oxidative stress.

\section{Two-photon (TP) excitation-based fluorescent sensors for cellular microenvironment}

$\mathrm{pH}$, polarity and viscosity are important cellular microenvironment related parameters and play crucial roles in controlling signal transduction, transportation, interactions with biomacromolecules within live cells. The imbalance of these factors are hallmarks for the occurrence of various metabolic diseases causing cellular disfunction. In addition, the microenvironment is heterogeneous within cells, varying in specific settings such as the cytosol, or suborganelles, or membrane. Hence, various probes have been developed to monitor microenvironmental distribution and fluxes. In this section, we will review some representative TP probes for cellular microenvironment $(\mathrm{pH}$, polarity, and viscosity), again an emphasis will be placed on both the mechanism and applications.

As an essential cellular microenvironmental factor, $\mathrm{pH}$ is strongly linked to various cellular behavior, such as cell proliferation and apoptosis, endocytosis processes and regulation of enzyme activity. $\mathrm{pH}$ values change from 4.0 to 8.0 in different cellular compartments, cytoplasmic $\mathrm{pH}$ is known to be near 7.2, while mitochondrial $\mathrm{pH}$ is roughly 8.0 and lysosomal $\mathrm{pH}$ is acidic ( $\mathrm{pH}$ 4.0-5.5). Abnormal changes of $\mathrm{pH}$ can be considered as a hallmark of many diseases, including inflammation, Alzheimer's disease, and cancers. Probe 66 is a 2-naphthol-based ratiometric TP probe suitable for the detection of mitochondrial $\mathrm{pH}$ that uses benzochromene-2-one as the fluorophore and triphenylphosphonium salt as mitochondria targeting unit (Scheme 29). ${ }^{40}$ 
a)

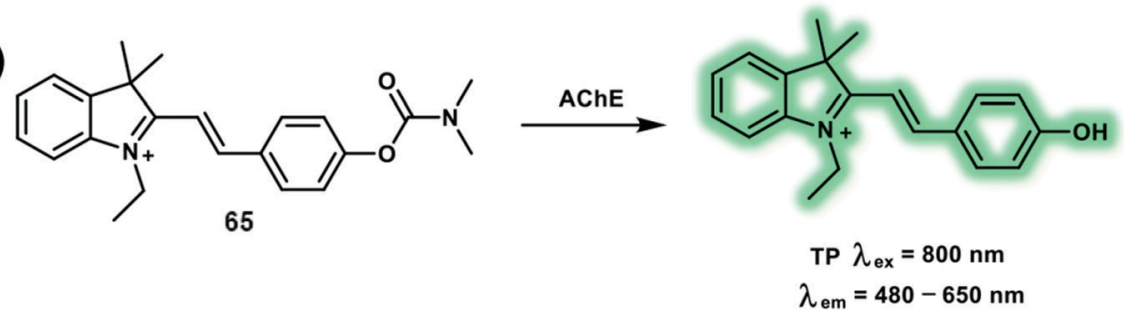

b)
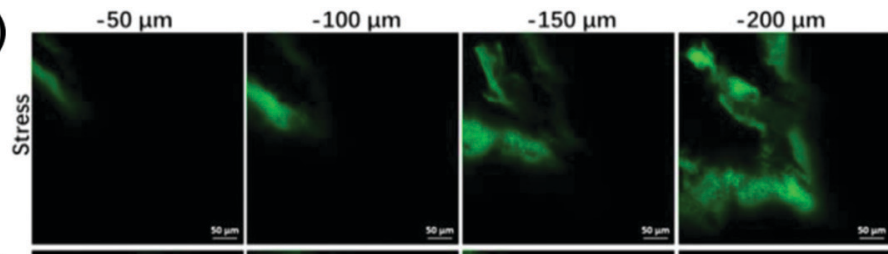
3D image

c)
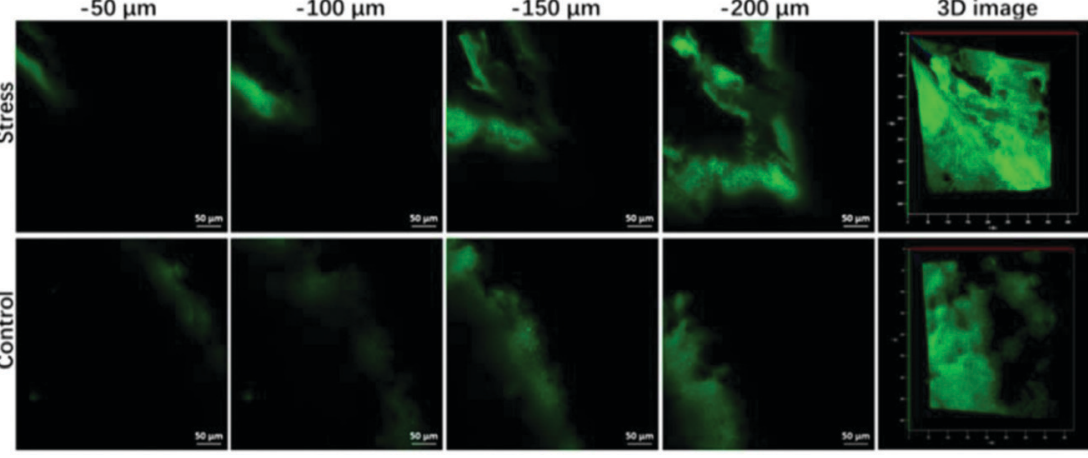

d)

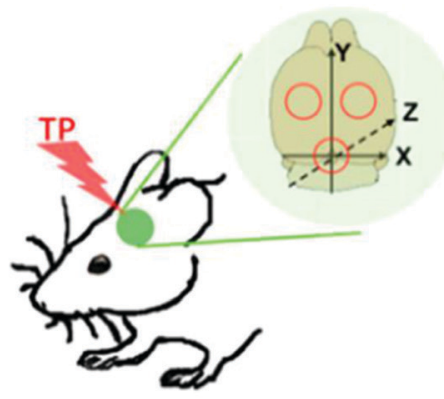

e)

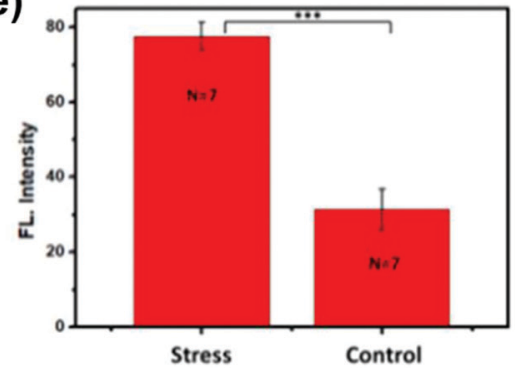

Scheme 28 (a) TP probe 65 for the detection of AChE. (b and c) In situ TP fluorescence imaging of the brains of mice. (b) Stress: mice exposed to 14 consecutive days of chronic-restraint stress. (c) Control: mice not subjected to chronic-restraint stress. (d) Three different TP fluorescence imaging areas. (e) Relative fluorescence intensities of mice in $\mathbf{b}$ and $\mathbf{c}$. The data are expressed as the mean $\pm \mathrm{SD}$; ${ }^{* \star} P<0.001$ for stress group compared with the control. Seven mice in each group. TP images, at a $20 \times$ magnification, of mice labeled with $0.15 \mathrm{mg} \mathrm{kg}^{-1} 65$ via intraperitoneal injection. Fluorescence emission window: $480-650 \mathrm{~nm}$. Scale bar $=50 \mu \mathrm{m}$. Reproduced with permission from ref. 39. Copyright (2019) American Chemical Society.

The fluorescence of probe 66 increases gradually at $604 \mathrm{~nm}$ with a concomitant decrease at $540 \mathrm{~nm}$ upon basification, a result of the enhanced ICT effect caused by formation of the stronger electrondonating phenolate. The measured $\mathrm{p} K_{\mathrm{a}}$ value of probe 66 is 7.95 \pm 0.05 , which is well-matched to mitochondrial $\mathrm{pH}$ (8.0). The maximum $\delta$ values of probe 66 are within the range of 20-70 GM at acidic pH (4.0) and alkaline pH (10.0). Probe 66 displays wellmerged fluorescence with mCherry-mito-7 (a mitochondriatargeting protein) regardless of changes in mitochondrial membrane potential using TPM. The heterogeneity of mitochondrial $\mathrm{pH}\left(\mathrm{pH}_{\text {mito }}\right)$ using probe 66-labeled HeLa cells were evaluated using the fluorescence ratio $\left(I_{\text {red }} / I_{\text {green }}\right)$ under TP excitation at $820 \mathrm{~nm}$. Additionally, $\mathrm{pH}$ values of mitochondria in the perinuclear position were higher than that in the periphery of cells. It was found that more acidic $\mathrm{pH}_{\text {mito }}$ values were observed in Parkinson's disease model astrocytes when compared to wildtype astrocytes using pseudocolored ratiometric TPM images. Finally, probe 66 was used to evaluate the heterogeneous $\mathrm{pH}_{\text {mito }}$ distribution in hippocampal tissues.
Classical approaches for constructing polarity probes are mostly based on ICT systems, by linking an electron donor and an electron receptor with a conjugated spacer. Then when the surrounding solvent polarity changes, a marked blue/red shift in fluorescence or large variation in $\Phi_{\mathrm{f}}$ will be observed. The TP probe 67 with a " $D-\pi-A$ " structure facilitates the detection of lysosomal polarity in living systems (Scheme 30). ${ }^{41}$ A 1,8 naphthalimide was used as the TP fluorophore and electron acceptor, diphenylamine was introduced as electron donor, which was linked by phenyl group. Morpholine was used as a lysosome-targeting group to facilitate accumulation of the probe in lysosomes. When the polarity was varied from the non-polar solvent toluene to the polar solvent DMSO, the fluorescence spectra of probe $\mathbf{6 7}$ displays a red-shift in emission of up to $106 \mathrm{~nm}$ and a 43-fold fluorescence decrease with $\Phi_{\mathrm{f}}$ from 0.308 to 0.009 . Stronger fluorescence in lower polar lysosomes while weaker fluorescence in the higher polar media were observed for 67 which is caused by a positive solvatokinetic effect. $^{42}$ Low lysosomal polarity monitored in inflammation, 
a)

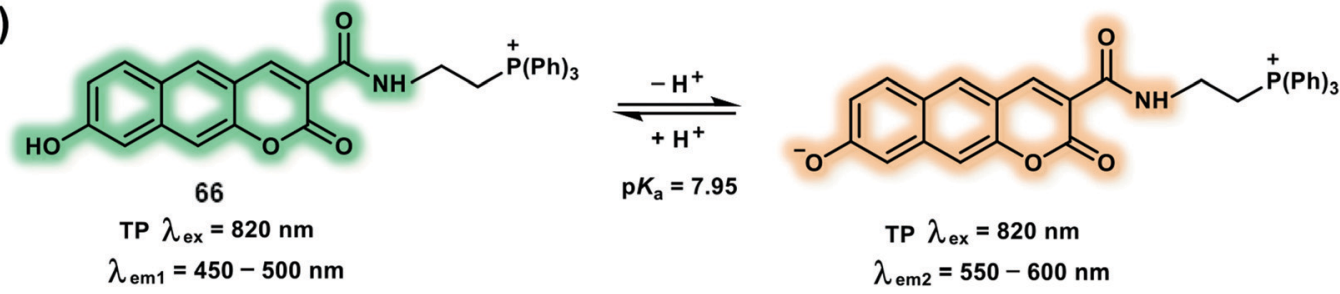

b)

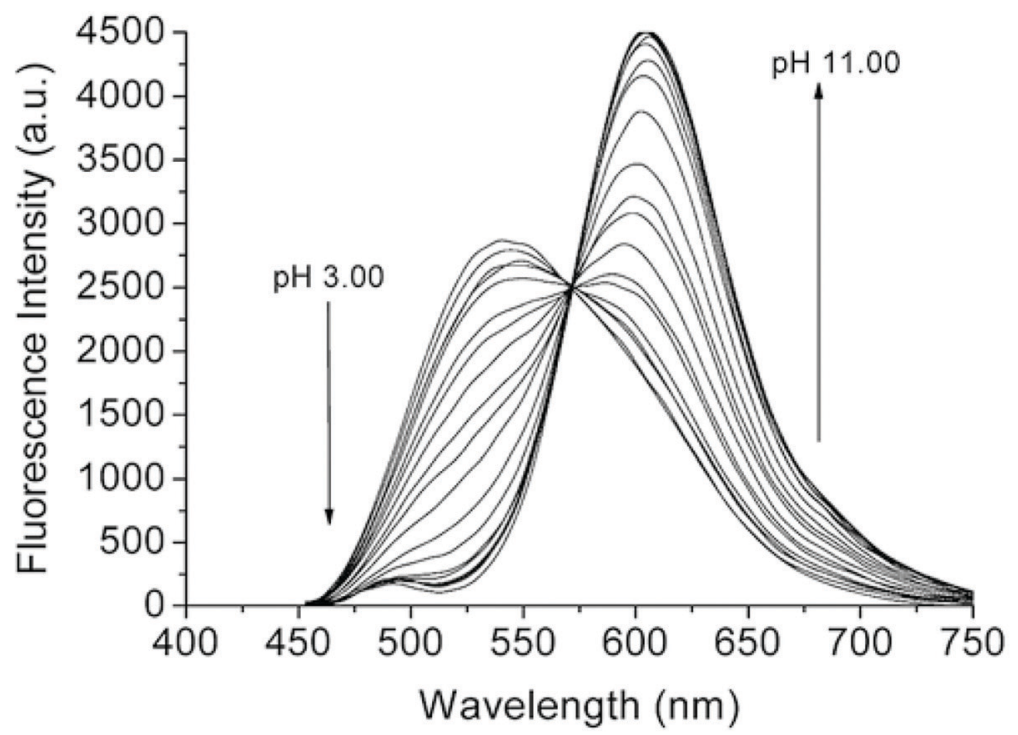

Scheme 29 (a) TP probe 66 for the ratiometric detection of mitochondrial $\mathrm{pH}$. (b) Change in fluorescence emission spectra of 66 with various pH in buffer solution $\left(\lambda_{\mathrm{ex}}=425 \mathrm{~nm}\right.$ ). Reproduced with permission from ref. 40. Copyright (2016) The Royal Society of Chemistry.

fatty liver and tumor mice using 67 in OP mode using excitation at $500 \mathrm{~nm}$. The TP photophysical properties were evaluated and upon TP excitation, 67 displayed a maximum $\delta$ of $384 \mathrm{GM}$ at $800 \mathrm{~nm}$. Considering that the polarity may change continuously in zebrafish development processes, probe $\mathbf{6 7}$ was used to image the polarity variation in embryo and adult zebrafish models. A 1.8-fold fluorescence enhancement was observed for embryonic zebrafish at 500-550 $\mathrm{nm}$, suggesting a low polarity environment for embryonic compared to adult zebrafish.

As a primary cellular property of living cells, subcellular viscosity plays an important role in controlling diffusion and bimolecular reaction rates in diffusion-mediated cellular processes. Abnormal changes of cellular viscosity are associated with many disorders and diseases, such as Alzheimer's disease, diabetes and hypertension. Most of the viscosity-responsive probes are molecular rotors, which contain a rotatable conjugated moiety, as such changes in environmental viscosity alter the fluorescence intensity through rotation restriction. Probe 68 is a turn-on TP probe for monitoring mitochondrial viscosity with TP excitation and deep red emission (Scheme 31). ${ }^{43}$ The probe was designed based on the concept that the restriction of free rotation of hemicyanine facilitates stronger fluorescence emission, and is constructed using carbazole, hemicyanine (indole salt) as molecular rotors and mitochondria-targeting group. Notably, when evaluated in methanol-glycerol systems of low viscosity $(1.4 \mathrm{cP})$, probe 68 was weakly fluorescent under $520 \mathrm{~nm}$ excitation, indicating that the fluorescence is quenched by hemicyanine rotation. However, in a high viscosity systems (956 cP), a 32-fold enhancement in emission intensity due to the inhibition of free rotation of the single bond between the carbazole moiety and indole salt was observed. The maximum $\delta$ of probe 68 was $121 \mathrm{GM}$ at $740 \mathrm{~nm}$. HeLa cells and zebrafish labeled with probe 68 after monensin or nystatin loading displayed enhanced fluorescence in both the OP mode and TP mode. The ability of probe $\mathbf{6 8}$ for tracking viscosity was verified in inflammation, fatty liver and tumor models, respectively, using OP excitation at $560 \mathrm{~nm}$.

\section{Two-photon (TP) excitation-based fluorescent sensors for subcellular localization/protein oxidization}

The development of TP probes that specifically localize in subcellular compartment is of great significance for elucidating cellular activities and processes. For instance, mitochondria produce ATP and supply energy through oxidative phosphorylation (OXPHOS) pathways in a chain of electron transport. While the Golgi complex is responsible for lipids and protein transportation from the endoplasmic reticulum. To detect subcellular organelles in living systems, TP excitation-based sensors that target specific organelle or biomacromolecule have been reported. This section will include some representative TP probes for subcellular localization and protein labelling. 

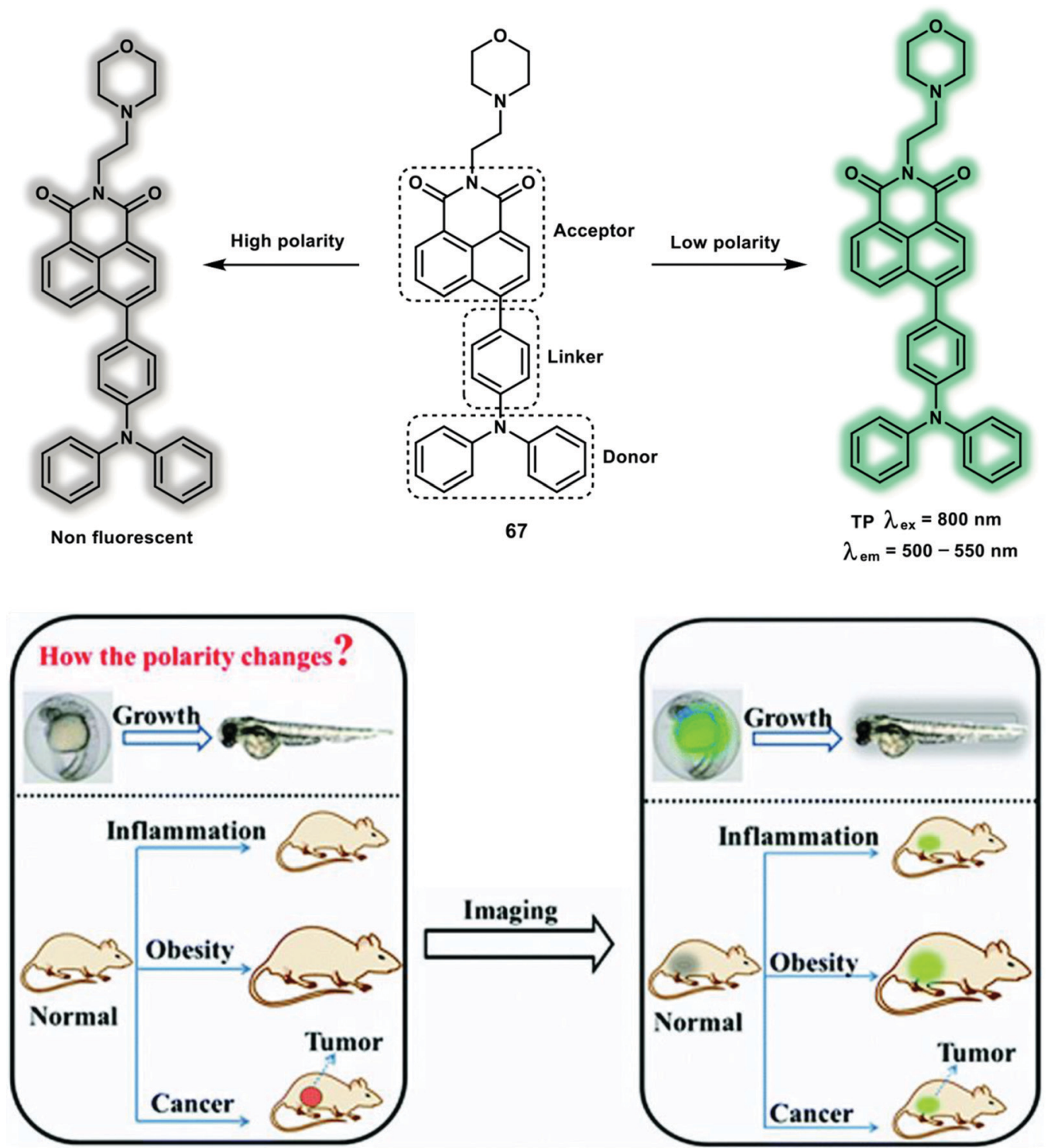

Scheme 30 The design concept of the TP probe 67 for monitoring lysosomal polarity changes. Reproduced with permission from ref. 41 . Copyright (2019) The Royal Society of Chemistry.

The most prominent role of the mitochondria is producing energy in the form of ATP. In addition, mitochondria are involved in controlling various cellular biological processes, such as the biosynthesis of amino acids and lipids, programmed cell death, cytosolic calcium ions $\left(\mathrm{Ca}^{2+}\right)$ and ROS levels. Given mitochondria play a key role in the regulation of apoptotic pathways, as such many anticancer drugs have been developed to target the mitochondria in order to create tumor cells more susceptible to anticancer treatment. A dual-mode mitochondriatargeting probe $\mathbf{7 0}$ with aggregation-induced emission (AIE) and Raman output was designed for mitochondrial imaging of living cells (Scheme 32). ${ }^{44}$ Dual-mode live-cell imaging with probe 70 was conducted using a homemade fluorescence-stimulated Raman scattering microscope system. Probe 70 developed containing three units, $\alpha$-cyanostilbene as the AIE skeleton, pyridinium salt as the targeting group for the mitochondria, and diphenylacetylene as Raman signal reporter with a Raman signal peak at $2225 \mathrm{~cm}^{-1}$. Dual-mode probe 70 is a hybrid of 69 (an AIE fluorophore) and diphenylacetylene unit. Probe 70 exhibits absorption at $380 \mathrm{~nm}$ and fluorescence output at around $500 \mathrm{~nm}$ with a large Stokes shift of $120 \mathrm{~nm}$ in DMSO. The $\delta$ of 70 was determined to be $14.2 \mathrm{GM}$ under TP excitation at $800 \mathrm{~nm}$. The AIE nature of 70 was evaluated in a mixed DMSO-water system. With water fraction increasing from $0 \%$ to $70 \%$, the fluorescence intensity decreased due to enhanced twisted intramolecular charge transfer (TICT) processes caused by increased polarity. Fluorescence increase was observed as the water fraction increased from $70 \%$ to $99 \%$ which was attributed to AIE. The relative Raman intensity versus 5-ethynyl-2'-deoxyuridine at $2223 \mathrm{~cm}^{-1}$ was 6.0. Stimulated Raman scattering (SRS) exhibited a linear relationship with the concentration of probe $70\left(I_{\mathrm{SRS}}=\right.$ $0.1567 c$ ), in which $c$ represents the concentration of the probe. In addition, probe 70 exhibited maximal TP excitation at $780 \mathrm{~nm}$, 

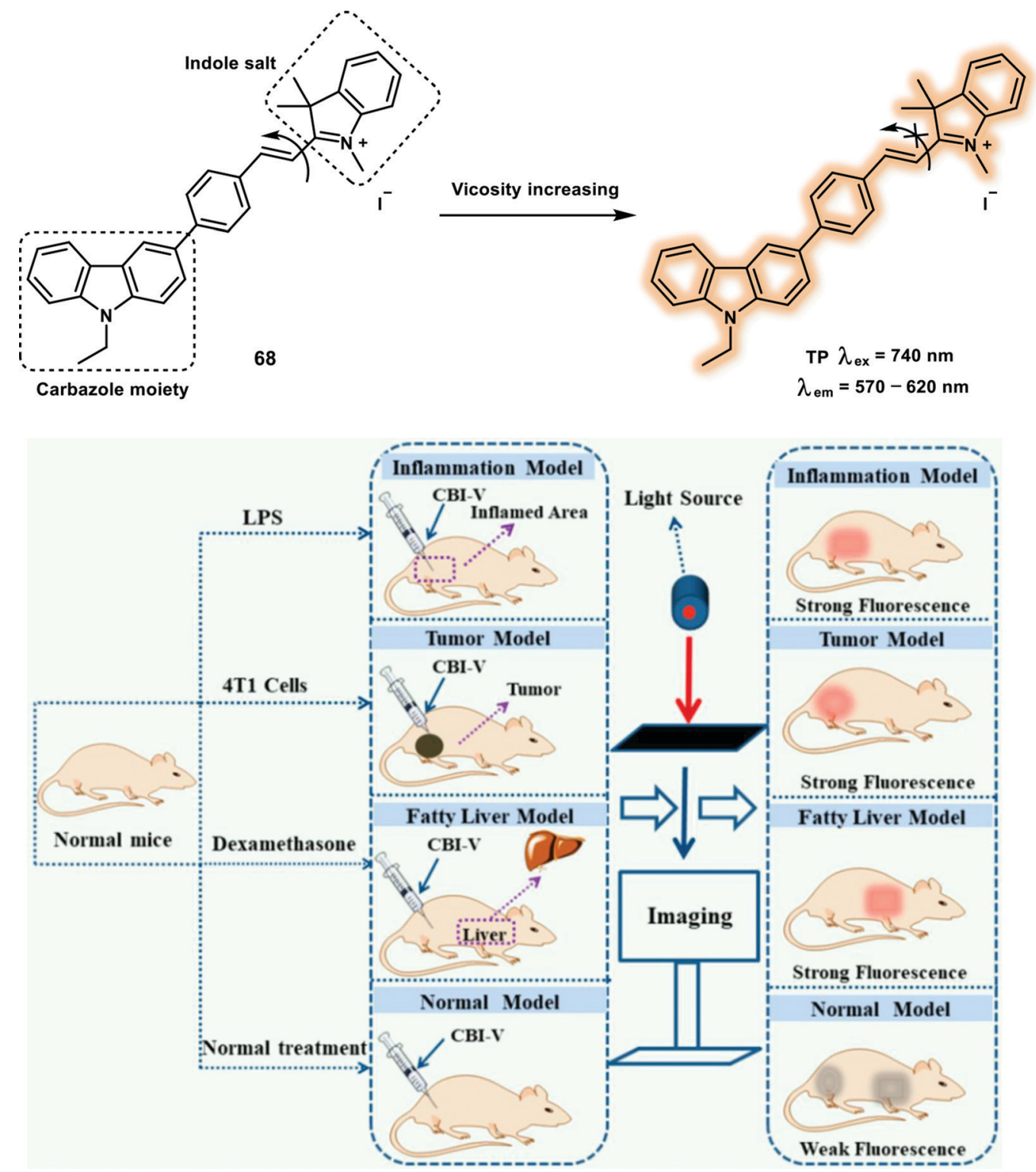

Scheme 31 TP probe $\mathbf{6 8}$ for the detection of mitochondrial viscosity and its application for imaging in live mice. Reproduced with permission from ref. 43. Copyright (2019) American Chemical Society.

and enhanced TPEF intensity upon increasing probe concentration. The TPEF fluorescence of probe $70(1 \mathrm{mM})$ increased by approximately $70 \%$ with increasing water fraction from 0 to $40 \mathrm{vol} \%$ in DMSO-water mixtures. Finally, the TPEF and SRS signals of HeLa cells stained with probe $\mathbf{7 0}$ were collected, the merged images indicate colocalization of TPEF and the SRS signal and a positive correlation between TPEF intensity and SRS signal was determined using statistical analysis.

The Golgi complex is the vital processing and sorting station, which transports lipids and proteins synthesized in the endoplasmic reticulum and packages them into vesicles to transport to other organelles. Moreover, the Golgi complex is involved in glycosylation of proteins, transformation of the membrane and proteolysis. Blue- and yellow-emitting TP probes (71 and 72) for the Golgi apparatus were designed. These two probes use 6-(benzo[d]oxazol-2-yl)-2-naphthalylamine (73) and 2,5-bis(benzo$[d]$ oxazol-2-yl)-pyrazine (74) derivatives as the fluorophores, and SDYQRL as the Golgi-apparatus-targeting unit (Fig. 2). ${ }^{45}$ Maximum $\delta \times \Phi_{\mathrm{f}}$ for probes 71 and 72 were determined in EtOH and 1,4-dioxane/ $\mathrm{H}_{2} \mathrm{O}(200: 1)$ respectively with a value of $96 \mathrm{GM}$ and $65 \mathrm{GM}$ under $750 \mathrm{~nm}$ excitation. Probe 71 emits TPEF at $462 \mathrm{~nm}$ in HeLa cells, which was separated from the emission fluorescence of probe 72 at $560 \mathrm{~nm}$. HeLa cells were labeled with TP probes $\mathbf{7 1}$ and $\mathbf{7 2}$ and exhibited superior Golgi apparatus staining compared to BODIPY TR ceramide, a OP commercial probe for the Golgi apparatus, revealing stronger interaction with TGN38 in the Golgi membrane. Then, probe 72 was used to monitor apoptosis in HeLa cells. Finally, both probe $\mathbf{7 1}$ and $\mathbf{7 2}$ were used to visualize the Golgi apparatus distribution in rat-hippocampal slices at depths of 120-270 $\mu \mathrm{m}$ using TPEF imaging. 
<smiles>CN(C)c1ccc(/C=C(\C#N)c2ccc(-c3cc[n+](C)cc3)cc2)cc1</smiles>

AIE-active

Mitochondria-targeting SRS: $2216 \mathrm{~cm}^{-1}$, RIE $=0.8$

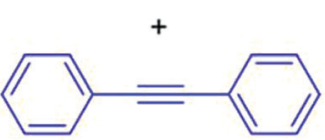

diphenylacetylene

\section{AlE-active \\ Mitochondria-targeting \\ SRS: $2223 \mathrm{~cm}^{-1}$, RIE $=6.0$}

SRS: $2225 \mathrm{~cm}^{-1}$, RIE = 3.2

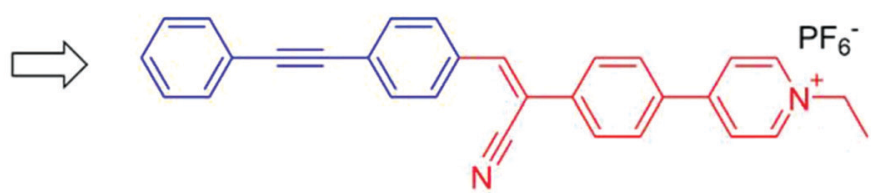

70

Two-photon excited fluorescence

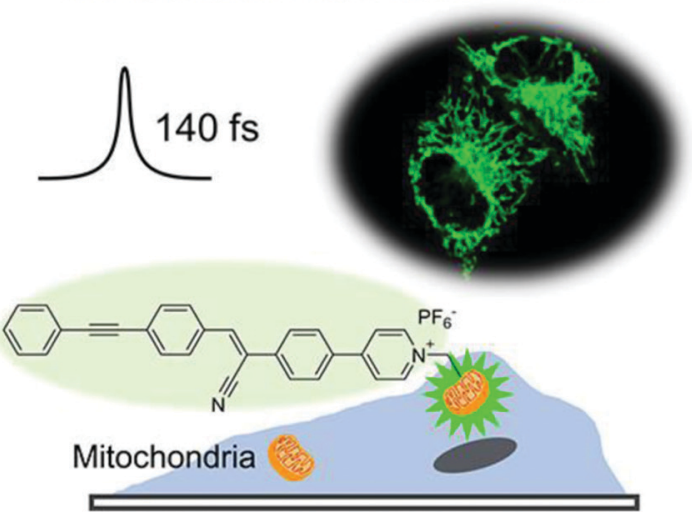

Stimulated Raman Scattering
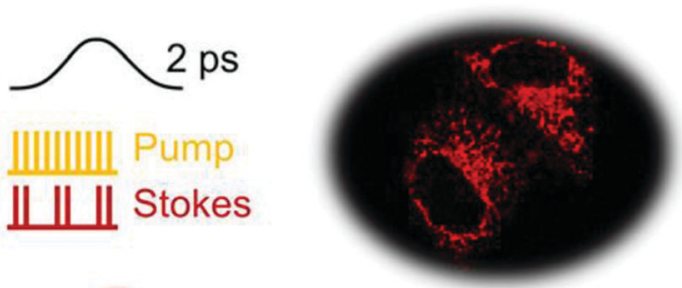

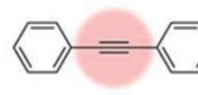

Mitochondria

Scheme 32 The design strategy and the application of an AIE-based probe $\mathbf{7 0}$ for the imaging of mitochondria using fluorescence and stimulated Raman scattering microscopy. Reproduced with permission from ref. 44. Copyright (2017) American Chemical Society.

PDT is a photon-activated therapeutic modality that uses highly toxic ROS to kill cancer cells. Metal complexes have been widely used as photosensitizers for PDT, because the heavyatom effect favors singlet-to-triplet intersystem crossing (ISC) and increases the excited-state lifetimes, leading to a boost in ${ }^{1} \mathrm{O}_{2}$ and other ROS generation. Two efficient novel organoiridium photosensitizer complexes 75 and 76 were developed (Fig. 3). ${ }^{46}$ Both 75 and 76 were nontoxic to cancer cells in the dark, whereas an increased in cytotoxicity towards cancer cells a result of ${ }^{1} \mathrm{O}_{2}$ generation was observed for OP or TP irradiation. The $\delta$ values of 75 and 76 were determined to be $115 \mathrm{GM}$ and $70 \mathrm{GM}$, respectively, at $750 \mathrm{~nm}$ excitation. The generation of ${ }^{1} \mathrm{O}_{2}$ by 75 and 76 with $\Phi_{\mathrm{f}}$ of 0.73 and 0.81 , respectively, under $465 \mathrm{~nm}$ irradiation, were evaluated using electron paramagnetic resonance spectroscopy. A549 spheroids incubated with 75 and 76 display a strong red phosphorescence at a depth up to 212 $\mu \mathrm{m}$ using TPM upon $750 \mathrm{~nm}$ excitation. The ${ }^{1} \mathrm{O}_{2}$ generated using 76 was found to oxidize specific histidines in the 70 kilodalton heat shock protein (Hsp 70) and in aldose reductase (AR). While, the ROS generated upon irradiation increased the levels of enzymes involved in the glycolytic pathway.

\section{Dual-responsive two-photon (TP) excitation-based fluorescent sensors}

Significant effort has been devoted to the development of single response fluorescent probes for specific analytes. However, a specific disease is usually associated with a variety of biological markers. For example, ROS exhibit crosstalk in redox homeostasis. With increased $\mathrm{ONOO}^{-}$and $\mathrm{H}_{2} \mathrm{O}_{2}$ in drug-induced liver injury (DILI) having been reported. Similarly, ROS and $\mathrm{A} \beta$ are associated with the progression Alzheimer's disease. ${ }^{15}$ While hypoxia can lead to a decrease of cellular GSH and upregulation of nitroreductase. Compared to single-responsive probes for one analyte, dual-responsive probes can provide different information by facilitating measurement of two analytes within the same biological system. Many dual-responsive OP probes have been developed, while dual-responsive probes with TPEF are relatively rare. Therefore, the development of dual-responsive TP probes is appropriate when exploring biologically-related effects associated with multiple analytes involved in many diseases and disorders. ${ }^{47}$ This section will include some representative sensors designed to detect more than one analyte using TP probes and their applications. 

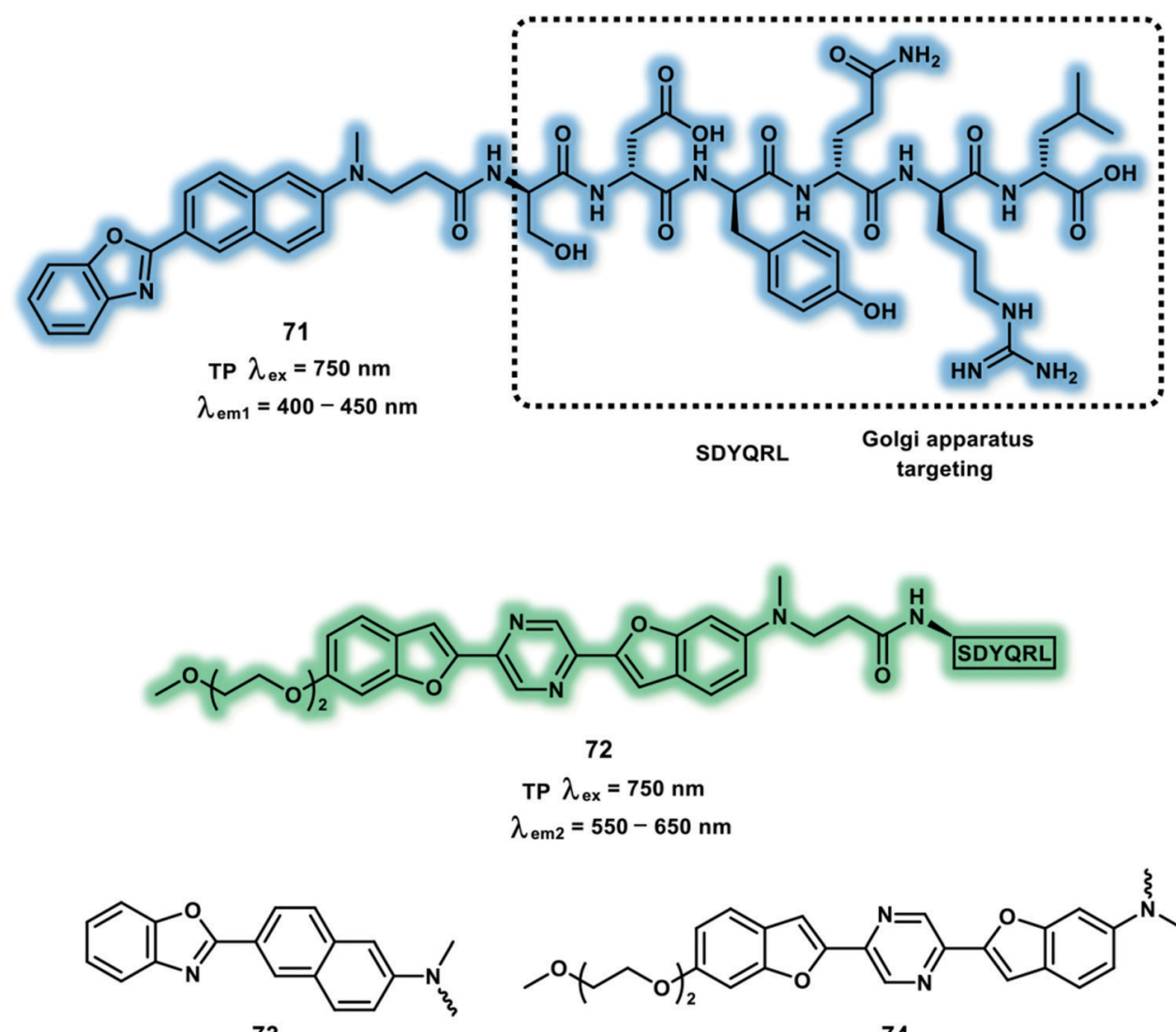

73

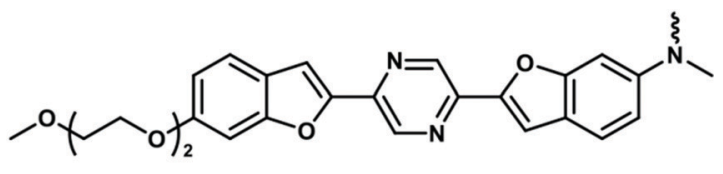

74

Fig. 2 TP probes $\mathbf{7 1}$ and $\mathbf{7 2}$ for the detection of Golgi apparatus and the structures of $\mathbf{7 3}$ and $\mathbf{7 4}$.
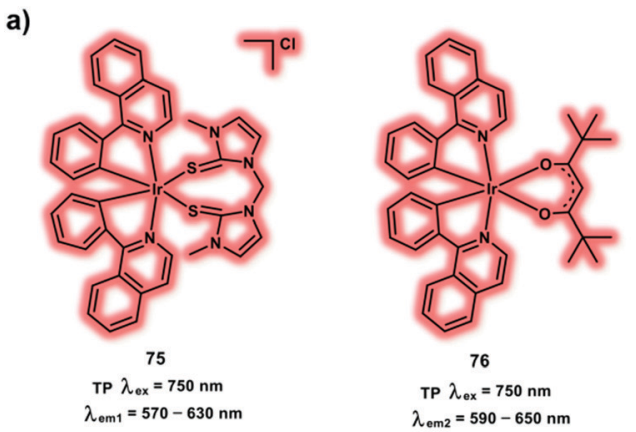

b)
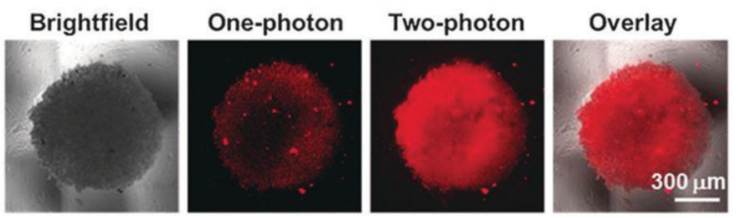

c)

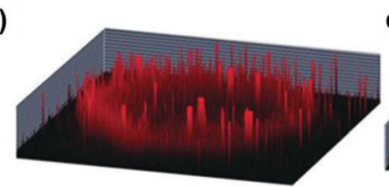

d)

Fig. 3 (a) Structures of the complexes 75 and 76. (b-d) Phosphorescence imaging of A549 spheroids. Spheroids were incubated with 76 (10 $\mu M)$ for $2 \mathrm{~h}$. (b) Comparison of brightfield, one-photon $\left(\lambda_{\mathrm{ex}}=458 \mathrm{~nm}\right.$ ), and two-photon $\left(\lambda_{\mathrm{ex}}=750 \mathrm{~nm}\right.$ ) excitation, $\lambda_{\mathrm{em}}=620 \pm 30 \mathrm{~nm}$. OP (c) and TP (d) 3D Z-stack images were taken every $16.3 \mu \mathrm{m}$ from the top to bottom of the spheroids. Images were taken under a $10 \times$ objective. Scale bar: $300 \mu \mathrm{m}$. Reproduced with permission from ref. 46. Copyright (2017) The Authors (P. Zhang, C. K. C. Chiu, H. Huang, Y. P. Y. Lam, A. Habtemariam, T. Malcomson, M. J. Paterson, G. J. Clarkson, P. B. O'Connor, H. Chao and P. J. Sadler). Published by Wiley-VCH Verlag GmbH \& Co. KGaA.

DILI has attracted significant attention, however the biological role and changes in fluxes of HOCl during DILI remain unknown. $N$-Acetyl cysteine (NAC) displays some protective effects against DILI. While, $\mathrm{H}_{2} \mathrm{~S}$, a downstream product of NAC, may be involved in DILI. Hence, developing a dualresponsive probe for $\mathrm{H}_{2} \mathrm{~S}$ and $\mathrm{HOCl}$ could help reveal the functions of $\mathrm{H}_{2} \mathrm{~S}$ and $\mathrm{HOCl}$ in DILI. To recognize and image $\mathrm{H}_{2} \mathrm{~S}$ and $\mathrm{HOCl}$ simultaneously, a TP probe 77 was constructed by linking 7 -amino coumarin and rhodamine $\mathrm{B}$ using a piperazine
(Scheme 33). ${ }^{48}$ Thiolactone and azido were exploited as HOCl and $\mathrm{H}_{2} \mathrm{~S}$ reactive group, respectively. Upon addition of $\mathrm{HOCl}$ $(0-100 \mu \mathrm{M})$, a gradual fluorescence increase at $580 \mathrm{~nm}$ was observed for $545 \mathrm{~nm}$ excitation. The separate addition of $\mathrm{H}_{2} \mathrm{~S}$ $(0-100 \mu \mathrm{M})$, resulted in an increase of the emission at $445 \mathrm{~nm}$ upon $360 \mathrm{~nm}$ excitation which was ascribed to $\mathrm{D}-\pi-\mathrm{A}$ structure formation of the coumarin derivative. With probe 77 in hand, endogenously generated $\mathrm{H}_{2} \mathrm{~S}$ and $\mathrm{HOCl}$ were imaged in NACinduced and LPS/PMA-stimulated RAW264.7 cells, respectively, 
<smiles></smiles><smiles></smiles>
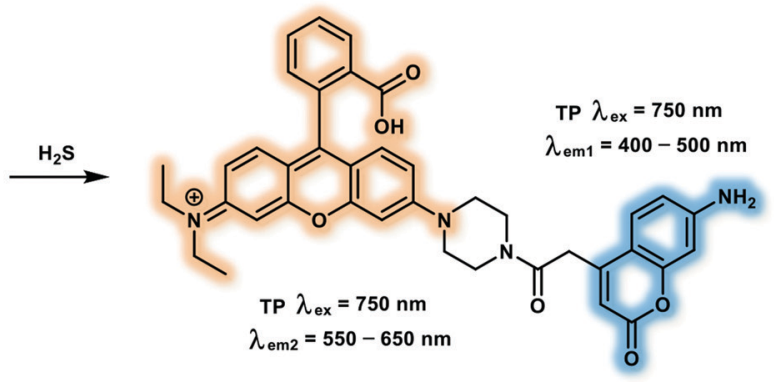

Scheme 33 Dual-responsive TP probe 77 for the discrimination of $\mathrm{HOCl}$ and $\mathrm{H}_{2} \mathrm{~S}$.

under TP excitation at $750 \mathrm{~nm}$. A significant green fluorescence enhancement with increased HOCl levels during DILI after combined administration of fluoxetine and duloxetine was observed, which indicates that HOCl could be an efficient indicator for DILI. In addition, NAC-pretreated cells displayed an increased blue fluorescence and decreased yellow fluorescence by TPM imaging, indicating an enhanced level of $\mathrm{H}_{2} \mathrm{~S}$ and suppressed concentration of HOCl. Dual-color fluorescence images of Kunming mice liver tissue confirmed the capability of probe 77 for visualizing $\mathrm{H}_{2} \mathrm{~S}$ and $\mathrm{HOCl}$ fluctuations during DILI.

$\mathrm{N}$-Methyl-D-aspartic acid (NMDA) receptor over-activation is strongly involved in depression. Zinc cation $\left(\mathrm{Zn}^{2+}\right)$ and hydrogen ion $\left(\mathrm{H}^{+}\right)$serve as binding partners of NMDA receptor and regulate the activity. Therefore, monitoring simultaneous changes of $\mathrm{Zn}^{2+}$ and $\mathrm{H}^{+}$levels are meaningful for understanding depressionrelated signal pathways. A dual-color fluorescent probe 78 was developed for monitoring of $\mathrm{Zn}^{2+}$ and $\mathrm{H}^{+}$fluctuations in mice brains with depression-like behavior (Scheme 34). ${ }^{49}$ 2,2'-Dipicolylamine (DPA) was used as the recognition site for $\mathrm{Zn}^{2+}$ and naphthalene fluorescein was used as the $\mathrm{H}^{+}$reporter. Fluorescence of the coumarin quenched by DPA, upon binding to $\mathrm{Zn}^{2+}$, was restored via a blocked PeT process. Probe $\mathbf{7 8}$ displays a linear relationship between the fluorescence emission intensity at $460 \mathrm{~nm}$ and the concentration of $\mathrm{Zn}^{2+}(0-10 \mu \mathrm{M})$. When the

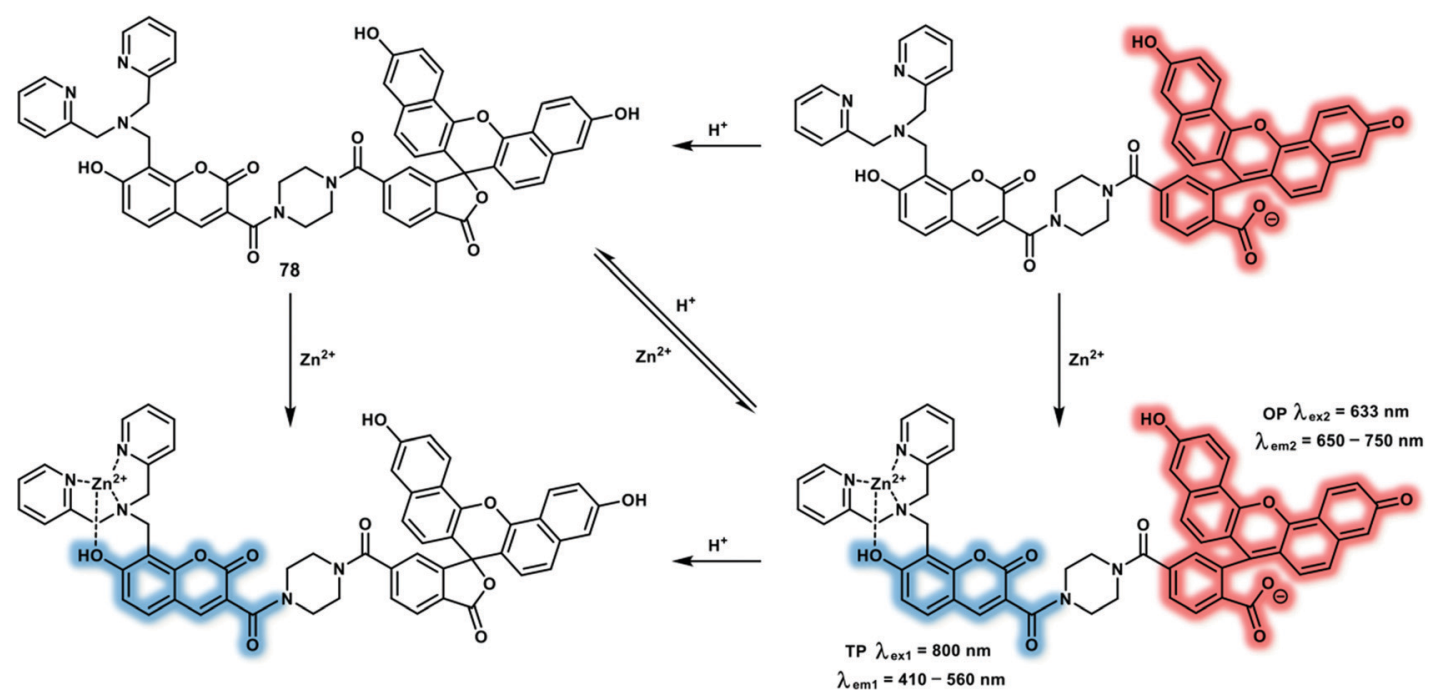

Scheme 34 Simultaneous detection of $\mathrm{Zn}^{2+}$ and $\mathrm{H}^{+}$using probe $\mathbf{7 8}$. 
pH changed from 6.5 to 9 , the emission intensity of probe 78 at $680 \mathrm{~nm}$ gradually increased linearly. While the well-separated fluorescence emission wavelength facilitated the simultaneous detection of $\mathrm{Zn}^{2+}$ and $\mathrm{H}^{+}$. Probe 78 was used to image $\mathrm{Zn}^{2+}$ and $\mathrm{H}^{+}$fluctuations in the brains of mice with depression. The mice with depression-like behavior exhibited decreased $\mathrm{Zn}^{2+}$-related TP blue fluorescence (excitation at $800 \mathrm{~nm}$ ) and $\mathrm{H}^{+}$-related red fluorescence, indicating a reduction in $\mathrm{Zn}^{2+}$ and $\mathrm{pH}$ levels in mice with depression-like behavior.

Disruption of mitochondrial dynamics including fusion, fission and movement, mitophagy are involved in many diseases, such as Huntington's, Alzheimer's, and Parkinson's diseases. To uncover the $\mathrm{O}_{2}{ }^{\bullet-}$ and $\mathrm{pH}$ flux changes within mitochondrial dysfunction of living cells, a TP probe 79 was developed for the simultaneous monitoring of $\mathrm{O}_{2}{ }^{--}$and $\mathrm{pH}$ (Scheme 35). ${ }^{50}$ With probe 79 a caffeoyl and fluorescein were used as responsive units towards $\mathrm{O}_{2}{ }^{\bullet-}$ and $\mathrm{pH}$, respectively, and the cationic triphenylphosphonium was used as a mitochondria-targeting unit. Under TP excitation at $800 \mathrm{~nm}$, the probe displays distinguishable blue and green fluorescence signals allowing for the simultaneous detection of $\mathrm{O}_{2}{ }^{--}$and $\mathrm{pH}$. In the presence of $\mathrm{O}_{2}^{\bullet-}$, a turn-on blue fluorescence signal at $450 \mathrm{~nm}$ was observed under excitation at $800 \mathrm{~nm}$ or $400 \mathrm{~nm}$. In addition, when the $\mathrm{pH}$ increased from 5.0 to 9.0 , a similar increase of green fluorescence at $520 \mathrm{~nm}$ was observed upon $488 \mathrm{~nm}$ excitation. Drp1 deficiency induced hyperfused mitochondrial accumulations can lead to apoptosis of cancer cells. Drp1-knocked down 4T1 cells displayed enhanced blue and green fluorescence upon excitation at $405 \mathrm{~nm}$ and $488 \mathrm{~nm}$, respectively. Moreover, elevated $\mathrm{O}_{2}{ }^{--}$and $\mathrm{pH}$ levels in mdivi-1 (an inhibitor of Drp1)-pretreated tumor-bearing mice was visualized using TPEF imaging.

The mitochondrion is an effective target for developing PDT agents, since it produces energy for cells and regulates apoptosis. Recently, a mitochondria-targeting agent 83 was developed for PDT in cancer cells, which is co-activatable by GSH and $\mathrm{H}_{2} \mathrm{O}_{2}$ (Scheme 36) ${ }^{51} \mathbf{8 0}$ is resistant to nucleophilic attack by GSH, while the boronic ester can be cleaved by $\mathrm{H}_{2} \mathrm{O}_{2}$, followed by a 1,6-benzyl elimination to release unprotected thiol-containing intermediate $\mathbf{8 1}$ which is converted into the photosensitizer 82. More importantly, 82 exhibits strong photosensitizer ability for the generation of both ${ }^{1} \mathrm{O}_{2} / \mathrm{O}_{2}{ }^{\bullet-}$. The $\delta$ of 82 was determined to be $41 \pm 4 \mathrm{GM}$ at $800 \mathrm{~nm}$ in methanol. The triphenylphosphine ligand of probe 83 was used to target mitochondria. Significant turn-on fluorescence

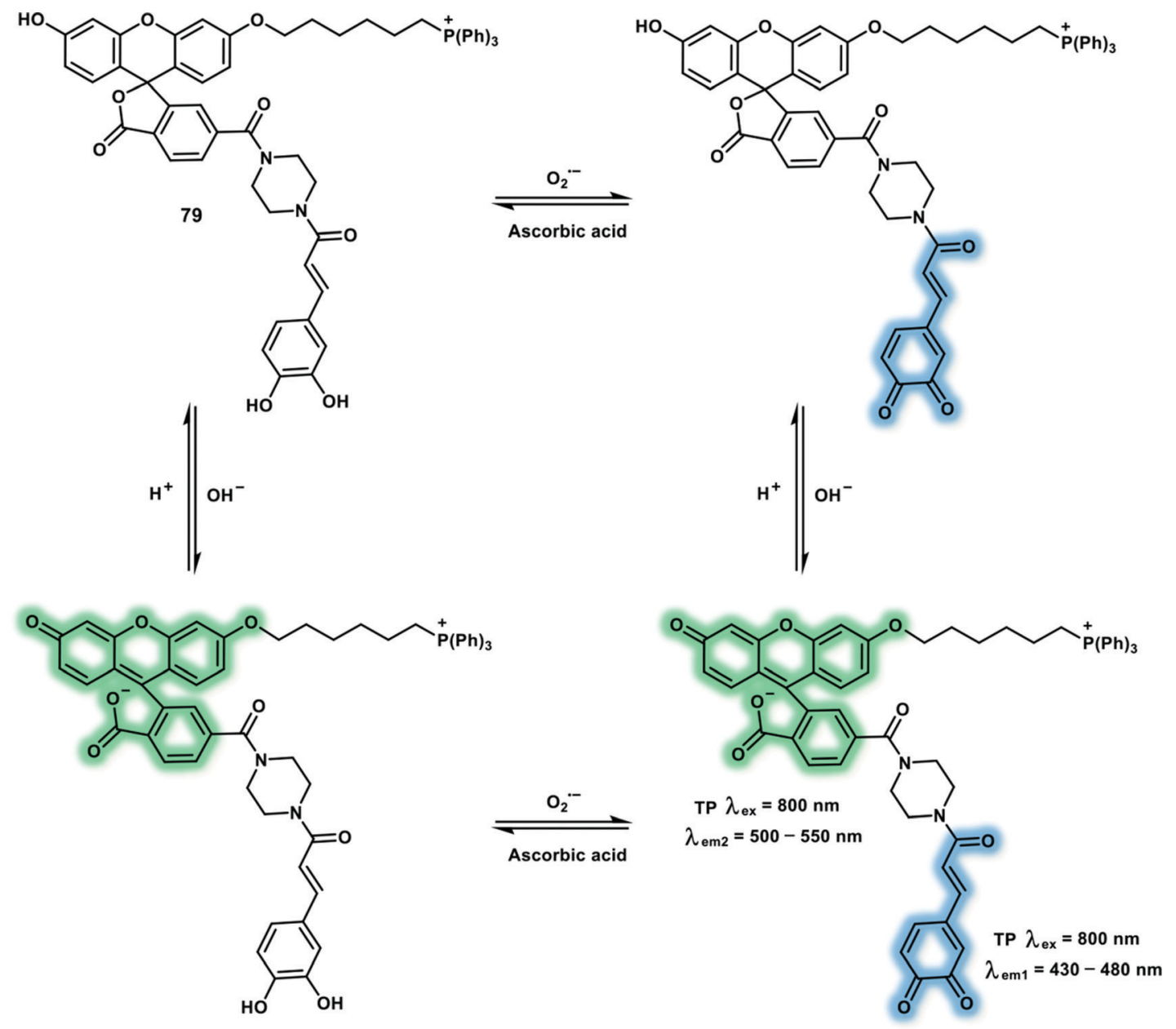

Scheme 35 Dual-responsive TP probe 79 for the detection of $\mathrm{O}_{2}{ }^{\bullet-}$ and $\mathrm{pH}$. 
a)

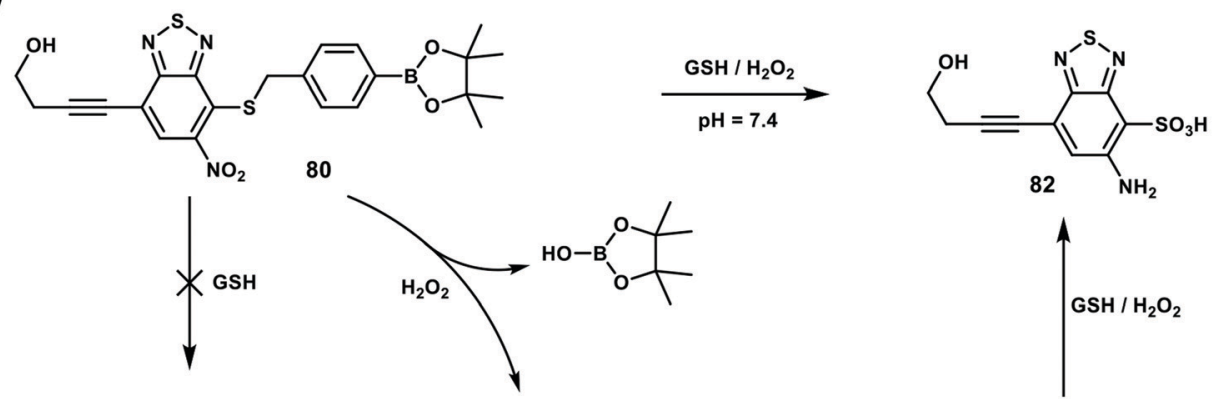<smiles>O=[N+]([O-])c1cc(C#CCCO)c2nsnc2c1[O-]</smiles>

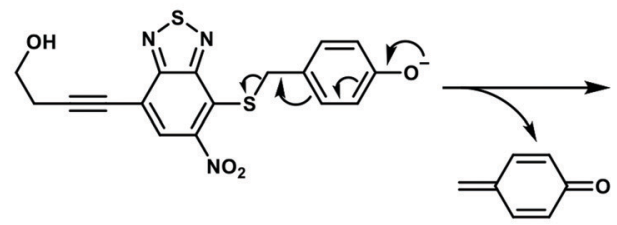<smiles>O=[N+]([O-])c1cc(Br)c2nsnc2c1[S-]</smiles>

b)

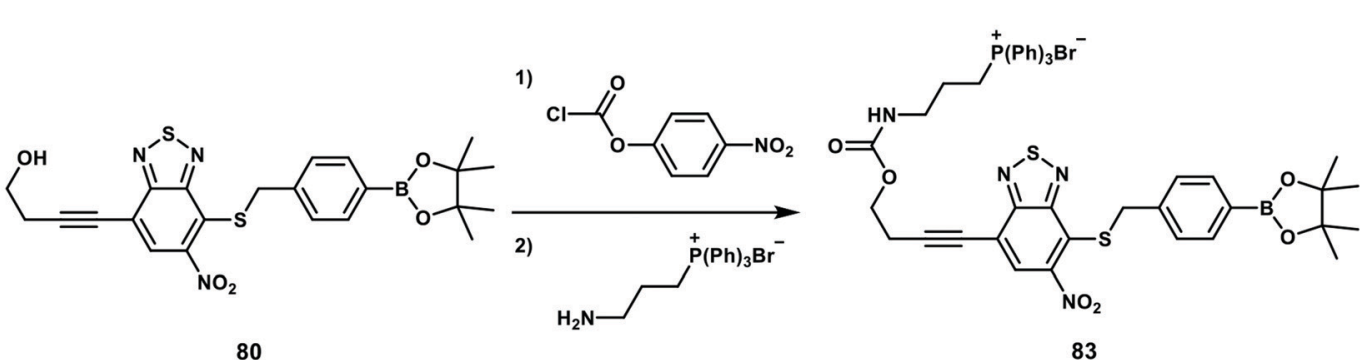

c)

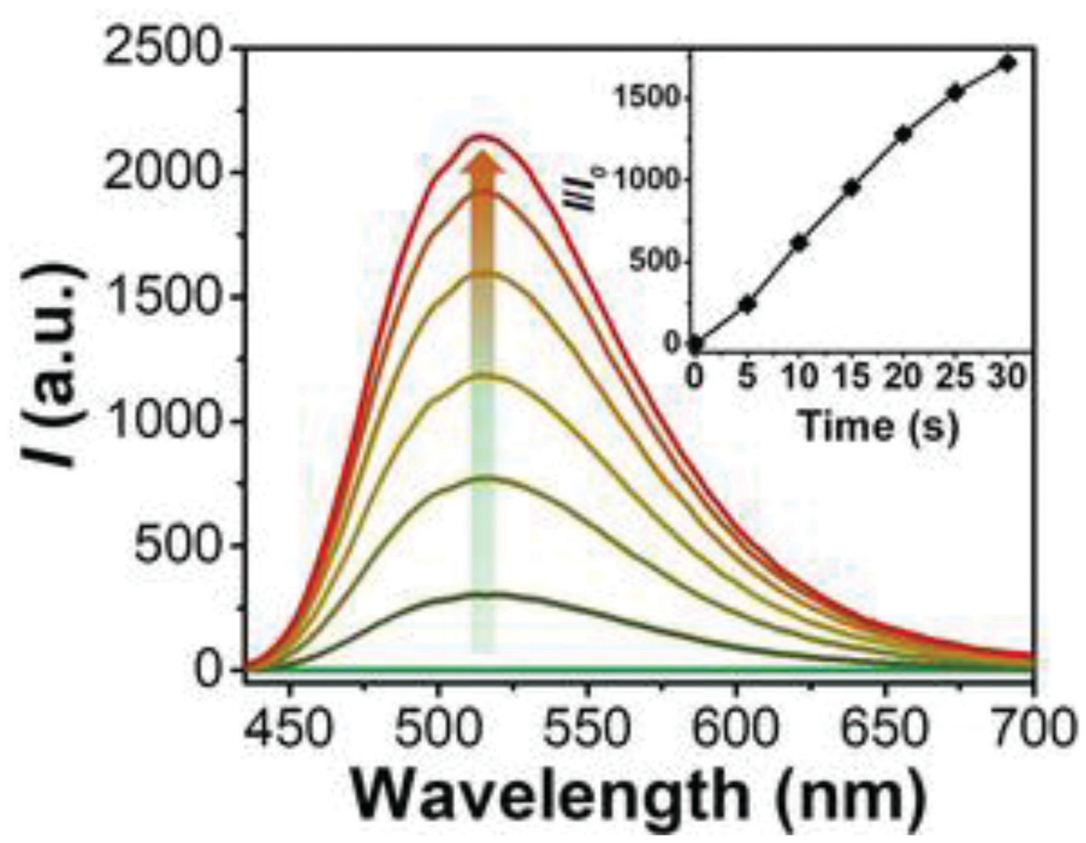

Scheme 36 (a) Schematic presentation for the $\mathrm{GSH} / \mathrm{H}_{2} \mathrm{O}_{2}$ mediated activation of $\mathbf{8 0}$. (b) Synthetic routes of probe $\mathbf{8 3}$. (c) Fluorescence response of $\mathbf{8 0}$ $(10 \mu \mathrm{M})$ to $\mathrm{GSH}(1 \mathrm{mM})$ and $\mathrm{H}_{2} \mathrm{O}_{2}(1 \mathrm{mM})$ in $20 \%$ acetonitrile $-\mathrm{PBS}$ buffer $(\mathrm{pH} 7.4)$ at $37^{\circ} \mathrm{C}$, $\lambda_{\text {ex }}=405 \mathrm{~nm}$. Inset: Fluorescence enhancement $\left(/ / I_{0}\right)$ over time. Reproduced with permission from ref. 51. Copyright (2020) Wiley-VCH Verlag GmbH \& Co. KGaA, Weinheim.

emission was observed when both $\mathrm{GSH}$ and $\mathrm{H}_{2} \mathrm{O}_{2}$ were present, but just a high concentration of GSH ( $c a .10 \mathrm{mM}$ ) in mitochondria did not induce a response by 83 prior to oxidation by $\mathrm{H}_{2} \mathrm{O}_{2}$.
Moreover, HeLa cells treated with $\mathrm{H}_{2} \mathrm{O}_{2}$ and $\mathbf{8 3}$ were killed upon irradiation using a TP laser (800 $\mathrm{nm})$, and were imaged using co-staining with calcein-AM and propidium iodide. 


\section{Conclusions and outlook}

This review describes research carried out within numerous research groups over the past five years towards the development of TP probes and the use of two photons in disease therapy. The probes developed should provide a better understanding of the various biologically-related species and their functions within physiology and pathology. We describe the development of dual-responsive sensors and theranostic systems based on TPEF, which we believe will pave a way in providing a deeper understanding of the complex role that different species play in disease-specific processes.

When starting the process of designing an efficient TP probe, it is vital not to forget important lessons derived from the development of successful OP probes. As such it is important to remember the most important fluorescent mechanisms used for the development of OP probes including ESIPT, FRET, PeT and ICT, still remain to be explored in the area of TP probes. Importantly, most current TP fluorophores have relatively short emission wavelengths though they can be excited using NIR wavelengths. As such we encourage researchers to start developing TP fluorophores with NIR emissions which are needed in order to minimize emission light scattering and achieve deeper penetration during imaging. In addition, TP fluorophores with large $\delta$ values should be designed and developed to reduce photodamage of samples due to the decreased need for highpower pulsed lasers. In addition to turn-on TP probes it is vital to develop ratiometric TP probes which can facilitate quantitative measurements in biomedical applications due to internal calibration. In particular, we believe that FRET based systems could provide a potential strategy for the design of ratiometric TP probes. Then, in order to gain insight into the complex nature of biological systems, the development of dual/multipleresponsive probes and multiple-color fluorophores is essential to develop TP systems capable of accurate and early disease diagnosis. Last but not least, factors including water solubility, $\Phi_{\mathrm{f}}$, photostability cytotoxicity and cell permeability currently well known in the design of OP probes should be considered when developing efficient TP probes.

\section{Conflicts of interest}

There are no conflicts to declare.

\section{Acknowledgements}

L. W. wishes to thank China Scholarship Council and The University of Bath for supporting his $\mathrm{PhD}$ in the UK. T. D. J. would like to thank the EPSRC and The University of Bath for funding. T. D. J. wishes to thank the Royal Society for a Wolfson Research Merit Award and the Open Research Fund of the School of Chemistry and Chemical Engineering, Henan Normal University for support (2020ZD01). J. L., P. L. and B. T. thank the support by the National Natural Science Foundation of China (22074083, 91753111, and 21927811), the Key Research and Development Program of Shandong Province
(2018YFJH0502), National Major Scientific and Technological Special Project for "Significant New Drugs Development" (2017ZX09301030004).

\section{References}

1 D. Wu, A. C. Sedgwick, T. Gunnlaugsson, E. U. Akkaya, J. Yoon and T. D. James, Chem. Soc. Rev., 2017, 46, 7105-7123.

2 J. Chan, S. C. Dodani and C. J. Chang, Nat. Chem., 2012, 4, 973-984.

3 H. M. Kim and B. R. Cho, Chem. Rev., 2015, 115, 5014-5055.

4 W. Denk, J. H. Strickler and W. W. Webb, Science, 1990, 248, 73-76.

5 M. Göppert-Mayer, Ann. Phys., 1931, 401, 273-294.

6 W. Kaiser and C. G. B. Garrett, Phys. Rev. Lett., 1961, 7, 229-231. 7 Y. Fu and N. S. Finney, RSC Adv., 2018, 8, 29051-29061.

8 B. Valeur and I. Leray, Coord. Chem. Rev., 2000, 205, 3-40.

9 L. Wu, C. Huang, B. P. Emery, A. C. Sedgwick, S. D. Bull, X.-P. He, H. Tian, J. Yoon, J. L. Sessler and T. D. James, Chem. Soc. Rev., 2020, 49, 5110-5139.

10 A. C. Sedgwick, L. Wu, H.-H. Han, S. D. Bull, X.-P. He, T. D. James, J. L. Sessler, B. Z. Tang, H. Tian and J. Yoon, Chem. Soc. Rev., 2018, 47, 8842-8880.

11 S. Xu, H.-W. Liu, L. Chen, J. Yuan, Y. Liu, L. Teng, S.-Y. Huan, L. Yuan, X.-B. Zhang and W. Tan, J. Am. Chem. Soc., 2020, 142, 2129-2133.

12 H.-J. Lee, C.-W. Cho, H. Seo, S. Singha, Y. W. Jun, K.-H. Lee, Y. Jung, K.-T. Kim, S. Park, S. C. Bae and K. H. Ahn, Chem. Commun., 2016, 52, 124-127.

13 W. Li, B. Fang, M. Jin and Y. Tian, Anal. Chem., 2017, 89, 2553-2560.

14 L. Zhou, Q. Wang, X.-B. Zhang and W. Tan, Anal. Chem., 2015, 87, 4503-4507.

15 L. Wu, A. C. Sedgwick, X. Sun, S. D. Bull, X.-P. He and T. D. James, Acc. Chem. Res., 2019, 52, 2582-2597.

16 L. C. Murfin, M. Weber, S. J. Park, W. T. Kim, C. M. LopezAlled, C. L. McMullin, F. Pradaux-Caggiano, C. L. Lyall, G. Kociok-Köhn, J. Wenk, S. D. Bull, J. Yoon, H. M. Kim, T. D. James and S. E. Lewis, J. Am. Chem. Soc., 2019, 141, 19389-19396.

17 D. Cheng, Y. Pan, L. Wang, Z. Zeng, L. Yuan, X. Zhang and Y.-T. Chang, J. Am. Chem. Soc., 2017, 139, 285-292.

18 X. Li, R.-R. Tao, L.-J. Hong, J. Cheng, Q. Jiang, Y.-M. Lu, M.-H. Liao, W.-F. Ye, N.-N. Lu, F. Han, Y.-Z. Hu and Y.-H. Hu, J. Am. Chem. Soc., 2015, 137, 12296-12303.

19 L. Yuan, L. Wang, B. K. Agrawalla, S.-J. Park, H. Zhu, B. Sivaraman, J. Peng, Q.-H. Xu and Y.-T. Chang, J. Am. Chem. Soc., 2015, 137, 5930-5938.

20 Z. Mao, M. Ye, W. Hu, X. Ye, Y. Wang, H. Zhang, C. Li and Z. Liu, Chem. Sci., 2018, 9, 6035-6040.

21 Y. L. Pak, S. J. Park, D. Wu, B. Cheon, H. M. Kim, J. Bouffard and J. Yoon, Angew. Chem., Int. Ed., 2018, 57, 1567-1571.

22 Q. Xu, C. H. Heo, G. Kim, H. W. Lee, H. M. Kim and J. Yoon, Angew. Chem., Int. Ed., 2015, 54, 4890-4894. 
23 U. Tamima, M. Santra, C. W. Song, Y. J. Reo and K. H. Ahn, Anal. Chem., 2019, 91, 10779-10785.

24 L. Chen, M. K. Cho, D. Wu, H. M. Kim and J. Yoon, Anal. Chem., 2019, 91, 14691-14696.

25 H. Li, Q. Yao, F. Xu, N. Xu, X. Ma, J. Fan, S. Long, J. Du, J. Wang and X. Peng, Anal. Chem., 2018, 90, 4641-4648.

26 Z. Mao, W. Feng, Z. Li, L. Zeng, W. Lv and Z. Liu, Chem. Sci., 2016, 7, 5230-5235.

27 Y. Li, Y. Shu, M. Liang, X. Xie, X. Jiao, X. Wang and B. Tang, Angew. Chem., Int. Ed., 2018, 57, 12415-12419.

28 B. Dong, X. Song, X. Kong, C. Wang, Y. Tang, Y. Liu and W. Lin, Adv. Mater., 2016, 28, 8755-8759.

29 H. Zhang, R. Liu, J. Liu, L. Li, P. Wang, S. Q. Yao, Z. Xu and H. Sun, Chem. Sci., 2016, 7, 256-260.

30 Y. Zhang, X. Wang, X. Bai, P. Li, D. Su, W. Zhang, W. Zhang and B. Tang, Anal. Chem., 2019, 91, 8591-8594.

31 K. Liu, X. Kong, Y. Ma and W. Lin, Angew. Chem., Int. Ed., 2017, 56, 13489-13492.

32 C. de la Torre, A. Toscani, C. Marín-Hernández, J. A. Robson, M. C. Terencio, A. J. P. White, M. J. Alcaraz, J. D. E. T. Wilton-Ely, R. Martínez-Máñez and F. Sancenón, J. Am. Chem. Soc., 2017, 139, 18484-18487.

33 Y. W. Jun, T. Wang, S. Hwang, D. Kim, D. Ma, K. H. Kim, S. Kim, J. Jung and K. H. Ahn, Angew. Chem., Int. Ed., 2018, 57, 10142-10147.

34 X. Wang, P. Li, Q. Ding, C. Wu, W. Zhang and B. Tang, Angew. Chem., Int. Ed., 2019, 58, 4674-4678.

35 H.-W. Liu, L. Chen, C. Xu, Z. Li, H. Zhang, X.-B. Zhang and W. Tan, Chem. Soc. Rev., 2018, 47, 7140-7180.

36 J. Zhang, X. Chai, X.-P. He, H.-J. Kim, J. Yoon and H. Tian, Chem. Soc. Rev., 2019, 48, 683-722.
37 W. Li, S. Yin, X. Gong, W. Xu, R. Yang, Y. Wan, L. Yuan and X. Zhang, Chem. Commun., 2020, 56, 1349-1352.

38 L. Ge, Z. Liu and Y. Tian, Chem. Sci., 2020, 11, 2215-2224.

39 X. Wang, P. Li, Q. Ding, C. Wu, W. Zhang and B. Tang, J. Am. Chem. Soc., 2019, 141, 2061-2068.

40 A. R. Sarkar, C. H. Heo, L. Xu, H. W. Lee, H. Y. Si, J. W. Byun and H. M. Kim, Chem. Sci., 2016, 7, 766-773.

41 J. Yin, M. Peng and W. Lin, Chem. Commun., 2019, 55, 11063-11066.

42 P. Wang and S. Wu, J. Photochem. Photobiol., A, 1995, 86, 109-113.

43 J. Yin, M. Peng and W. Lin, Anal. Chem., 2019, 91, 8415-8421.

44 X. Li, M. Jiang, J. W. Y. Lam, B. Z. Tang and J. Y. Qu, J. Am. Chem. Soc., 2017, 139, 17022-17030.

45 J.-W. Choi, S. T. Hong, M. S. Kim, K. C. Paik, M. S. Han and B. R. Cho, Anal. Chem., 2019, 91, 6669-6674.

46 P. Zhang, C. K. C. Chiu, H. Huang, Y. P. Y. Lam, A. Habtemariam, T. Malcomson, M. J. Paterson, G. J. Clarkson, P. B. O'Connor, H. Chao and P. J. Sadler, Angew. Chem., Int. Ed., 2017, 56, 14898-14902.

47 S. Erbas-Cakmak, S. Kolemen, A. C. Sedgwick, T. Gunnlaugsson, T. D. James, J. Yoon and E. U. Akkaya, Chem. Soc. Rev., 2018, 47, 2228-2248.

48 X. Jiao, Y. Xiao, Y. Li, M. Liang, X. Xie, X. Wang and B. Tang, Anal. Chem., 2018, 90, 7510-7516.

49 X. Wang, X. Bai, D. Su, Y. Zhang, P. Li, S. Lu, Y. Gong, W. Zhang and B. Tang, Anal. Chem., 2020, 92, 4101-4107.

50 W. Zhang, X. Wang, P. Li, H. Xiao, W. Zhang, H. Wang and B. Tang, Anal. Chem., 2017, 89, 6840-6845.

51 J. Sun, K. Du, J. Diao, X. Cai, F. Feng and S. Wang, Angew. Chem., Int. Ed., 2020, 59, 12122-12128. 